Identification of novel Theileria parva candidate vaccine antigens and discovery of new therapeutic drugs for the control of East Coast fever

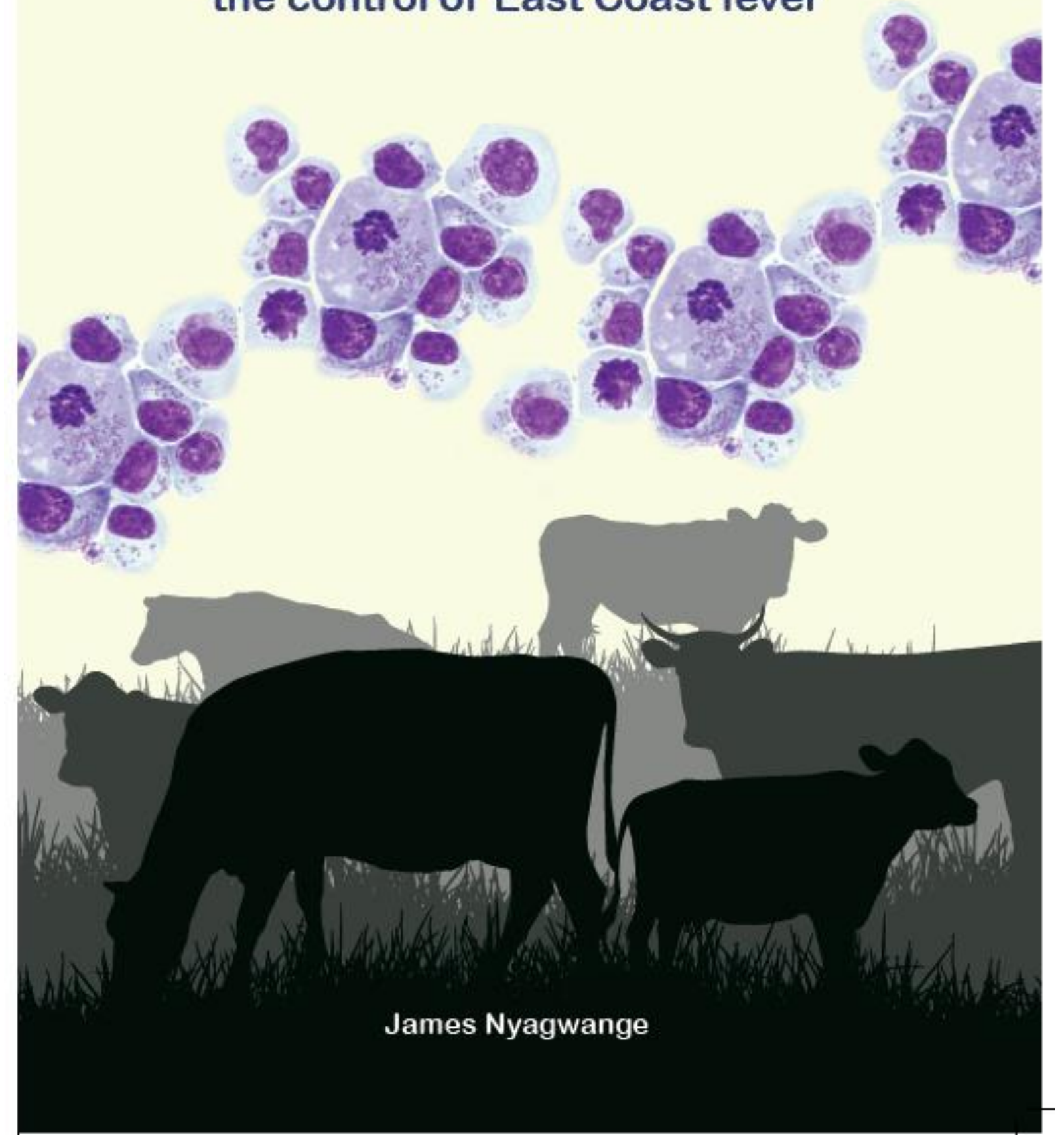


Identification of novel Theileria parva candidate vaccine antigens and discovery of new therapeutic drugs for the control of East Coast fever

James J. Nyagwange 


\section{Thesis committee}

\section{Promotors}

Prof. Dr H.F.J. Savelkoul

Professor of Cell Biology and Immunology

Wageningen University \& Research

Prof. Dr V. Nene

Director and co-leader, Animal and Human Health program

International Livestock Research Institute, Nairobi, Kenya

\section{Co-promotors}

Dr E.J. Tijhaar

Assistant professor, Cell Biology and Immunology

Wageningen University \& Research

Dr Roger Pelle

Principal scientist, Biosciences Eastern and Central Africa

International Livestock Research Institute, Nairobi, Kenya

\section{Other members}

Prof. Dr V.P.M.G. Rutten, Utrecht University

Prof. Dr M.M. van Oers, Wageningen University \& Research

Prof. Dr G.F. Wiegertjes, Wageningen University \& Research

Dr H.K. Parmentier, Wageningen University \& Research

This research was conducted under the auspices of the Graduate School Wageningen Institute of Animal Sciences 


\title{
Identification of novel Theileria parva candidate vaccine antigens and discovery of new therapeutic drugs for the control of East Coast fever
}

\author{
James J. Nyagwange
}

Thesis

submitted in fulfilment of the requirements for the degree of doctor at Wageningen University

by the authority of the Rector Magnificus,

Prof. Dr A.P.J. Mol,

in the presence of the

Thesis Committee appointed by the Academic Board

to be defended in public

on Tuesday 14 May 2019

at 1:30 p.m. in the Aula. 
James Jimmy Nyagwange

Identification of novel Theileria parva candidate vaccine antigens and discovery of new therapeutic drugs for the control of East Coast fever 154 pages

$\mathrm{PhD}$ thesis, Wageningen University, Wageningen, the Netherlands (2019)

With references, with summary in English

ISBN 978-94-6343-578-9

DOI https://doi.org/10.18174/467903 


\section{Contents}

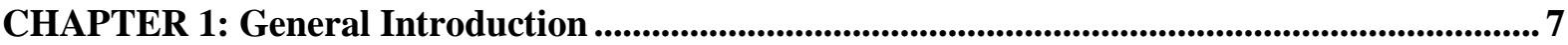

CHAPTER 2: Characterization of the Theileria parva sporozoite proteome

CHAPTER 3: Characterization of Rhipicephalus appendiculatus salivary glands proteins copurified with Theileria parva sporozoites.

CHAPTER 4: Antibodies to in silico selected GPI-anchored Theileria parva proteins neutralize sporozoite infection in vitro 81

CHAPTER 5: Leveraging the Medicines for Malaria Venture malaria and pathogen boxes to discover lead chemical inhibitors of East Coast fever .99

CHAPTER 6: Summarizing Discussion. 



\section{CHAPTER}

1

General Introduction 


\section{East Coast fever}

East Coast fever (ECF) is lymphoproliferative disease of cattle caused by Theileria parva, an apicomplexan parasite transmitted by ticks (Hayashida, Abe et al. 2013). Dr. Arnold Theiler working in South Africa in the early1900s, identified T. parva as the causal organism of ECF and distinguished the disease from Redwater that is caused by Babesia (Theiler 1912). He also identified the three host tick Rhipicephalus appendiculatus as the main vector for ECF transmission (Theiler 1912). In the past, T. parva was thought to comprise three distinct subspecies; T. parva parva, T. parva lawrencei and T. parva bovis, causing ECF, Corridor disease and January disease respectively. However, it is now known that T. parva is genetically a single species and the sub-species nomenclature was abandoned (Perry and Young 1993). Parasite isolates are now described as either cattle-derived or buffalo-derived depending on their originating host species (reviewed in Nene, Kiara et al. 2016). The most common form of the disease caused by cattle-derived $T$. parva is called classical ECF. It presents with high parasitemia and high mortality in cattle. A less virulent form of the disease known as January disease caused by cattle derived T. parva is found in Zimbabwe (reviewed in Latif and Hove 2011). The latter disease occurs seasonally, with outbreaks occurring in January simultaneously with emergence of adult ticks from diapause (Matson 1967). It presents with high morbidity but with low mortality and low parasitemia (reviewed in Latif and Hove 2011). However, another form of the disease caused by buffalo derived parasite known as Corridor disease is more acute than ECF and in the face of an outbreak, the mortality rate can exceed $90 \%$ (reviewed in Norval, Perry et al. 1992, Mbizeni, Potgieter et al. 2013). Classical ECF was introduced to South Africa and Zimbabwe in the 1900s following importation of cattle from East Africa for restocking after devastation of cattle by Rinderpest in 1895 (Lawrence 1979). Currently, ECF is present in 12 countries in eastern, central and southern Africa namely; Kenya, Tanzania, Uganda, South Sudan, Burundi, Rwanda, Democratic Republic of Congo, Malawi, Mozambique, Zambia, Zimbabwe and Comoro Islands (Nene, Kiara et al. 2016).

T. parva pathogenicity to cattle varies per breed and mortality appears to be higher in Bos taurus and their crosses compared to Bos indicus (reviewed in Morrison, Connelley et al. 2015). In Bos taurus mortality can approach $100 \%$ and T. parva is considered a major factor undermining the introduction and sustenance of highly productive taurine breeds of cattle in sub-Saharan Africa (reviewed in Morrison, Connelley et al. 2015). Rearing taurine breeds in T. parva endemic regions is usually accompanied by high costs associated with the use of toxic and expensive acaricides to kill the tick vector. Epidemics of ECF in areas previously unaffected by $T$. parva infection are renowned for their devastating effect on cattle populations. For smallholder farmers, extinction of the entire herd is common when actions are not taken to mitigate the outbreaks. This has dramatic social, economic and health effects due to loss of food and income. On regional basis, it was estimated that ECF kills approximately 1 million cattle/year causing annual losses of approximately USD 300 million (McLeod and Kristjanson 1999). However, these estimates were made several years ago and it is likely that the current impact is much larger.

T. parva has probably made a host jump from the African Cape buffalo in which it does not cause disease (reviewed in Norval, Perry et al. 1992) to cattle, where it causes ECF (review ed in Norval, Perry et al. 1992). The African buffalo plays an important role as parasite reservoir and drives the epidemiology of the disease (figure 1). In regions where there is wildlife-cattle interface, the buffaloes provide a source of infection for the ticks which in turn infect cattle. Indigenous cattle that spontaneously recover from the disease after mild reactions are solidly immune to reinfection and form another reservoir for the parasite since they do not usually clear the infection (Kariuki, Young et al. 1995). ECF is characterised by high fever, leukocytopenia, severe damage to the lymphoid system and pronounced clinical symptoms 
develop as the schizont infected lymphocytes disseminate rapidly (Brown 1990). Acute lethal disease usually lasts about three weeks after infection with sporozoites, before death occurs. The ECF death cases show evidence of pneumonia and pulmonary oedema with froth in the nostrils, trachea and bronchi (Brown 1990).

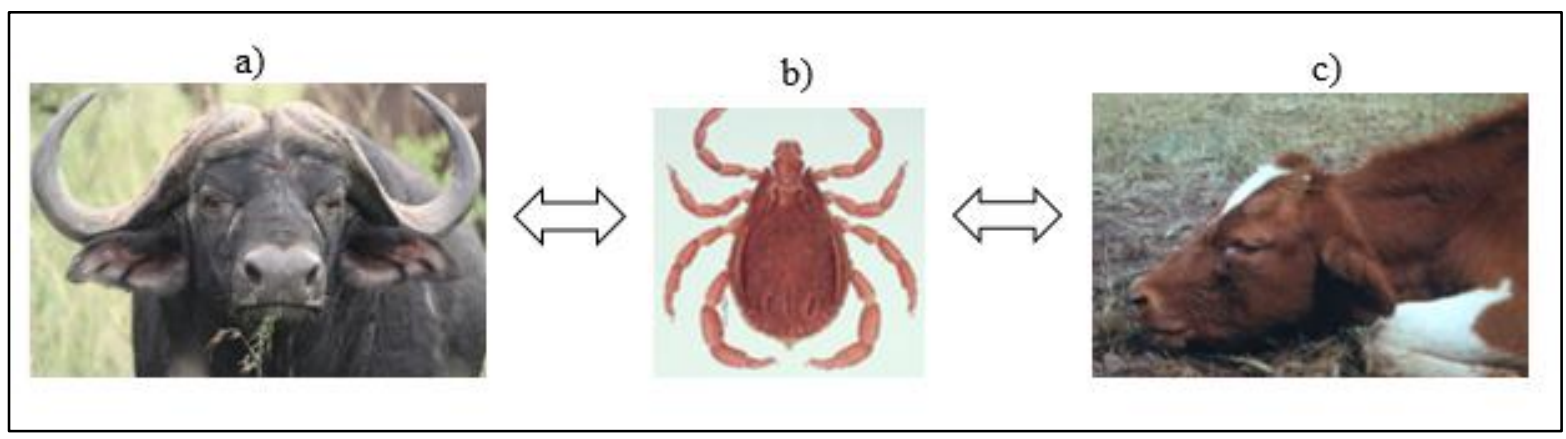

Figure 1. Theileria parva transmission. The African Cape buffalo, Syncerus caffer (a) is a reservoir for $T$. parva parasite and provides a source of infection for the $R$. appendiculatus vector (b) during the tick feeding. Once infected, the tick provides a source of infection to susceptible cattle (c) which die about 3 weeks after infection from the acute form of ECF disease.

Pictures adapted from (http://www.afrivip.org/sites/default/files/theileria_1_introduction.pdf)

\section{Life cycle of Theileria parva}

The features of the lifecycle of $T$. parva are illustrated in figure 2. Like other apicomplexans, T. parva is an obligate intracellular parasite which invades and survives inside a mammalian or tick host cell. $R$. appendiculatus is the principal vector for the transmission of T. parva and larvae and nymphal stages of this tick acquire an infection from the piroplasm stage present in red blood cells (RBCs) of infected cattle, during feeding. In the tick gut the piroplasms differentiate into macro- and micro-gametes that fuseto form zygotes. These enter cells of the tick gut epithelium and develop into motile kinetes, which are released into the tick hemocel. Sporogony occurs in e-cells in type III acini and the release of sporozoites from tick salivary glands occurs4-8 days after attachment of the tick to the host. Infected nymphs and adults transmit sporozoites, the life-cycle stage infective to cattle, during blood meal.

Unlike other apicomplexans, Theileria sporozoites are immotile, have a less defined apical complex and host cell entry is not orientation-specific (Shaw 2003). Sporozoites bind and enter host cells by a "zippering" process of the host and the sporozoite cell membranes (Fawcett, Doxsey et al. 1982b). After entry into the host cell, rhoptries/microspheres are discharged with a rapid escape of the sporozoite from the surrounding host cell membrane. Sporozoites differentiate to the schizont stage, which resides free in the host cytoplasm surrounded by host cell microtubules that are seemingly nucleated by parasite molecules (reviewed in Shaw 2003). Establishment of the multinucleate schizont stage is associated with activation of the infected cells, which start to proliferate and acquire a cancer-like phenotype and are the principal cause of disease (Norval, Perry et al. 1992). The schizonts associate with host mitotic spindle during cell division and this allows them to divide simultaneously with the host cell, leading to maintenance of infection in the daughter cells (Hulliger, Wilde et al. 1964, von Schubert, Xue et al. 2010). T. parva sporozoites bind and enter lymphocytes and macrophages/afferent lymph veiled cells, although only lymphocytes are susceptible to transformation as sporozoites appear to only differentiate to an early schizont stage in the latter cell types (Shaw, Tilney et al. 1993). 
Schizonts undergo merogony, from approximately 10-14 days post infection, producing merozoites which are released by host cell rapture (reviewed in Morrison, Connelley et al. 2015). Through a similar process like sporozoite entry into lymphocytes, merozoites invade red blood cells where they develop into the tick infective piroplasm stage which resides freely in the cytoplasm (Shaw and Tilney 1995). Piroplasms undergo limited multiplication and anaemia caused by destruction of the erythrocytes does not contribute significantly to the pathology of ECF (reviewed in Morrison, Connelley et al. 2015). However, in animals that recover from infection, parasites persist for several months or years and are not detectable by microscopy, this asymptomatic carrier state functions as an important source of infection for ticks (Kariuki, Young et al. 1995).

\section{Transformation of the host cells}

Schizont-infected B and T-cells acquire a cancer-like phenotype characterized by proliferation, immortality and dissemination throughout the lymphoid system and other tissues, especially the lungs and gut mucosa (Irvin and Morrison 1987, Sivakumar, Hayashida et al. 2014). Transformation occurs more in the infected T-cell lineage than in the infected B-cell lineage and high level pathology is associated with T-cell transformation (Morrison, MacHugh et al. 1996). Proliferation of the infected cells is independent of exogenous growth factors and is completely dependent on the presence of live parasites (Dobbelaere, Roditi et al. 1991). Killing of the parasites by anti-theilerial drugs such as buparvaquone results in the cells reverting to non-proliferative state (Brown, Shaw et al. 1989). 


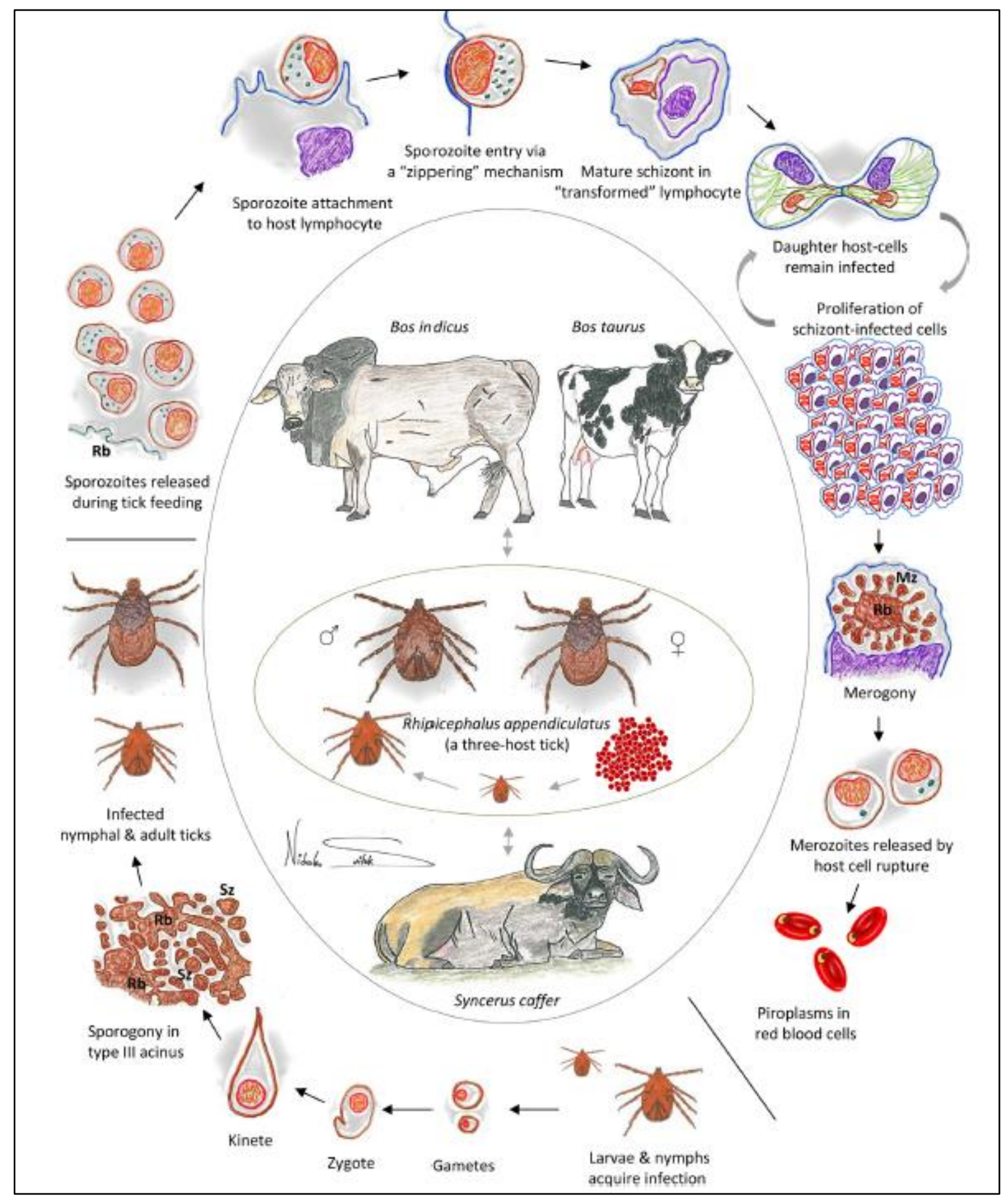

Figure 2. Life cycle of Theileria parva (Nene, Kiara et al. 2016). Sporozoites enter lymphocytes where they develop to the schizont stage, which causes host cell transformation resulting proliferation of schizont-infected cells. Some of the schizonts undergo merogony, producing merozoites, which mature into the piroplasm stage in RBCs, and are infective to ticks. Tick larvae and nymphs acquire an infection while feeding on infected cattle or buffalo, and transmit the parasites.

Parasite molecules that are associated with the transformation process have been tentatively identified by taking advantage of comparative genomics and cancer biology (Shiels, Langsley et al. 2006, Hayashida, Hara et al. 2012, Tretina, Gotia et al. 2015). A parasite- 
encoded prolyl isomerase has been recently identified as playing a key role in this complex host cell transformation process (Marsolier, Perichon et al. 2015). In addition, several host cellsignalling pathways that contribute to host cell transformation have been studied (reviewed in Dobbelaere and Küenzi 2004, Dessauge, Lizundia et al. 2005). Understanding the mechanisms of host cell transformation by these parasites presents opportunities for cancer therapy and control of ECF as novel drugs may target these pathways for disruption.

\section{Control of ECF by vaccination}

A live parasite-based vaccine, which immunizes the animals by an infection and treatment method (ITM), is available (Radley, Brown et al. 1975, Radley, Brown et al. 1975b). It involves deliberate infection of the animals with live parasite followed by treatment with antibiotic such as long acting oxytetracycline. The antibiotic controls but does not kill the parasite, allowing the animal to develop a protective acquired immune response. For control of ECF in southern Africa ITM is performed with a single parasite isolate and in parts of eastern Africa a composite ITM vaccine, the Muguga cocktail, is used (Morzaria, Nene et al. 2000). The Muguga cocktail consists of three isolates namely; Muguga, Serengeti transformed and Kiambu-5. These isolates have been shown to confer broad-spectrum protection against ECF. The use of combinations of isolates in ITM followed the discovery that a single parasite isolate did not offer sufficient protection against isolates of different geographical location. The choice of parasite isolates/strains included in the vaccine is based on the degree of cross-protection among the isolates/strains. Usually, there is $20-30 \%$ cross-protection between the individual isolates in different cross-immunity groups (reviewed in Nene, Kiara et al. 2016).

Although the ITM vaccine is effective in controlling ECF, it has serious disadvantages. It requires a liquid nitrogen cold chain for delivery and oxytetracycline co-treatment. In addition, the very laborious production of the vaccine from infected ticks, which takes 18 months, makes it expensive and animals vaccinated by the ITM protocol remain life-long carries of the parasite, which could pose a risk for spread of the disease (reviewed in Di Giulio, Lynen et al. 2009). Therefore, there is need for development of subunit vaccines without these disadvantages.

Over the years, there have been efforts in identifying antigens that are targets of neutralizing antibodies and $\mathrm{CD}^{+} \mathrm{T}$-cells (reviewed in Nene, Kiara et al. 2016). Neutralizing antibodies are directed against sporozoite surface proteins to prevent it from infecting host cells while CD8+ cytotoxic T cells (CTLs) are directed against antigens of the schizont stage to interrupt the infection by killing the schizont infected host cells. A number of antigens that are targets of neutralizing antibodies have been identified before, including p67, p32, p104, PIM and $\mathrm{p} 150$. The most preferred antigen, p67 was identified by murine monoclonal antibodies which neutralized sporozoite infection in vitro (Dobbelaere, Spooner et al. 1984, Musoke, Nantulya et al. 1984, Dobbelaere, Shapiro et al. 1985). This 709 amino acid residue protein, is totally conserved among cattle derived $T$. parva strains, making it a suitable candidate to function as cross-protective immunogen among cattle derived T. parva strains (Nene, Musoke et al. 1996). It can also function as immunogen among buffalo derived T. parva strains because even though it's polymorphic among buffalo derived $T$. parva strains, its alleles share greater than $90 \%$ sequence identity (Nene, Musoke et al. 1996). There have been several vaccine trial experiments using several constructs of full length and recombinant fragments of the protein with a number of adjuvants and gene based delivery systems. Results from these experimental vaccine trials were recently summarized by Nene et al (2016) and protection from parasite challenge following p67 immunization ranges from 13 to $70 \%$ depending on construct, concentration, dosage regimen and formulation (Nene, Kiara et al. 2016). The best outcome of these experiments involved p67C fragment, an 80 amino acid peptide from the $\mathrm{C}$-terminal with 
epitopes recognized by sporozoite neutralizing monoclonal antibodies (Bishop, Nene et al. 2003). This fragment is easier to express in E. coli in a stable manner and in high yield than the p67 full length protein and it induces comparable immunity, suggesting it represents a critical target (Bishop, Nene et al. 2003). The consistent evidence of immunity induced by p67 constructs, although variable, cements p67 as a strong candidate vaccine antigen and research is ongoing to increase its efficacy by testing different formulations and immunization schemes. The limitation with p67 is that in most experiments, there has been no consistent correlate of the various antibody assays (such as antibody titres, $\mathrm{CD} 4^{+} \mathrm{T}$-cell proliferation, etc.) with immunity, and immunity in field trials is relatively lower than laboratory challenge experiments (Musoke, Morzaria et al. 1992, Nene, Musoke et al. 1996, Schetters, Arts et al. 2015). Although the field vs laboratory based experimental differences can be attributed to some cattle naturally recovering from infection in the control group under field conditions, Schetters et al (2015) recently reported susceptibility to disease in immunized and control cattle in the field following p67 immunization (Schetters, Arts et al. 2015).

Research was discontinued on the $32 \mathrm{kDa}$ (p32) protein, identified through immunoprecipitation of biotin labeled sporozoites with the murine monoclonal $\mathrm{mAb}$ 4C9 (Skilton, Musoke et al. 2000). A recombinant p32 protein produced bovine antisera that did not induce neutralizing antibodies and the p32 immunized cattle were susceptible to parasite challenge (Skilton, Musoke et al. 2000). A series of murine monoclonal antibodies raised to the schizont stage of the parasite identified another antigen, the polymorphic immunodominant molecule (PIM). Named for its polymorphic nature and identification by a number of antibodies, PIM is localized in the rhoptries/micronemes in the sporozoites (Toye, Nyanjui et al. 1996) but located on surface of the schizonts (Shapiro, Fujisaki et al. 1987). However, due to its highly polymorphic sequence in both cattle- and buffalo-derived T. parva strains (Geysen, Bazarusanga et al. 2004) and findings that rats immunized by PIM produce neutralizing antibodies,(Toye, Metzelaar et al. 1995) but cattle immunized by PIM do not make sporozoite neutralizing antibodies, the role of PIM as a vaccine candidate antigen was not been evaluated (Toye, Nyanjui et al. 1996). We have investigated a role of p104 antigen in this study but the role of p150 as a candidate vaccine antigen remains to be evaluated. Based on the large number of apicomplexan proteins involved in host cell entry, it possible that there are additional novel $T$. parva candidate sporozoite vaccine antigens to be discovered. The main aim of this project was to identify novel sporozoite vaccine candidates that can be used by themselves or in combination with p67 to increase the effectiveness of vaccination for ECF.

\section{Control of ECF by chemotherapy}

In addition to vaccination, ECF is controlled by direct killing of the parasites using chemotherapeutic drugs and indirectly by using acaricides to kill the tick vectors responsible for transmission of the parasites. Regular spraying and/or dipping of cattle in acaricide have effectively been used in preventing ECF but have limitations. Firstly, the acaricides are toxic chemicals, raising concerns about environmental pollution and possible contamination of the food chain by leaving residues in milk and meat products. Secondly, many of the poor farmers in the affected regions cannot afford the chemicals for spraying and dipping. Finally, the ticks are increasingly developing resistance to the acaricides. Therefore, control by acaricides seems unsustainable.

Halofuginone lactate under trade name Terit ${ }^{\circledR}$ was the first commercial drug to be licensed against Theileria (Kaba 2003). It was followed by hydroxynaphthoquinone parvaquone traded as Clexon ${ }^{\circledR}$ (Kaba 2003). Buparvaquone traded as Butalex ${ }^{\circledR}$, a derative of 
parvaquone was subsequently synthesized and found to be more active and since its discovery about 30 years ago, it has remained the frontline drug of choice for the control of both T. parva and T. annulata infections (Nene, Kiara et al. 2016).

Buparvaquone effectiveness requires administration during the early stage of parasite infection before widespread immune system destruction by the advanced stages. During the latter stage several doses of the drug are required to resolve infection (Morrison and McKeever 2006). Buparvaquone is also relatively expensive to small holder farmers and is not always available to these farmers (Morrison and McKeever 2006). As with other hydroxynaphtoquinones, buparvaquone most likely inhibits mitochondrial electron transport in the parasite (McHardy, Wekesa et al. 1985) (Birth, Kao et al. 2014). Resistance to the drug has been described in T. annulata and is associated with mutations in cytochrome b (cytb) gene encoding for ubiquinone reductase of the respiratory chain (Sharifiyazdi, Namazi et al. 2012, Mhadhbi, Chaouch et al. 2015). Therefore, recent identification of nuclear encoded peptidylprolyl isomerase in $T$. annulata as a potential target for burpavaquone resistance was not expected (Marsolier, Perichon et al. 2015). Nevertheless, the findings of buparavaquone resistance in $T$. annulata are of great concern for future control of theileriosis and ECF (Mhadhbi, Naouach et al. 2010). Although resistance in T. parva has not been documented, it might just be a matter of time before it happens. We have undertaken studies to identify new drug compounds as starting points to anti-theilerial drug discovery and part of this thesis describes these efforts.

\section{Scope of thesis}

This work is part of a larger theme focused on improvement of vaccines for the control of ECF in cattle in Africa. The larger theme aimed on improving aspects of the live infection and treatment method of vaccination against ECF, inducing antibody based immunity by targeting the sporozoite stage of the parasite and inducing a T-cell mediated immunity by targeting the schizont stage of the parasite.

In Chapter 1, and overview of ECF biology and the different approaches to control the disease are discussed, with a focus on vaccine development.

In Chapter 2, to identify novel potential sporozoite vaccine candidates the proteome of T. parva sporozoites, purified by ion-exchange chromatography (Musoke, Morzaria et al. 1992), was characterized by a Multidimensional Protein Identification Technology (MudPIT) mass spectrometry-based approach (reviewed in Schirmer, Yates et al. 2003) To the 2,007 parasite proteins revealed by this approach bioinformatics analysis identified orthologs of Plasmodium falciparum surface proteins and proteins involved in host cell infection, of which some may represent novel $T$. parva vaccine candidates.

In Chapter 3, using bioinformatics and literature review, we analyzed the 2,773 vector proteins co-purified with the sporozoite proteins in the infected salivary glands and identified known $R$. appendiculatus antigens that are targets of transmission blocking vaccines and novel antigens that may be involved in sporozoite infection of lymphocytes. The control of ECF may benefit from vaccines that can block sporozoite infection of lymphocytes as well as $R$. appendiculatus attachment and feeding.

Chapter 4 describes selection of potential sporozoite surface proteins, recombinant expression of putative vaccine candidate antigens and in vitro neutralization assay with antisera 
against the recombinant proteins. The proteins, which in majority were identified in Chapter 2 , were selected based on the presence of a predicted C-terminal Glycosylphosphatidylinositol (GPI) anchor signal and /or N-terminal signal peptide, since proteins with such features are likely to be located on the surface of the cell where they are involved in extracellular interaction (Ferguson 1999).

In Chapter 5 the results of screening the MMV malaria box, pathogen box and dasatanib drug compounds against $T$. parva infected lymphocytes is presented. Dasatanib, a tyrosine kinase inhibitor indicated in certain leukemias was found to inhibit proliferation of $T$. parva infected lymphocytes comparable to buparvaquone and non-toxic $(\mathrm{CC} 50>8 \mu \mathrm{M})$ on bovine PBMCs immortalized by Concanavalin A (Con A blasts). One of the 400 malaria box compounds and one of the 396 pathogen box compounds inhibited proliferation of T. parva infected lymphocytes with a therapeutic index greater than five.

Finally, in Chapter 6, we discuss the implications of our research for the rational design of intervention strategies for ECF and propose future research opportunities. 


\section{References}

Abdelhaleem, M. (2004). "Do human RNA helicases have a role in cancer?" Biochimica et Biophysica Acta (BBA) - Reviews on Cancer 1704(1): 37-46.

Aurrecoechea, C., J. Brestelli, B. P. Brunk, S. Fischer, B. Gajria, X. Gao, A. Gingle, G. Grant, O. S. Harb, M. Heiges, F. Innamorato, J. Iodice, J. C. Kissinger, E. T. Kraemer, W. Li, J. A. Miller, V. Nayak, C. Pennington, D. F. Pinney, D. S. Roos, C. Ross, G. Srinivasamoorthy, J. C. J. Stoeckert, R. Thibodeau, C. Treatman and H. Wang (2010). "EuPathDB: a portal to eukaryotic pathogen databases." Nucleic Acids Research 38(suppl_1): D415-D419.

Babo Martins, S., G. Di Giulio, G. Lynen, A. Peters and J. Rushton (2010). "Assessing the impact of East Coast Fever immunisation by the infection and treatment method in Tanzanian pastoralist systems." Preventive Veterinary Medicine 97(3-4): 175-182.

Baldwin, C. L., S. J. Black, W. C. Brown, P. A. Conrad, B. M. Goddeeris, S. W. Kinuthia, P. A. Lalor, N. D. MacHugh, W. I. Morrison and S. P. Morzaria (1988). "Bovine T cells, B cells, and null cells are transformed by the protozoan parasite Theileria parva." Infection and Immunity 56(2): 462-467.

Ballingall, K. T., D. M. Mwangi, N. D. MacHugh, E. L. N. Taracha, P. Totte and D. J. McKeever (2000). "A highly sensitive, non-radioactive assay for T cell activation in cattle: applications in screening for antigens recognised by CD4+ and CD8+ T cells." Journal of Immunological Methods 239(1-2): 85-93.

Beaufays, J., B. Adam, C. Menten-Dedoyart, L. Fievez, A. Grosjean, Y. Decrem, P. P. Prevot, S. Santini, R. Brasseur, M. Brossard, M. Vanhaeverbeek, F. Bureau, E. Heinen, L. Lins, L. Vanhamme and E. Godfroid (2008). "Ir-LBP, an ixodes ricinus tick salivary LTB4-binding lipocalin, interferes with host neutrophil function." PLoS One 3(12): e3987.

Birth, D., W. C. Kao and C. Hunte (2014). "Structural analysis of atovaquone-inhibited cytochrome bc1 complex reveals the molecular basis of antimalarial drug action." Nat Commun 5: 4029.

Bishop, R., B. Lambson, C. Wells, P. Pandit, J. Osaso, C. Nkonge, S. Morzaria, A. Musoke and V. Nene (2002). "A cement protein of the tick Rhipicephalusappendiculatus, located in the secretory e cell granules of the type III salivary gland acini, induces strong antibody responses in cattle." International Journal for Parasitology 32(7): 833-842.

Bishop, R., V. Nene, J. Staeyert, J. Rowlands, J. Nyanjui, J. Osaso, S. Morzaria and A. Musoke (2003). "Immunity to East Coast fever in cattle induced by a polypeptide fragment of the major surface coat protein of Theileria parva sporozoites." Vaccine 21(11-12): 1205-1212. 
Brown, C. G. (1990). "Control of tropical theileriosis (Theileria annulata infection) of cattle." Parassitologia 32(1): 23-31.

Brown, W. C., T. F. McElwain, G. H. Palmer, S. E. Chantler and D. M. Estes (1999). "Bovine CD4+ T-Lymphocyte Clones Specific for Rhoptry-Associated Protein 1 of Babesia bigemina Stimulate Enhanced Immunoglobulin G1 (IgG1) and IgG2 Synthesis." Infection and Immunity 67(1): 155-164.

Brown, W. C., M. K. Shaw, P. A. Conrad and T. T. Dolan (1989). "Theileria parva: reappearance of schizonts in infected lymphoblastoid cells treated with parvaquone is dependent on interleukin 2-like growth factors." Exp Parasitol 68(3): 308-325.

Brown, W. C., C. Sugimoto and D. J. Grab (1989). "Theileria parva: Bovine helper T cell clones specific for both infected lymphocytes and schizont membrane antigens." Experimental Parasitology 69(2): 234-248.

Brown, W. C., S. Zhao, K. S. Logan, D. J. Grab and A. C. Rice-Ficht (1995). "Identification of candidate vaccine antigens of bovine hemoparasites Theileria parva and Babesia bovis by use of helper T cell clones." Vet Parasitol 57(1-3): 189-203.

Budu, A. and C. R. S. Garcia (2012). "Generation of second messengers in Plasmodium." Microbes and Infection 14(10): 787-795.

Büscher, G. and J. Tangus (1986). "Quantitative studies on Theileria parva in the salivary glands of Rhipicephalus appendiculatus adults: Search for conditions for high infections." International Journal for Parasitology 16(2): 121-129.

Cao, J., O. Kaneko, A. Thongkukiatkul, M. Tachibana, H. Otsuki, Q. Gao, T. Tsuboi and M. Torii (2009). "Rhoptry neck protein RON2 forms a complex with microneme protein AMA1 in Plasmodium falciparum merozoites." Parasitology International 58(1): 29-35.

Chen, Z., F. Y. Lee, K. N. Bhalla and J. Wu (2006). "Potent inhibition of platelet-derived growth factor-induced responses in vascular smooth muscle cells by BMS-354825 (dasatinib)." Mol Pharmacol 69(5): 1527-1533.

Cingolani, P., A. Platts, L. L. Wang, M. Coon, T. Nguyen, L. Wang, S. J. Land, X. Lu and D. M. Ruden (2012). "A program for annotating and predicting the effects of single nucleotide polymorphisms, SnpEff: SNPs in the genome of Drosophila melanogaster strain w1118; iso-2; iso-3." Fly 6(2): 80-92.

Cowman, A. F. and B. S. Crabb (2006). "Invasion of Red Blood Cells by Malaria Parasites." Cell 124(4): 755-766. 
Crane, M. S., P. K. Murray, M. J. Gnozzio and T. T. MacDonald (1988). "Passive protection of chickens against Eimeria tenella infection by monoclonal antibody." Infection and Immunity 56(4): 972-976.

Cruz, F. M., J. D. Colbert, E. Merino, B. A. Kriegsman and K. L. Rock (2017). "The Biology and Underlying Mechanisms of Cross-Presentation of Exogenous Antigens on MHC-I Molecules." Annual Review of Immunology 35(1): 149-176.

Cui, L., S. Mharakurwa, D. Ndiaye, P. K. Rathod and P. J. Rosenthal (2015). "Antimalarial Drug Resistance: Literature Review and Activities and Findings of the ICEMR Network." The American Journal of Tropical Medicine and Hygiene 93(3_Suppl): 57-68.

Cupp, E. W. (1991). "Biology of Ticks." Veterinary Clinics of North America: Small Animal Practice 21(1): 1-26.

Curtidor, H., L. C. Patiño, G. Arévalo-Pinzón, M. E. Patarroyo and M. A. Patarroyo (2011). "Identification of the Plasmodium falciparum rhoptry neck protein 5 (PfRON5)." Gene 474(12): 22-28.

Daban, J.-R., S. Bartolomé and A. Bermúdez (1996). Rapid Staining of Proteins in Polyacrylamide Gels with Nile Red. The Protein Protocols Handbook. J. M. Walker. Totowa, NJ, Humana Press: 179-185.

Dalmo, R. A. (2018). "DNA vaccines for fish: Review and perspectives on correlates of protection." Journal of Fish Diseases 41(1): 1-9.

De Deken, R., V. Martin, A. Saido, M. Madder, J. Brandt and D. Geysen (2007). "An outbreak of East Coast Fever on the Comoros: A consequence of the import of immunised cattle from Tanzania?" Veterinary Parasitology 143(3): 245-253.

Decrem, Y., J. Beaufays, V. Blasioli, K. Lahaye, M. Brossard, L. Vanhamme and E. Godfroid (2008). "A family of putative metalloproteases in the salivary glands of the tick Ixodes ricinus." Febs j 275(7): 1485-1499.

Delorenzi, M., A. Sexton, H. Shams-Eldin, R. T. Schwarz, T. Speed and L. Schofield (2002). "Genes for Glycosylphosphatidylinositol Toxin Biosynthesis in Plasmodium falciparum." Infection and Immunity 70(8): 4510-4522.

Dessauge, F., R. Lizundia, M. Baumgartner, M. Chaussepied and G. Langsley (2005). "Taking the Myc is bad for Theileria." Trends in Parasitology 21(8): 377-385. 
Di Giulio, G., G. Lynen, S. Morzaria, C. Oura and R. Bishop (2009). "Live immunization against East Coast fever - current status." Trends in Parasitology 25(2): 85-92.

Dobbelaere, D. and V. Heussler (1999). "Transformation of Leukocytes by Theileria parva and T. annulata." Annual Review of Microbiology 53(1): 1-42.

Dobbelaere, D., S. Z. Shapiro and P. Webster (1985). "Identification of a surface antigen on Theileria parva sporozoites by monoclonal antibody." Proceedings of the National Academy of Sciences 82(6): 1771-1775.

Dobbelaere, D. A. E. and P. Küenzi (2004). "The strategies of the Theileria parasite: a new twist in host-pathogen interactions." Current Opinion in Immunology 16(4): 524-530.

Dobbelaere, D. A. E., I. J. Roditi, T. s. M. Coquerelle, C. Kelke, M. Eichhorn and R. O. Williams (1991). "Lymphocytes infected with Theileria parva require both cell-cell contact and growth factor to proliferate." European Journal of Immunology 21(1): 89-95.

Dobbelaere, D. A. E., P. R. Spooner, W. C. Barry and A. D. Irvin (1984). "Monoclonal antibody neutralizes the sporozoite stage of different Theileria parva stocks." Parasite Immunology 6(4): 361-370.

Duffy, S., M. L. Sykes, A. J. Jones, T. B. Shelper, M. Simpson, R. Lang, S.-A. Poulsen, B. E. Sleebs and V. M. Avery (2017). "Screening the Medicines for Malaria Venture Pathogen Box across Multiple Pathogens Reclassifies Starting Points for Open-Source Drug Discovery." Antimicrobial Agents and Chemotherapy 61(9).

Dvorin, J. D., D. C. Martyn, S. D. Patel, J. S. Grimley, C. R. Collins, C. S. Hopp, A. T. Bright, S. Westenberger, E. Winzeler, M. J. Blackman, D. A. Baker, T. J. Wandless and M. T. Duraisingh (2010). "A Plant-Like Kinase in Plasmodium falciparum Regulates Parasite Egress from Erythrocytes." Science 328(5980): 910-912.

Ebel, T., J. Gerhards, B. R. Binder and J. Lipp (1999). "Theileria parva 104 kDa micronemerhoptry protein is membrane-anchored by a non-cleaved amino-terminal signal sequence for entry into the endoplasmic reticulum." Molecular and Biochemical Parasitology 100(1): 19-26.

Emanuelsson, O., H. Nielsen, S. Brunak and G. von Heijne (2000). "Predicting Subcellular Localization of Proteins Based on their N-terminal Amino Acid Sequence." Journal of Molecular Biology 300(4): 1005-1016.

Emery, D. L. (1981). "Adoptive transfer of immunity to infection with Theileria parva (East Coast fever) between cattle twins." Research in Veterinary Science 30(3): 364-367. 
Fankhauser, N. and P. Mäser (2005). "Identification of GPI anchor attachment signals by a Kohonen self-organizing map." Bioinformatics 21(9): 1846-1852.

Fawcett, D. W., G. Büscher and S. Doxsey (1982). "Salivary gland of the tick vector of east coast fever. IV. Cell type selectivity and host cell responses to Theileria parva." Tissue and Cell 14(2): 397-414.

Fawcett, D. W., S. Doxsey, D. A. Stagg and A. S. Young (1982b). "The entry of sporozoites of Theileria parva into bovine lymphocytes in vitro. Electron microscopic observations." European journal of cell biology 27(1): 10-21.

Fenner, F. (2000). "Adventures with poxviruses of vertebrates." FEMS Microbiology Reviews 24(2): 123-133.

Ferguson, M. A. (1999). "The structure, biosynthesis and functions of glycosylphosphatidylinositol anchors, and the contributions of trypanosome research." Journal of Cell Science 112(17): 2799-2809.

Ferguson MAJ, K. T., Hart GW (2009). Essentials of Glycobiology. Cold Spring Harbor (NY), Cold Spring Harbor Laboratory Press.

Finn, R. S., J. Dering, C. Ginther, C. A. Wilson, P. Glaspy, N. Tchekmedyian and D. J. Slamon (2007). "Dasatinib, an orally active small molecule inhibitor of both the src and abl kinases, selectively inhibits growth of basal-type/"triple-negative" breast cancer cell lines growing in vitro." Breast Cancer Research and Treatment 105(3): 319-326.

Florens, L., M. P. Washburn, J. D. Raine, R. M. Anthony, M. Grainger, J. D. Haynes, J. K. Moch, N. Muster, J. B. Sacci, D. L. Tabb, A. A. Witney, D. Wolters, Y. Wu, M. J. Gardner, A. A. Holder, R. E. Sinden, J. R. Yates and D. J. Carucci (2002). "A proteomic view of the Plasmodium falciparum life cycle." Nature 419(6906): 520-526.

Francischetti, I. M. B., V. My Pham, B. J. Mans, J. F. Andersen, T. N. Mather, R. S. Lane and J. M. C. Ribeiro (2005). "The transcriptome of the salivary glands of the female western blacklegged tick Ixodes pacificus (Acari: Ixodidae)." Insect Biochemistry and Molecular Biology 35(10): 1142-1161.

Gachet, C. (2008). "P2 receptors, platelet function and pharmacological implications." Thromb Haemost 99(3): 466-472.

Gardner, M. J., R. Bishop, T. Shah, E. P. de Villiers, J. M. Carlton, N. Hall, Q. Ren, I. T. Paulsen, A. Pain, M. Berriman, R. J. M. Wilson, S. Sato, S. A. Ralph, D. J. Mann, Z. Xiong, S. J. Shallom, J. Weidman, L. Jiang, J. Lynn, B. Weaver, A. Shoaibi, A. R. Domingo, D. Wasawo, J. Crabtree, J. R. Wortman, B. Haas, S. V. Angiuoli, T. H. Creasy, C. Lu, B. Suh, J. C. Silva, 
T. R. Utterback, T. V. Feldblyum, M. Pertea, J. Allen, W. C. Nierman, E. L. N. Taracha, S. L. Salzberg, O. R. White, H. A. Fitzhugh, S. Morzaria, J. C. Venter, C. M. Fraser and V. Nene (2005). "Genome Sequence of Theileria parva, a Bovine Pathogen That Transforms Lymphocytes." Science 309(5731): 134-137.

Garrison, E. and G. Marth (2012). "Haplotype-based variant detection from short-read sequencing." arXiv preprint arXiv:1207.3907.

Geysen, D., T. Bazarusanga, J. Brandt and T. T. Dolan (2004). "An unusual mosaic structure of the PIM gene of Theileria parva and its relationship to allelic diversity." Molecular and Biochemical Parasitology 133(2): 163-173.

Gilson, P. R., T. Nebl, D. Vukcevic, R. L. Moritz, T. Sargeant, T. P. Speed, L. Schofield and B. S. Crabb (2006). "Identification and Stoichiometry of Glycosylphosphatidylinositolanchored Membrane Proteins of the Human Malaria Parasite Plasmodium falciparum." Molecular \& Cellular Proteomics 5(7): 1286-1299.

Graham, S. P., Y. Honda, R. Pellé, D. M. Mwangi, E. J. Glew, E. P. de Villiers, T. Shah, R. Bishop, P. van der Bruggen, V. Nene and E. L. N. Taracha (2007). "A novel strategy for the identification of antigens that are recognised by bovine MHC class I restricted cytotoxic T cells in a protozoan infection using reverse vaccinology." Immunome Research 3: 2-2.

Graham, S. P., R. Pelle, Y. Honda, D. M. Mwangi, N. J. Tonukari, M. Yamage, E. J. Glew, E. P. de Villiers, T. Shah, R. Bishop, E. Abuya, E. Awino, J. Gachanja, A. E. Luyai, F. Mbwika, A. M. Muthiani, D. M. Ndegwa, M. Njahira, J. K. Nyanjui, F. O. Onono, J. Osaso, R. M. Saya, C. Wildmann, C. M. Fraser, I. Maudlin, M. J. Gardner, S. P. Morzaria, S. Loosmore, S. C. Gilbert, J. C. Audonnet, P. van der Bruggen, V. Nene and E. L. Taracha (2006). "Theileria parva candidate vaccine antigens recognized by immune bovine cytotoxic T lymphocytes." Proc Natl Acad Sci U S A 103(9): 3286-3291.

Graham, S. P., R. Pellé, M. Yamage, D. M. Mwangi, Y. Honda, R. S. Mwakubambanya, E. P. de Villiers, E. Abuya, E. Awino, J. Gachanja, F. Mbwika, A. M. Muthiani, C. Muriuki, J. K. Nyanjui, F. O. Onono, J. Osaso, V. Riitho, R. M. Saya, S. A. Ellis, D. J. McKeever, N. D. MacHugh, S. C. Gilbert, J.-C. Audonnet, W. I. Morrison, P. van der Bruggen and E. L. N. Taracha (2008). "Characterization of the Fine Specificity of Bovine CD8 T-Cell Responses to Defined Antigens from the Protozoan Parasite Theileria parva." Infection and Immunity 76(2): 685-694.

Hall, R., N. R. Boulter, C. G. Brown, G. Wilkie, E. Kirvar, V. Nene, A. J. Musoke, E. J. Glass and S. P. Morzaria (2000). "Reciprocal cross-protection induced by sporozoite antigens SPAG1 from Theileria annulata and p67 from Theileria parva." Parasite Immunology 22(5): 223-230.

Han, X., A. Aslanian and J. R. Yates (2008). "Mass spectrometry for proteomics." Current Opinion in Chemical Biology 12(5): 483-490. 
Hansson, M., P.-A. k. Nygren and S. Sta ${ }^{\circ}$ hl (2000). "Design and production of recombinant subunit vaccines." Biotechnology and Applied Biochemistry 32(2): 95-107.

Hashemi-Fesharki, R. (1991). "Chemotherapeutic value of parvaquone and buparvaquone against Theileria annulata infection of cattle." Research in Veterinary Science 50(2): 204-207.

Havlíková, S., L. Roller, J. Koči, A. R. Trimnell, M. Kazimírová, B. Klempa and P. A. Nuttall (2009). "Functional role of 64P, the candidate transmission-blocking vaccine antigen from the tick, Rhipicephalus appendiculatus." International Journal for Parasitology 39(13): 1485-1494.

Hayashida, K., T. Abe, W. Weir, R. Nakao, K. Ito, K. Kajino, Y. Suzuki, F. Jongejan, D. Geysen and C. Sugimoto (2013). "Whole-genome sequencing of Theileria parva strains provides insight into parasite migration and diversification in the African continent." DNA Res 20(3): 209-220.

Hayashida, K., Y. Hara, T. Abe, C. Yamasaki, A. Toyoda, T. Kosuge, Y. Suzuki, Y. Sato, S. Kawashima, T. Katayama, H. Wakaguri, N. Inoue, K. Homma, M. Tada-Umezaki, Y. Yagi, Y. Fujii, T. Habara, M. Kanehisa, H. Watanabe, K. Ito, T. Gojobori, H. Sugawara, T. Imanishi, W. Weir, M. Gardner, A. Pain, B. Shiels, M. Hattori, V. Nene and C. Sugimoto (2012). "Comparative Genome Analysis of Three Eukaryotic Parasites with Differing Abilities To Transform Leukocytes Reveals Key Mediators of Theileria-Induced Leukocyte Transformation." $\underline{\text { mBio } 3(5) .}$

Hayashida, K., M. Hattori, R. Nakao, Y. Tanaka, J.-Y. Kim, N. Inoue, V. Nene and C. Sugimoto (2010). "A schizont-derived protein, TpSCOP, is involved in the activation of NF$\kappa \mathrm{B}$ in Theileria parva-infected lymphocytes." Molecular and Biochemical Parasitology 174(1): 8-17.

Hochhaus, A., M. Baccarani, M. Deininger, J. F. Apperley, J. H. Lipton, S. L. Goldberg, S. Corm, N. P. Shah, F. Cervantes, R. T. Silver, D. Niederwieser, R. M. Stone, H. Dombret, R. A. Larson, L. Roy, T. Hughes, M. C. Müller, R. Ezzeddine, A. M. Countouriotis and H. M. Kantarjian (2008). "Dasatinib induces durable cytogenetic responses in patients with chronic myelogenous leukemia in chronic phase with resistance or intolerance to imatinib." Leukemia 22: 1200 .

Holder, A. A., M. A. Mohd Ridzuan and J. L. Green (2012). "Calcium dependent protein kinase 1 and calcium fluxes in the malaria parasite." Microbes and Infection 14(10): 825-830.

Hostettler, I., J. Müller and A. Hemphill (2016). "In vitro screening of the open source MMV malaria box reveals novel compounds with profound activities against Theileria annulata schizonts." Antimicrobial Agents and Chemotherapy. 
Huber, S., R. Theiler, D. de Quervain, O. Wiens, T. Karangenc, V. Heussler, D. Dobbelaere and K. Woods (2017). "The Microtubule-Stabilizing Protein CLASP1 Associates with the $<e m>$ Theileria annulata</em $>$ Schizont Surface via Its Kinetochore-Binding Domain." mSphere 2(4).

Hulliger, L., K. H. Wilde, C. G. Brown and L. Turner (1964). "MODE OF MULTIPLICATION OF THEILERIA IN CULTURES OF BOVINE LYMPHOCYTIC CELLS." Nature 203: 728730 .

Iams, K. P., J. R. Young, V. Nene, J. Desai, P. Webster, O. K. ole-MoiYoi and A. J. Musoke (1990). "Characterisation of the gene encoding a 104-kilodalton micronemerhoptry protein of Theileria parva." Molecular and Biochemical Parasitology 39(1): 47-60.

Ikezawa, H. (2002). "Glycosylphosphatidylinositol (GPI)-Anchored Proteins." Biological and Pharmaceutical Bulletin 25(4): 409-417.

Imamura, S., S. Konnai, S. Vaz Ida, S. Yamada, C. Nakajima, Y. Ito, T. Tajima, J. Yasuda, M. Simuunza, M. Onuma and K. Ohashi (2008). "Effects of anti-tick cocktail vaccine against Rhipicephalus appendiculatus." Jpn J Vet Res 56(2): 85-98.

Imamura, S., B. Namangala, T. Tajima, M. E. Tembo, J. Yasuda, K. Ohashi and M. Onuma (2006). "Two serine protease inhibitors (serpins) that induce a bovine protective immune response against Rhipicephalus appendiculatus ticks." Vaccine 24(13): 2230-2237.

Irvin, A. D. and W. I. Morrison (1987). Immunopathology, immunology, and immunoprophylaxis of Theileria infections. Boca Raton, Florida, CRC Press, Inc.: 223-274.

Ishihama, Y., Y. Oda, T. Tabata, T. Sato, T. Nagasu, J. Rappsilber and M. Mann (2005). "Exponentially Modified Protein Abundance Index (emPAI) for Estimation of Absolute Protein Amount in Proteomics by the Number of Sequenced Peptides per Protein." Molecular \& Cellular Proteomics 4(9): 1265-1272.

Jaworski, D. C., F. A. Simmen, W. Lamoreaux, L. B. Coons, M. T. Muller and G. R. Needham (1995). "A secreted calreticulin protein in ixodid tick (Amblyomma americanum) saliva." Journal of Insect Physiology 41(4): 369-375.

Jeon, K. I., M. S. Byun and D. M. Jue (2003). "Gold compound auranofin inhibits IkappaB kinase (IKK) by modifying Cys-179 of IKKbeta subunit." Exp Mol Med 35(2): 61-66.

Johnson, F. M., B. N. Bekele, L. Feng, I. Wistuba, X. M. Tang, H. T. Tran, J. J. Erasmus, L.L. Hwang, N. Takebe, G. R. Blumenschein, S. M. Lippman and D. J. Stewart (2010). "Phase II Study of Dasatinib in Patients With Advanced Non-Small-Cell Lung Cancer." Journal of Clinical Oncology 28(30): 4609-4615. 
Jones, M. L., E. L. Kitson and J. C. Rayner (2006). "Plasmodium falciparum erythrocyte invasion: A conserved myosin associated complex." Molecular and Biochemical Parasitology 147(1): 74-84.

Kaba, S. A. (2003). Development of a novel subunit vaccine against East Coast fever based on the Theileria parva sporozoite surface protein $\mathrm{p} 67$.

Kariu, T., T. Ishino, K. Yano, Y. Chinzei and M. Yuda (2006). "CelTOS, a novel malarial protein that mediates transmission to mosquito and vertebrate hosts." Molecular Microbiology 59(5): 1369-1379.

Kariuki, D. P., A. S. Young, S. P. Morzaria, A. C. Lesan, S. K. Mining, P. Omwoyo, J. L. Wafula and D. H. Molyneux (1995). "Theileria parva carrier state in naturally infected and artificially immunised cattle." Trop Anim Health Prod 27(1): 15-25.

Khan, S. M., B. Franke-Fayard, G. R. Mair, E. Lasonder, C. J. Janse, M. Mann and A. P. Waters (2005). "Proteome Analysis of Separated Male and Female Gametocytes Reveals Novel SexSpecific Plasmodium Biology." Cell 121(5): 675-687.

Krogh, A., B. Larsson, G. von Heijne and E. L. L. Sonnhammer (2001). "Predicting transmembrane protein topology with a hidden markov model: application to complete genomes1." Journal of Molecular Biology 305(3): 567-580.

Kumar, K. A., G. A. Oliveira, R. Edelman, E. Nardin and V. Nussenzweig (2004). "Quantitative Plasmodium sporozoite neutralization assay (TSNA)." Journal of Immunological Methods 292(1): 157-164.

Lancet (2015). "Efficacy and safety of RTS,S/AS01 malaria vaccine with or without a booster dose in infants and children in Africa: final results of a phase 3, individually randomised, controlled trial." Lancet 386(9988): 31-45.

Lasonder, E., C. J. Janse, G.-J. van Gemert, G. R. Mair, A. M. W. Vermunt, B. G. Douradinha, V. van Noort, M. A. Huynen, A. J. F. Luty, H. Kroeze, S. M. Khan, R. W. Sauerwein, A. P. Waters, M. Mann and H. G. Stunnenberg (2008). "Proteomic Profiling of <italic>Plasmodium</italic> Sporozoite Maturation Identifies New Proteins Essential for Parasite Development and Infectivity." PLoS Pathog 4(10): e1000195.

Latif, A. A. and T. Hove (2011). "History and critical review of Theileria parva (Boleni), the vaccine stock against Zimbabwean cattle theileriosis." Ticks and Tick-borne Diseases 2(3): 163-167.

Lauterbach, S. B. and T. L. Coetzer (2008). "The M18 aspartyl aminopeptidase of Plasmodium falciparum binds to human erythrocyte spectrin in vitro." Malaria Journal 7: 1-10. 
Lawrence, J. A. (1979). "The differential diagnosis of the bovine theilerias of southern Africa." Journal of the South African Veterinary Association 50(4): 311-313.

Li, L., C. J. Stoeckert and D. S. Roos (2003). "OrthoMCL: Identification of Ortholog Groups for Eukaryotic Genomes." Genome Research 13(9): 2178-2189.

Liljeqvist, S. and S. Ståhl (1999). "Production of recombinant subunit vaccines: protein immunogens, live delivery systems and nucleic acid vaccines." Journal of Biotechnology 73(1): 1-33.

Lindner, S. E., K. E. Swearingen, A. Harupa, A. M. Vaughan, P. Sinnis, R. L. Moritz and S. H. Kappe (2013). "Total and putative surface proteomics of malaria parasite salivary gland sporozoites." Mol Cell Proteomics 12(5): 1127-1143.

Marsolier, J., M. Perichon, J. D. DeBarry, B. O. Villoutreix, J. Chluba, T. Lopez, C. Garrido, X. Z. Zhou, K. P. Lu, L. Fritsch, S. Ait-Si-Ali, M. Mhadhbi, S. Medjkane and J. B. Weitzman (2015). "Theileria parasites secrete a prolyl isomerase to maintain host leukocyte transformation." Nature 520(7547): 378-382.

Marsolier, J., M. Perichon, J. D. DeBarry, B. O. Villoutreix, J. Chluba, T. Lopez, C. Garrido, X. Z. Zhou, K. P. Lu, L. Fritsch, S. Ait-Si-Ali, M. Mhadhbi, S. Medjkane and J. B. Weitzman (2015). "Theileria parasites secrete a prolyl isomerase to maintain host leukocyte transformation." Nature 520: 378.

Matson, B. A. (1967). "Theileriosis in Rhodesia: 1. A study of diagnostic specimens over two seasons." Journal of the South African Veterinary Association 38(1): 93-102.

Mbizeni, S., F. T. Potgieter, C. Troskie, B. J. Mans, B. L. Penzhorn and A. A. Latif (2013). "Field and laboratory studies on Corridor disease (Theileria parva infection) in cattle population at the livestock/game interface of uPhongolo-Mkuze area, South Africa." Ticks and Tick-borne Diseases 4(3): 227-234.

McHardy, N., L. S. Wekesa, A. T. Hudson and A. W. Randall (1985). "Antitheilerial activity of BW720C (buparvaquone): a comparison with parvaquone." Research in Veterinary Science 39(1): 29-33.

McKeever, D. J., E. L. Taracha, E. L. Innes, N. D. MacHugh, E. Awino, B. M. Goddeeris and W. I. Morrison (1994). "Adoptive transfer of immunity to Theileria parva in the CD8+ fraction of responding efferent lymph." Proceedings of the National Academy of Sciences 91.

McLeod, A. and R. Kristjanson (1999). "Impact of ticks and associated diseases on cattle in Asia, Australia and Africa. ILRI and eSYS report to ACIAR." 
Mhadhbi, M., M. Chaouch, K. Ajroud, M. A. Darghouth and S. BenAbderrazak (2015). "Sequence Polymorphism of Cytochrome b Gene in Theileria annulata Tunisian Isolates and Its Association with Buparvaquone Treatment Failure." PLoS ONE 10(6): e0129678.

Mhadhbi, M., A. Naouach, A. Boumiza, M. F. Chaabani, S. BenAbderazzak and M. A. Darghouth (2010). "In vivo evidence for the resistance of Theileria annulata to buparvaquone." Veterinary Parasitology 169(3-4): 241-247.

Mogire, R. M., H. M. Akala, R. W. Macharia, D. W. Juma, A. C. Cheruiyot, B. Andagalu, M. L. Brown, H. A. El-Shemy and S. G. Nyanjom (2017). "Target-similarity search using Plasmodium falciparum proteome identifies approved drugs with anti-malarial activity and their possible targets." PLOS ONE 12(10): e0186364.

Morrison, W. I. (2009). "Progress towards understanding the immunobiology of Theileria parasites." Parasitology 136.

Morrison, W. I., T. Connelley, J. D. Hemmink and N. D. MacHugh (2015). "Understanding the basis of parasite strain-restricted immunity to Theileria parva." Annu Rev Anim Biosci 3: 397-418.

Morrison, W. I. and B. M. Goddeeris (1990). Cytotoxic T Cells in Immunity to Theileria parva in Cattle. T-Cell Paradigms in Parasitic and Bacterial Infections. S. H. E. Kaufmann. Berlin, Heidelberg, Springer Berlin Heidelberg: 79-93.

Morrison, W. I., N. D. MacHugh and P. A. Lalor (1996). "Pathogenicity of Theileria parva is influenced by the host cell type infected by the parasite." Infection and Immunity 64(2): 557562.

Morrison, W. I. and D. J. McKeever (2006). "Current status of vaccine development against Theileria parasites." Parasitology 133(S2): S169-S187.

Morrissette, N. S. and L. D. Sibley (2002). "Cytoskeleton of Apicomplexan Parasites." Microbiology and Molecular Biology Reviews 66(1): 21-38.

Morzaria, S., V. Nene, R. Bishop and A. Musoke (2000). "Vaccines against Theileria parva." Annals of the New York Academy of Sciences 916(1): 464-473.

Morzaria, S. P., J. Katende, A. Musoke, V. Nene, R. Skilton and R. Bishop (1999). "Development of sero-diagnostic and molecular tools for the control of important tick-borne pathogens of cattle in Africa." Parassitologia 41 Suppl 1: 73-80. 
Mulenga, A., C. Sugimoto and M. Onuma (2000). "Issues in tick vaccine development: identification and characterization of potential candidate vaccine antigens." Microbes and Infection 2(11): 1353-1361.

Musoke, A., S. Morzaria, C. Nkonge, E. Jones and V. Nene (1992). "A recombinant sporozoite surface antigen of Theileria parva induces protection in cattle." Proceedings of the National Academy of Sciences 89(2): 514-518.

Musoke, A. J., V. M. Nantulya, G. Buscher, R. A. Masake and B. Otim (1982). "Bovine immune response to Theileria parva: neutralizing antibodies to sporozoites." Immunology 45(4): 663-668.

Musoke, A. J., V. M. Nantulya, F. R. Rurangirwa and G. Buscher (1984). "Evidence for a common protective antigenic determinant on sporozoites of several Theileria parva strains." Immunology 52(2): 231-238.

Nam, S., A. Williams, A. Vultur, A. List, K. Bhalla, D. Smith, F. Y. Lee and R. Jove (2007). "Dasatinib (BMS-354825) inhibits Stat5 signaling associated with apoptosis in chronic myelogenous leukemia cells." Mol Cancer Ther 6(4): 1400-1405.

Nene, V., H. Kiara, A. Lacasta, R. Pelle, N. Svitek and L. Steinaa (2016). "The biology of Theileria parva and control of East Coast fever - Current status and future trends." Ticks and Tick-borne Diseases 7(4): 549-564.

Nene, V., D. Lee, S. Kang'a, R. Skilton, T. Shah, E. de Villiers, S. Mwaura, D. Taylor, J. Quackenbush and R. Bishop (2004). "Genes transcribed in the salivary glands of female Rhipicephalus appendiculatus ticks infected with Theileria parva." Insect Biochemistry and Molecular Biology 34(10): 1117-1128.

Nene, V. and W. I. Morrison (2016). "Approaches to vaccination against Theileria parva and Theileria annulata." Parasite Immunology 38(12): 724-734.

Nene, V., A. Musoke, E. Gobright and S. Morzaria (1996). "Conservation of the sporozoite p67 vaccine antigen in cattle-derived Theileria parva stocks with different cross-immunity profiles." Infection and Immunity 64(6): 2056-2061.

Nixon, G. L., D. M. Moss, A. E. Shone, D. G. Lalloo, N. Fisher, P. M. O'Neill, S. A. Ward and G. A. Biagini (2013). "Antimalarial pharmacology and therapeutics of atovaquone." Journal of Antimicrobial Chemotherapy 68(5): 977-985.

Norval, R. A. I., B. D. Perry and A. Young (1992). The epidemiology of theileriosis in Africa, Academic press, London. 
Nyagwange, J., E. Tijhaar, N. Ternette, F. Mobegi, K. Tretina, J. C. Silva, R. Pelle and V. Nene (2018). "Characterization of the Theileria parva sporozoite proteome." International Journal for Parasitology 48(3): 265-273.

O'Flaherty, J. T. and J. F. Cordes (1994). "Human neutrophil degranulation responses to nucleotides." Lab Invest 70(6): 816-821.

O. Salas, C., M. Faundez, A. Morello, J. Diego Maya and R. A. Tapia (2011). "Natural and Synthetic Naphthoquinones Active Against Trypanosoma Cruzi: An Initial Step Towards New Drugs for Chagas Disease." Current Medicinal Chemistry 18(1): 144-161.

Odongo, D. O., J. D. Sunter, H. K. Kiara, R. A. Skilton and R. P. Bishop (2010). "A nested PCR assay exhibits enhanced sensitivity for detection of Theileria parva infections in bovine blood samples from carrier animals." Parasitol Res 106(2): 357-365.

Oxberry, M. E., T. G. Gear and R. K. Prichard (2001). "Assessment of benzimidazole binding to individual recombinant tubulin isotypes from Haemonchus contortus." Parasitology $122(\mathrm{Pt}$ 6): 683-687.

Paesen, G. C., P. L. Adams, K. Harlos, P. A. Nuttall and D. I. Stuart (1999). "Tick histaminebinding proteins: isolation, cloning, and three-dimensional structure." Mol Cell 3(5): 661-671.

Pain, A., H. Renauld, M. Berriman, L. Murphy, C. A. Yeats, W. Weir, A. Kerhornou, M. Aslett, R. Bishop, C. Bouchier, M. Cochet, R. M. R. Coulson, A. Cronin, E. P. de Villiers, A. Fraser, N. Fosker, M. Gardner, A. Goble, S. Griffiths-Jones, D. E. Harris, F. Katzer, N. Larke, A. Lord, P. Maser, S. McKellar, P. Mooney, F. Morton, V. Nene, S. Neil, C. Price, M. A. Quail, E. Rabbinowitsch, N. D. Rawlings, S. Rutter, D. Saunders, K. Seeger, T. Shah, R. Squares, S. Squares, A. Tivey, A. R. Walker, J. Woodward, D. A. E. Dobbelaere, G. Langsley, M.-A. Rajandream, D. McKeever, B. Shiels, A. Tait, B. Barrell and N. Hall (2005). "Genome of the Host-Cell Transforming Parasite Theileria annulata Compared with T. parva." Science 309(5731): 131.

Palacios, R. (1982). "Concanavalin A triggers T lymphocytes by directly interacting with their receptors for activation." The Journal of Immunology 128(1): 337-342.

Parizi, L. F., N. W. Githaka, C. Logullo, S. Konnai, A. Masuda, K. Ohashi and I. da Silva Vaz (2012). "The quest for a universal vaccine against ticks: Cross-immunity insights." The Veterinary Journal 194(2): 158-165.

Patel, E., S. Mwaura, H. Kiara, S. Morzaria, A. Peters and P. Toye (2016). "Production and dose determination of the Infection and Treatment Method (ITM) Muguga cocktail vaccine used to control East Coast fever in cattle." Ticks and Tick-borne Diseases 7(2): 306-314. 
Pelle, R., S. P. Graham, M. N. Njahira, J. Osaso, R. M. Saya, D. O. Odongo, P. G. Toye, P. R. Spooner, A. J. Musoke, D. M. Mwangi, E. L. N. Taracha, W. I. Morrison, W. Weir, J. C. Silva and R. P. Bishop (2011). "Two Theileria parva CD8 T Cell Antigen Genes Are More Variable in Buffalo than Cattle Parasites, but Differ in Pattern of Sequence Diversity." PLOS ONE 6(4): e19015.

Perry, B. D. and A. S. Young (1993). "The naming game: the changing fortunes of East Coast fever and Theileria parva." Vet Rec 133(25-26): 613-616.

Perryman, L. E., M. W. Riggs, P. H. Mason and R. Fayer (1990). "Kinetics of Cryptosporidium parvum sporozoite neutralization by monoclonal antibodies, immune bovine serum, and immune bovine colostrum." Infection and Immunity 58(1): 257-259.

Petersen, T. N., S. Brunak, G. von Heijne and H. Nielsen (2011). "SignalP 4.0: discriminating signal peptides from transmembrane regions." Nature Methods 8(10): 785-786.

Pierleoni, A., P. L. Martelli and R. Casadio (2008). "PredGPI: a GPI-anchor predictor." BMC Bioinformatics 9(1): 392.

Pradel, G. (2007). "Proteins of the malaria parasite sexual stages: expression, function and potential for transmission blocking strategies." Parasitology 134(14): 1911-1929.

Quintas-Cardama, A., H. Kantarjian and J. Cortes (2006). "Targeting ABL and SRC kinases in chronic myeloid leukemia: experience with dasatinib." Future Oncol 2(6): 655-665.

Radley, D. E. (1981). Infection and Treatment Method of Immunization Against Theileriosis. Advances in the Control of Theileriosis: Proceedings of an International Conference held at the International Laboratory for Research on Animal Diseases in Nairobi, 9-13th February, 1981. A. D. Irvin, M. P. Cunningham and A. S. Young. Dordrecht, Springer Netherlands: 227-237.

Radley, D. E., C. G. D. Brown, M. J. Burridge, M. P. Cunningham, I. M. Kirimi, R. E. Purnell and A. S. Young (1975). "East coast fever: 1. Chemoprophylactic immunization of cattle against Theileria parva (Muguga) and five theilerial strains." Veterinary Parasitology 1(1): 3541.

Radley, D. E., C. G. D. Brown, M. P. Cunningham, C. D. Kimber, F. L. Musisi, R. C. Payne, R. E. Purnell, S. M. Stagg and A. S. Young (1975b). "East coast fever: 3. Chemoprophylactic immunization of cattle using oxytetracycline and a combination of theilerial strains." Veterinary Parasitology 1(1): 51-60.

Remarque, E. J., B. W. Faber, C. H. M. Kocken and A. W. Thomas (2008). "Apical membrane antigen 1: a malaria vaccine candidate in review." Trends in Parasitology 24(2): 74-84. 
Ribeiro, J. M., J. M. Anderson, N. C. Manoukis, Z. Meng and I. M. Francischetti (2011). "A further insight into the sialome of the tropical bont tick, Amblyomma variegatum." BMC Genomics 12(1): 136.

Ribeiro, J. M. and T. N. Mather (1998). "Ixodes scapularis: salivary kininase activity is a metallo dipeptidyl carboxypeptidase." Exp Parasitol 89(2): 213-221.

Ribeiro, J. M. C. (1987). "Role of Saliva in Blood-Feeding by Arthropods." Annual Review of Entomology 32(1): 463-478.

Ribeiro, J. M. C., F. Alarcon-Chaidez, I. M. B. Francischetti, B. J. Mans, T. N. Mather, J. G. Valenzuela and S. K. Wikel (2006). "An annotated catalog of salivary gland transcripts from Ixodes scapularis ticks." Insect Biochemistry and Molecular Biology 36(2): 111-129.

Ridley, R. G., B. Takacs, H. Etlinger and J. G. Scaife (1990). "A rhoptry antigen of Plasmodium falciparum is protective in Saimiri monkeys." Parasitology 101(2): 187-192.

Rigobello, M. P., A. Folda, M. C. Baldoin, G. Scutari and A. Bindoli (2005). "Effect of auranofin on the mitochondrial generation of hydrogen peroxide. Role of thioredoxin reductase." Free Radic Res 39(7): 687-695.

Sabadin, G. A., L. F. Parizi, I. Kiio, M. A. Xavier, R. da Silva Matos, M. I. Camargo-Mathias, N. W. o. Githaka, V. Nene and I. da Silva Vaz (2017). "Effect of recombinant glutathione Stransferase as vaccine antigen against Rhipicephalus appendiculatus and Rhipicephalus sanguineus infestation." Vaccine.

Sam-Yellowe, T. Y., L. Florens, T. Wang, J. D. Raine, D. J. Carucci, R. Sinden and J. R. Yates (2004). "Proteome Analysis of Rhoptry-Enriched Fractions Isolated from Plasmodium Merozoites." Journal of Proteome Research 3(5): 995-1001.

Sauer, J. R., R. C. Essenberg and A. S. Bowman (2000). "Salivary glands in ixodid ticks: control and mechanism of secretion." Journal of Insect Physiology 46(7): 1069-1078.

Schetters, T., G. Arts, R. Niessen, R. Van Binsbergen, L. Sanders, T. Mols-Vorstemans, T. Strydom, D. Geysen and D. Schaap (2015). "A recombinant P67 vaccine against Theileria parva in cattle: conflicting results from experimental and field challenges." ICOPA XIII, Mexico.

Schirmer, E. C., J. R. Yates, 3rd and L. Gerace (2003). "MudPIT: A powerful proteomics tool for discovery." Discov Med 3(18): 38-39. 
Schmuckli-Maurer, J., C. Casanova, S. Schmied, S. Affentranger, I. Parvanova, S. Kang'a, V. Nene, F. Katzer, D. McKeever, J. Müller, R. Bishop, A. Pain and D. A. E. Dobbelaere (2009). "Expression Analysis of the Theileria parva Subtelomere-Encoded Variable Secreted Protein Gene Family." PLoS ONE 4(3): e4839.

Shapiro, S. Z., K. Fujisaki, S. P. Morzaria, P. Webster, T. Fujinaga, P. R. Spooner and A. D. Irvin (1987). "A life-cycle stage-specific antigen of Theileria parva recognized by antimacroschizont monoclonal antibodies." Parasitology 94(1): 29-37.

Sharifiyazdi, H., F. Namazi, A. Oryan, R. Shahriari and M. Razavi (2012). "Point mutations in the Theileria annulata cytochrome $\mathrm{b}$ gene is associated with buparvaquone treatment failure." Vet Parasitol 187(3-4): 431-435.

Shaw, M. K. (1995). "Mobilization of intrasporozoite Ca2+ is essential for Theileria parva sporozoite invasion of bovine lymphocytes." Eur J Cell Biol 68(1): 78-87.

Shaw, M. K. (1996). "Theileria parvaSporozoite Entry into Bovine Lymphocytes Involves both Parasite and Host Cell Signal Transduction Processes." Experimental Parasitology 84(3): 344354.

Shaw, M. K. (2003). "Cell invasion by Theileria sporozoites." Trends in Parasitology 19(1): 26.

Shaw, M. K. and L. G. Tilney (1995). "The entry of Theileria parva merozoites into bovine erythrocytes occurs by a process similar to sporozoite invasion of lymphocytes." Parasitology 111 ( Pt 4): 455-461.

Shaw, M. K., L. G. Tilney and D. J. McKeever (1993). "Tick salivary gland extract and interleukin-2 stimulation enhance susceptibility of lymphocytes to infection by Theileria parva sporozoites." Infection and Immunity 61(4): 1486-1495.

Shaw, M. K. and A. S. Young (2009). "Differential development and emission of Theileria parva sporozoites from the salivary gland of Rhipicephalus appendiculatus." Parasitology 111(2): 153-160.

Shiels, B., G. Langsley, W. Weir, A. Pain, S. McKellar and D. Dobbelaere (2006). "Alteration of host cell phenotype by Theileria annulata and Theileria parva: mining for manipulators in the parasite genomes." International Journal for Parasitology 36(1): 9-21.

Šimo, L., M. Kazimirova, J. Richardson and S. I. Bonnet (2017). "The Essential Role of Tick Salivary Glands and Saliva in Tick Feeding and Pathogen Transmission." Frontiers in Cellular and Infection Microbiology 7(281). 
Sivakumar, T., K. Hayashida, C. Sugimoto and N. Yokoyama (2014). "Evolution and genetic diversity of Theileria." Infection, Genetics and Evolution 27: 250-263.

Skilton, R. A., R. P. Bishop, C. W. Wells, P. R. Spooner, E. Gobright, C. Nkonge, A. J. Musoke, M. Macklin and K. P. Iams (1998). "Cloning and characterization of a $150 \mathrm{kDa}$ microsphere antigen of Theileria parva that is immunologically cross-reactive with the polymorphic immunodominant molecule (PIM)." Parasitology 117 ( Pt 4): 321-330.

Skilton, R. A., A. J. Musoke, C. W. Wells, Y. Yagi, V. Nene, P. R. Spooner, J. Gachanja, J. Osaso, R. P. Bishop and S. P. Morzaria (2000). "A $32 \mathrm{kDa}$ surface antigen of Theileria parva: characterization and immunization studies." Parasitology 120 ( Pt 6): 553-564.

Steinberg, M. (2007). "Dasatinib: a tyrosine kinase inhibitor for the treatment of chronic myelogenous leukemia and philadelphia chromosome-positive acute lymphoblastic leukemia." Clin Ther 29(11): 2289-2308.

Tachado, S. D., P. Gerold, M. J. McConville, T. Baldwin, D. Quilici, R. T. Schwarz and L. Schofield (1996). "Glycosylphosphatidylinositol toxin of Plasmodium induces nitric oxide synthase expression in macrophages and vascular endothelial cells by a protein tyrosine kinasedependent and protein kinase C-dependent signaling pathway." The Journal of Immunology 156(5): 1897-1907.

Talpaz, M., N. P. Shah, H. Kantarjian, N. Donato, J. Nicoll, R. Paquette, J. Cortes, S. O'Brien, C. Nicaise, E. Bleickardt, M. A. Blackwood-Chirchir, V. Iyer, T. T. Chen, F. Huang, A. P. Decillis and C. L. Sawyers (2006). "Dasatinib in imatinib-resistant Philadelphia chromosomepositive leukemias." N Engl J Med 354(24): 2531-2541.

Tan, A. W. L., I. M. B. Francischetti, M. Slovak, R. M. Kini and J. M. C. Ribeiro (2015). "Sexual differences in the sialomes of the zebra tick, Rhipicephalus pulchellus." Journal of Proteomics 117: 120-144.

Tebaldi, G., L. B. Williams, A. E. Verna, F. Macchi, V. Franceschi, L. M. Fry, D. P. Knowles and G. Donofrio (2017). "Assessment and optimization of Theileria parva sporozoite fulllength p67 antigen expression in mammalian cells." PLOS Neglected Tropical Diseases 11(8): e0005803.

Theiler, A. (1912). "The immunisation of cattle against East Coast fever." Second Rep. Dir. Vet. Res. 1912: 216-314.

Toye, P., J. Nyanjui, B. Goddeeris and A. J. Musoke (1996). "Identification of neutralization and diagnostic epitopes on PIM, the polymorphic immunodominant molecule of Theileria parva." Infection and Immunity 64(5): 1832-1838. 
Toye, P., J. Nyanjui, B. Goddeeris and A. J. Musoke (1996). "Identification of neutralization and diagnostic epitopes on PIM, the polymorphic immunodominant molecule of Theileria parva." Infection and Immunity 64(5): 1832-1838.

Toye, P. G., B. M. Goddeeris, K. Iams, A. J. Musoke and W. I. Morrison (1991). "Characterization of a polymorphic immunodominant molecule in sporozoites and schizonts of Theileria parva." Parasite Immunology 13(1): 49-62.

Toye, P. G., M. J. Metzelaar, P. L. Wijngaard, V. Nene, K. Iams, J. Roose, J. K. Nyanjui, E. Gobright, A. J. Musoke and H. C. Clevers (1995). "Characterization of the gene encoding the polymorphic immunodominant molecule, a neutralizing antigen of Theileria parva." The Journal of Immunology 155(3): 1370-1381.

Treeck, M., S. Zacherl, S. Herrmann, A. Cabrera, M. Kono, N. S. Struck, K. Engelberg, S. Haase, F. Frischknecht, K. Miura, T. Spielmann and T. W. Gilberger (2009). "Functional Analysis of the Leading Malaria Vaccine Candidate AMA-1 Reveals an Essential Role for the Cytoplasmic Domain in the Invasion Process." PLoS Pathog 5(3): e1000322.

Tretina, K., H. T. Gotia, D. J. Mann and J. C. Silva (2015). "Theileria-transformed bovine leukocytes have cancer hallmarks." Trends in Parasitology 31(7): 306-314.

Tretina, K., R. Pelle and J. C. Silva (2016). "Cis regulatory motifs and antisense transcriptional control in the apicomplexan Theileria parva." BMC Genomics 17(1): 128.

Tyagi, N., L. S. Swapna, S. Mohanty, G. Agarwal, V. S. Gowri, K. Anamika, M. L. Priya, O. Krishnadev and N. Srinivasan (2009). "Evolutionary Divergence of Plasmodium falciparum: Sequences, Protein- Protein Interactions, Pathways and Processes." Infectious Disorders - Drug TargetsDisorders) 9(3): 257-271.

Uilenberg, G. (1999). "Immunization against diseases caused by Theileria parva." Tropical Medicine and International Health 4: A12-A20.

Van Voorhis, W. C., J. H. Adams, R. Adelfio, V. Ahyong, M. H. Akabas, P. Alano, A. Alday, Y. Alemán Resto, A. Alsibaee, A. Alzualde, K. T. Andrews, S. V. Avery, V. M. Avery, L. Ayong, M. Baker, S. Baker, C. Ben Mamoun, S. Bhatia, Q. Bickle, L. Bounaadja, T. Bowling, J. Bosch, L. E. Boucher, F. F. Boyom, J. Brea, M. Brennan, A. Burton, C. R. Caffrey, G. Camarda, M. Carrasquilla, D. Carter, M. Belen Cassera, K. Chih-Chien Cheng, W. Chindaudomsate, A. Chubb, B. L. Colon, D. D. Colón-López, Y. Corbett, G. J. Crowther, N. Cowan, S. D’Alessandro, N. Le Dang, M. Delves, J. L. DeRisi, A. Y. Du, S. Duffy, S. Abd ElSalam El-Sayed, M. T. Ferdig, J. A. Fernández Robledo, D. A. Fidock, I. Florent, P. V. T. Fokou, A. Galstian, F. J. Gamo, S. Gokool, B. Gold, T. Golub, G. M. Goldgof, R. Guha, W. A. Guiguemde, N. Gural, R. K. Guy, M. A. E. Hansen, K. K. Hanson, A. Hemphill, R. Hooft van Huijsduijnen, T. Horii, P. Horrocks, T. B. Hughes, C. Huston, I. Igarashi, K. Ingram-Sieber, M. A. Itoe, A. Jadhav, A. Naranuntarat Jensen, L. T. Jensen, R. H. Y. Jiang, A. Kaiser, J. 
Keiser, T. Ketas, S. Kicka, S. Kim, K. Kirk, V. P. Kumar, D. E. Kyle, M. J. Lafuente, S. Landfear, N. Lee, S. Lee, A. M. Lehane, F. Li, D. Little, L. Liu, M. Llinás, M. I. Loza, A. Lubar, L. Lucantoni, I. Lucet, L. Maes, D. Mancama, N. R. Mansour, S. March, S. McGowan, I. Medina Vera, S. Meister, L. Mercer, J. Mestres, A. N. Mfopa, R. N. Misra, S. Moon, J. P. Moore, F. Morais Rodrigues da Costa, J. Müller, A. Muriana, S. Nakazawa Hewitt, B. Nare, C. Nathan, N. Narraidoo, S. Nawaratna, K. K. Ojo, D. Ortiz, G. Panic, G. Papadatos, S. Parapini, K. Patra, N. Pham, S. Prats, D. M. Plouffe, S.-A. Poulsen, A. Pradhan, C. Quevedo, R. J. Quinn, C. A. Rice, M. Abdo Rizk, A. Ruecker, R. St. Onge, R. Salgado Ferreira, J. Samra, N. G. Robinett, U. Schlecht, M. Schmitt, F. Silva Villela, F. Silvestrini, R. Sinden, D. A. Smith, T. Soldati, A. Spitzmüller, S. M. Stamm, D. J. Sullivan, W. Sullivan, S. Suresh, B. M. Suzuki, Y. Suzuki, S. J. Swamidass, D. Taramelli, L. R. Y. Tchokouaha, A. Theron, D. Thomas, K. F. Tonissen, S. Townson, A. K. Tripathi, V. Trofimov, K. O. Udenze, I. Ullah, C. Vallieres, E. Vigil, J. M. Vinetz, P. Voong Vinh, H. Vu, N.-a. Watanabe, K. Weatherby, P. M. White, A. F. Wilks, E. A. Winzeler, E. Wojcik, M. Wree, W. Wu, N. Yokoyama, P. H. A. Zollo, N. Abla, B. Blasco, J. Burrows, B. Laleu, D. Leroy, T. Spangenberg, T. Wells and P. A. Willis (2016). "Open Source Drug Discovery with the Malaria Box Compound Collection for Neglected Diseases and Beyond." PLOS Pathogens 12(7): e1005763.

von Heijne, G. (1990). "The signal peptide." The Journal of Membrane Biology 115(3): 195201.

von Schubert, C., G. Xue, J. Schmuckli-Maurer, K. L. Woods, E. A. Nigg and D. A. E. Dobbelaere (2010). "The Transforming Parasite Theileria Co-opts Host Cell Mitotic and Central Spindles to Persist in Continuously Dividing Cells." PLOS Biology 8(9): e1000499.

Wampande, E. M., J. Richard McIntosh and G. W. Lubega (2007). "Classical ligands interact with native and recombinant tubulin from Onchocerca volvulus with similar rank order of magnitude." Protein Expr Purif 55(2): 236-245.

Witschi, M., D. Xia, S. Sanderson, M. Baumgartner, J. M. Wastling and D. A. E. Dobbelaere (2013). "Proteomic analysis of the Theileria annulata schizont." International Journal for Parasitology 43(2): 173-180.

Xu, T., A. Lew-Tabor and M. Rodriguez-Valle (2016). "Effective inhibition of thrombin by Rhipicephalus microplus serpin-15 (RmS-15) obtained in the yeast Pichia pastoris." Ticks and Tick-borne Diseases 7(1): 180-187.

Xue, G., C. von Schubert, P. Hermann, M. Peyer, R. Maushagen, J. Schmuckli-Maurer, P. Bütikofer, G. Langsley and D. A. E. Dobbelaere (2010). "Characterisation of gp34, a GPIanchored protein expressed by schizonts of Theileria parva and T. annulata." Molecular and Biochemical Parasitology 172(2): 113-120.

Zhang, H., M. K. Compaore, E.-g. Lee, M. Liao, G. Zhang, C. Sugimoto, K. Fujisaki, Y. Nishikawa and X. Xuan (2007). "Apical membrane antigen 1 is a cross-reactive antigen 
between Neospora caninum and Toxoplasma gondii, and the anti-NcAMA1 antibody inhibits host cell invasion by both parasites." Molecular and biochemical parasitology 151(2): 205-212. 
$36 \mid \mathrm{Ch}$ apter 1 
CHAPTER

Characterization of the Theileria parva sporozoite proteome

\author{
James Nyagwange \\ Edwin Tijhaar \\ Nicola Ternette \\ Fredrick Mobegi \\ Kyle Tretina \\ Joana C Silva \\ Roger Pelle \\ Vishvanath Nene
}

Published in International Journal for Parasitology, 2018; 48(3): 265-273 


\begin{abstract}
East Coast fever (ECF) is a lymphoproliferative disease caused by the tick-borne protozoan parasite Theileria parva. The sporozoite stage of this parasite, harbored and released from the salivary glands of the tick Rhipicephalus appendiculatus during feeding, invades and establishes infection in bovine lymphocytes. Blocking this initial stage of invasion presents a promising vaccine strategy for control of ECF and can in part be achieved by targeting the major sporozoite surface protein p67. To support research on the biology of T. parva and the identification of additional candidate vaccine antigens we report on the sporozoite proteome, as defined by LC-MS/MS analysis. In total, 4,780 proteins were identified in an enriched preparation of sporozoites. Of these, 2,007 were identified as $T$. parva proteins, representing close to $50 \%$ of the total predicted parasite proteome. The remaining 2,773 proteins were derived from the tick vector. The identified sporozoite proteins include a set of known T. parva antigens targeted by antibodies and cytotoxic T cells from cattle that are immune to ECF. We also identified proteins predicted to be orthologs of Plasmodium falciparum sporozoite surface molecules and invasion organelle proteins, and proteins that may contribute to the phenomenon of bovine lymphocyte transformation. Overall, these data establish a protein expression profile of $T$. parva sporozoites as an important starting point for further study of a parasitic species of considerable agricultural impact.
\end{abstract}

\title{
Keywords
}

Theileria, sporozoites, proteomics, mudPIT, antigens, East Coast fever 


\section{Introduction}

East Coast fever (ECF), a fatal bovine disease, is caused by the apicomplexan parasite T. parva (Norval, Perry et al. 1992). The disease kills about one million cattle every year in Africa and causes significant economic losses to small holder farmers in eastern, central and southern Africa in the range of $\$ 300$ million annually (reviewed in Nene, Kiara et al. 2016) . These estimates were derived several years ago and it is highly likely that the current losses due to ECF are much larger. Vaccination against ECF by an infection and treatment method (ITM) is available (Radley, Brown et al. 1975). For control of ECF in southern Africa, except South Africa where vaccination is not permitted as it is free of ECF, ITM is performed with a single parasite isolate, and in parts of eastern Africa a composite ITM vaccine, the Muguga cocktail, is used (Morzaria, Nene et al. 2000). Although ITM confers solid and long-lived immunity it has disadvantages in that it is an unstable and potentially lethal product, and animals vaccinated by the ITM protocol remain life-long asymptomatic carries of the parasite that poses risk for spread of the disease. It also requires a liquid nitrogen cold chain for storage and oxytetracycline for co-treatment (reviewed in Di Giulio, Lynen et al. 2009). The vaccine is expensive and laborious to produce, and it requires skilled personnel for delivery (reviewed in Di Giulio, Lynen et al. 2009). Therefore, development of a subunit vaccine that is easier to produce and with minimal risks is necessary.

Although classified in the phylum Apicomplexa, aspects of the biology of Theileria are atypical of such organisms. For example, Theileria sporozoites are not motile, they have a less defined apical complex and host cell entry is not orientation-specific (Shaw 2003). Sporozoites bind and enter lymphocytes by a "zippering" process of the host and the sporozoite cell membranes (Fawcett, Doxsey et al. 1982b). After entry into the host cell, rhoptries/microspheres are discharged with a rapid escape of the sporozoite from the surrounding host cell membrane. Sporozoites differentiate to the schizont stage, which resides free in the host cytoplasm surrounded by host cell microtubules that are seemingly nucleated by parasite molecules (reviewed in Shaw 2003). Schizont-infected cells acquire a cancer-like phenotype and are the cause of disease (Norval, Perry et al. 1992). Sporozoites also bind and enter macrophages/afferent lymph veiled cells by a zippering process, but these cells are not susceptible to transformation and sporozoites appear to only differentiate to an early schizont stage (Shaw, Tilney et al. 1993). Several host cell-signaling pathways that contribute to host cell transformation have been studied (Dobbelaere and Küenzi 2004, Dessauge, Lizundia et al. 2005). In addition, parasite molecules that are associated with the transformation process have been tentatively identified by taking advantage of comparative genomics and cancer biology (Shiels, Langsley et al. 2006, Hayashida, Hara et al. 2012, Tretina, Gotia et al. 2015). A parasite-encoded prolyl isomerase has been recently identified as playing a key role in this complex host cell transformation process (Marsolier, Perichon et al. 2015).

There is good evidence for a role of T. parva sporozoite and schizont antigens as candidate vaccine antigens. Several schizont antigens are targets of cytotoxic T lymphocytes (CTLs) that lyse schizont-infected cells (Graham, Pelle et al. 2006, Graham, Honda et al. 2007, Graham, Pellé et al. 2008) and two sporozoite antigens are targets of neutralizing antibodies (Dobbelaere, Shapiro et al. 1985, Shapiro, Fujisaki et al. 1987). One of the latter antigens, p67, has been shown to consistently protect a proportion of immunized cattle against challenge with needle-injected sporozoite and by infected ticks in field trials (reviewed in Nene, Kiara et al. 2016). The p67-based vaccine might be improved by including additional antigens that can neutralize sporozoite infectivity. 
As a first step towards improving our molecular understanding of the biology of T. parva we have undertaken a Multidimensional Protein Identification Technology (MudPIT) mass spectrometry-based approach (reviewed in Schirmer, Yates et al. 2003) to characterize the proteome of $T$. parva sporozoites purified by ion-exchange chromatography (Musoke, Morzaria et al. 1992). We have employed bioinformatic tools to analyze 2,007 parasite proteins that we were able to detect and identified T. parva orthologs of PlasmodiumPlasmodium falciparum invasion organelle proteins, calcium signaling proteins and surface proteins. Some of these may represent novel $T$. parva vaccine candidates. 


\section{Materials and methods \\ Animals and sporozoite production}

The procedure for sporozoites production has been described in detail before (Patel, Mwaura et al. 2016). Briefly, cattle, aged seven to nine months, previously managed under strict acaricide regime, were maintained for at least two months and tested for exposure to $T$. parva, Theileria mutans, Babesia bigemina, and Anaplasma marginale using ELISA and, in certain instances, PCR analysis (Morzaria, Katende et al. 1999, Odongo, Sunter et al. 2010). The naïve cattle were then inoculated with $T$. parva stabilates of the Muguga isolate and infection of the cattle was assessed. A colony of $R$. appendiculatus nymphs, previously tested for viruses, such as Bovine Viral Diarrhea virus (BVDV) and Bunya viruses, and demonstrated to be free from tick-borne haemoparasites (Patel, Mwaura et al. 2016), was then applied to the infected cattle. The fully-fed nymphs were collected and incubated for 6 weeks at $24^{\circ} \mathrm{C}$ to induce molting into adults and infection rates assessed by microscopy as described before (Büscher and Tangus 1986). A total of 300 adult ticks infected with T. parva Muguga isolate (mean infection rate of 167 acini per tick) were allowed to feed on rabbits to induce sporozoite maturation. After four days, the tick salivary glands were dissected from the ticks.

\section{Sporozoite purification}

Dissected tick salivary glands were collected in a tube with $2 \mathrm{ml}$ cold PBS, transferred to a chilled glass hand homogenizer ('UNI-FORM' 4-5 ml homogenizer) and disrupted by gentle up, down and circular motion of the pestle until a uniform cloudy suspension was formed. The suspension was then centrifuged at $1000 \mathrm{x} g$ at $4^{\circ} \mathrm{C}$ for $5 \mathrm{~min}$. The resulting supernatant containing sporozoites was applied to an $8 \mathrm{ml}$ diethylaminoethyl cellulose (DE-52; Sigma-Aldrich Cat. No. D3764) column (Musoke, Morzaria et al. 1992). Flow-through fractions of $3.5 \mathrm{ml}$ were collected in siliconised $10 \mathrm{ml}$ conical bottomed glass tubes on ice. The sporozoite rich cloudy fractions (number 2 to 5) were pooled and centrifuged at 12,000 x $g$ at $4^{\circ} \mathrm{C}$ for $5 \mathrm{~min}$. The resulting sporozoite rich small yellowish pellet was re-suspended in SDSPAGE sample buffer and heated at $100^{\circ} \mathrm{C}$ for 5 min prior to fractionation on $10 \%$ onedimensional SDS-PAGE and staining with Coomassie Blue.

\section{In-gel trypsin digestion for LC-MS/MS analysis}

The gel lane containing sporozoite material was excised and divided into four fractions of different size proteins ( $>100 \mathrm{kDa}, 100-55 \mathrm{kDa}, 55-35 \mathrm{kDa}$ and $<35 \mathrm{kDa})$. The gel pieces were de-stained overnight in 50\% methanol, 5\% acetic acid in water. After dehydration with acetonitrile, proteins were reduced with $10 \mathrm{mM}$ DTT in $100 \mathrm{mM}$ ammonium bicarbonate and subsequently alkylated using $50 \mathrm{mM}$ iodoacetamide in ammonium bicarbonate for $30 \mathrm{~min}$ at room temperature. Following washing the gel pieces in $100 \mathrm{mM}$ ammonium bicarbonate, proteolytic digestion was carried out with $100 \mathrm{ng}$ trypsin in $50 \mathrm{mM}$ ammonium bicarbonate over night at $37^{\circ} \mathrm{C}$. Tryptic peptides were extracted from each gel with $50 \%$ acetonitrile, $5 \%$ acetic acid in water, dried and re-suspended in $20 \mu 12 \%$ acetonitrile, $0.1 \%$ formic acid in water for LC-MS/MS analysis.

\section{LC-MS/MS analysis}

Peptides from each gel fraction were separated on an Ultimate 3000 RSLC nano System utilizing a PepMap C18 column, $2 \mu \mathrm{m}$ particle size, $75 \mu \mathrm{m}$ x $50 \mathrm{~cm}$ (Thermo Scientific) and 
subsequently analyzed on a QExactive mass spectrometer (Thermo Scientific). Peptides were introduced into the mass spectrometer using an EASY-Spray ${ }^{\mathrm{TM}}$ nano source at a flow rate of $250 \mathrm{nl} / \mathrm{min}$ at approximately 400-600 bar. The 15 most intense precursors were selected for MS/MS analysis using higher-energy collisional dissociation (HCD) fragmentation and all fragmented precursor ions were actively excluded from repeated MS/MS analysis for 27s.

\section{Data Analysis}

\section{Protein identification and relative abundance}

RNAseq data of the schizont stage of $T$. parva has recently been made available in Genbank (BioSample accession SAMN03981746) and used to improve the annotation of the genome (in preparation, as cited in Tretina, Pelle et al. 2016). The format for open reading frame (ORF) locus tags in the re-annotated genome of the Muguga strain has been changed from TPXX_YYYY (Gardner, Bishop et al. 2005) to TpMuguga_0Xg0YYYY, where X stands for the chromosome number and YYYY for the gene number. This study relied on the re-annotated genome and the new format for T. parva ORF locus tags has been adopted.

Raw MS/MS data files were analysed with the Peaks software (Bioinformatics solutions) using a database containing all Uniprot database entries for $R$. appendiculatus and the reannotated proteome of $T$. parva (a total of 16,969 protein entries with 4,084 $T$. parva and 12,884 R. appendiculatus protein entries, July 2016). A peptide false discovery rate (FDR) of $1.2 \%$ was applied and only proteins with unique peptide identification were included in the final sporozoite proteome list.

In order to rank the identified proteins by their abundance in the sample, an Exponentially Modified Protein Abundance Index (emPAI) was calculated using Mascot (Matrix Science) (Ishihama, Oda et al. 2005). EmPAI is the exponential form of protein abundance index (PAI) minus 1 (emPAI $=10^{\mathrm{PAI}}-1$ ) and is proportional to protein content in a protein mixture (Ishihama, Oda et al. 2005). PAI is calculated by dividing the number of observed peptides by the number of observable peptides per protein.

\section{Classification of subcellular localization of the identified T. parva sporozoite proteins}

Proteins were classified according to their putative localization in the sporozoite using TargetP (Emanuelsson, Nielsen et al. 2000). Trans-membrane domains (TMDs) were predicted by TMHMM Server v. 2.0 (Krogh, Larsson et al. 2001), signal peptides (SP) by SignalP 4.1 (Petersen, Brunak et al. 2011) and GPI-anchor signal by GPI-SOM (Fankhauser and Mäser 2005).

\section{Classification of the identified T. parva sporozoite proteins by orthology}

We clustered all sporozoite protein coding sequences of $T$. parva with the complete predicted proteome of $P$. falciparum into putative orthologous groups using the OrthoMCL standalone software Version 2.0.2 (Li, Stoeckert et al. 2003). The blast step of OrthoMCL was performed using an E-value cut-off of $1 \mathrm{e}^{-10}$, and minimum $70 \%$ sequence identity over $75 \%$ sequence coverage. PlasmodiumPlasmodium falciparum 3D7 release of 26-06-2017 sequence data was downloaded from PlasmoDB (Aurrecoechea, Brestelli et al. 2010) 


\section{Results}

Sporozoite proteome determination and relative quantification of expressed sporozoite proteins

LC-MS/MS was used to identify proteins expressed in a sample of semi-purified $T$. parva sporozoites. A complete list of all the proteins identified in this study is provided in the supplemental information (Supplementary Table S1). In total 4,780 proteins were identified of which 2,007 originated from T. parva and 2,773 from $R$. appendiculatus. Most proteins $(3,847)$ were identified with two or more peptides, while 933 protein identifications were based on a single peptide match, which includes 296 T. parva proteins (Supplementary Table S2). Thus, there is a higher confidence in the identification of 1,711 expressed parasite proteins. Sequence coverage of over $85 \%$ was achieved for three proteins, glyceraldehyde 3-phosphate dehydrogenase NAD binding domain, histone H2B.1 and ribosomal protein S21e, all encoded by single copy genes. Protein TpMuguga_03g00168, annotated as a hypothetical protein, was identified by as many as 94 unique peptides.

The 2,007 T. parva sporozoites proteins that were identified represent approximately $50 \%$ of the 4084 proteins predicted to be encoded by the re-annotated $T$. parva genome (in preparation, as cited in Tretina, Pelle et al. 2016). Of the 2,007 proteins, 1,287 were further ranked by calculation of relative abundance in the sample using emPAI values (Supplementary Table S3), a parameter that is useful for obtaining an overview of proteome profiles with a wide dynamic range of concentrations (30 fmol to $1.8 \mathrm{pmol} / \mu \mathrm{l}$ ) (Ishihama, Oda et al. 2005). The 20 most abundant $T$. parva sporozoite proteins are shown in Table 1. Even within this data set, there is a large range in the abundance of parasite proteins with histones being the most abundant. Other housekeeping proteins, e.g., ribosomal proteins, heat shock protein 70, phosphoglycerate mutase and glyceraldehyde 3-phosphate dehydrogenase, feature in this list.

\section{Identification of known T. parva antigens within the sporozoite proteome}

The major circumsporozoite surface protein of T. parva, p67, which is a target of sporozoite neutralizing antibodies (Dobbelaere, Spooner et al. 1984), was identified among the 20 most abundant proteins (Table 1). Additional antigens that had been previously characterized were also identified in this study, e.g., p104 (Ebel, Gerhards et al. 1999), p150 microneme/rhoptry proteins (Skilton, Bishop et al. 1998) and p32, a merozoite antigen (Skilton, Musoke et al. 2000). We searched the sporozoite proteome data (Supplementary Table S1) for characterized schizont CD8 T cell antigens (Graham, Pelle et al. 2006, Graham, Pellé et al. 2008) and found evidence for expression of all known CTL antigens (reviewed in Nene and Morrison 2016) at the sporozoite stage. In contrast to CD8 T cell antigens, CD4 T cell antigens still require better characterization. CD4 antigens are presented by intact schizont-infected cells (Brown, Sugimoto et al. 1989) as well as cell extracts (Ballingall, Mwangi et al. 2000). Soluble cytosolic parasite antigens stimulatory to CD4 T cell clones with fractions ranging between 10 and 24 $\mathrm{kDa}$ (Brown, Zhao et al. 1995) have been described, but further analysis and identification of the specific constituent proteins is required. However, among the most abundant sporozoite proteins we identified a protein that is homologous to a $T$. annulata protein annotated as rhoptry associated protein-1 (RAP-1) (Table 1). RAP-1 of Babesia bigemina has been shown to be a CD4 T cell antigen (Brown, McElwain et al. 1999), suggesting that the T. parva RAP-1 is a potential CD4 $\mathrm{T}$ cell antigen. 
Table 1. Abundant T. parva sporozoite proteins.

\begin{tabular}{llll}
\hline ORF locus tag & Annotation ${ }^{\text {a }}$ & Mass (Da) & emPAI \\
\hline TpMuguga_04g00404 & Histone H2B.1 & 12040 & 7228.34 \\
TpMuguga_04g00071 & Histone H2B & 13682 & 900.39 \\
TpMuguga_04g00675 & Histone H4 & 11362 & 457.35 \\
TpMuguga_04g00690 & phosphoglycerate mutase 1 family & 29221 & 105.17 \\
TpMuguga_04g00050 & Ribosomal protein S19 & 17150 & 99.38 \\
TpMuguga_03g00655 & hypothetical protein & 17296 & 96.5 \\
TpMuguga_04g00036 & AhpC/TSA family & 22120 & 84.68 \\
TpMuguga_02g00487 & Ribosomal protein S6e & 25553 & 67.36 \\
TpMuguga_02g00903 & Actin & 42270 & 60.62 \\
TpMuguga_04g00322 & Histone H2A & 13498 & 60.26 \\
TpMuguga_03g00067 & hypothetical protein & 11572 & 54.06 \\
TpMuguga_01g00726 & elF-Tu GTP binding domain & 49779 & 52.64 \\
TpMuguga_01g00541 & hypothetical protein & 24796 & 52.36 \\
TpMuguga_04g00383 & GAPDH NAD binding domain & 36883 & 51.37 \\
TpMuguga_01g00701 & RAP-1* & $\mathbf{7 0 4 4 1}$ & $\mathbf{4 7 . 7 3}$ \\
TpMuguga_02g00148 & Heat shock 70 kDa protein & 71445 & 42.22 \\
TpMuguga_04g00179 & RanBP1 domain & 38982 & 41.34 \\
TpMuguga_03g00700 & hypothetical protein & 23995 & 40 \\
TpMuguga_03g00287 & Sporozoite P67 surface antigen & $\mathbf{7 5 4 5 3}$ & $\mathbf{3 9 . 1 6}$ \\
TpMuguga_01g00067 & Acyl CoA binding protein & 10043 & 39.11 \\
\hline
\end{tabular}

Proteins detected from whole cell lysates of sporozoites are ranked by relative abundance in the sample. Data presented include the ORF locus tag, annotation, mass in Daltons (Da) and relative protein abundance in sample (emPAI). Known antigens are in bold face.

aAhpC/TSA (Alkyl hydroperoxide reductase subunit C/ Thiol specific antioxidant) family, elF (Elongation factor), RAP-1* (this protein was a homolog of a Theileria annulata protein annotated as Rhoptry-associated protein 1), GAPDH (Glyceraldehyde 3-phosphate dehydrogenase), NAD (Nicotinamide adenine dinucleotide), RanBP1 (Ran binding protein 1), CoA (Co-enzyme A) and hypothetical is of unknown function. 


\section{T. parva sporozoite proteins associated with apicomplexan invasion of host cells}

Sporozoite secretory organelle proteins are typically located in the micronemes, rhoptries and dense granules in P. falciparum (reviewed in Lindner, Swearingen et al. 2013). To determine whether these proteins are present in $T$. parva sporozoites, we clustered our identified T. parva sporozoite proteins using OrthoMCL into orthologous groups with all $P$. falciparum genes. A total of 1105 proteins of the 2,007 T. parva proteins were defined as $P$. falciparum orthologs (Supplementary Table S 4) and we searched this list for apical organelle proteins. We identified $T$. parva orthologs of eight rhoptry proteins, three microneme proteins and a dense granule protein (Table 2). Featured in the list are orthologs of $P$. falciparum AMA1, a microneme protein essential during host cell invasion (Treeck, Zacherl et al. 2009), and CelTOS, a malarial antigen mediating host cell invasion (Kariu, Ishino et al. 2006). AMA-1 is a leading malaria vaccine candidate (Remarque, Faber et al. 2008), and orthologs of it are also found in Neospora caninum and Toxoplasma gondii (Zhang, Compaore et al. 2007). 
Table 2. Invasion organelle proteins. Proteins detected from whole cell lysates of $T$. parva salivary gland sporozoites are aligned by orthology with $P$. falciparum sporozoites proteins.

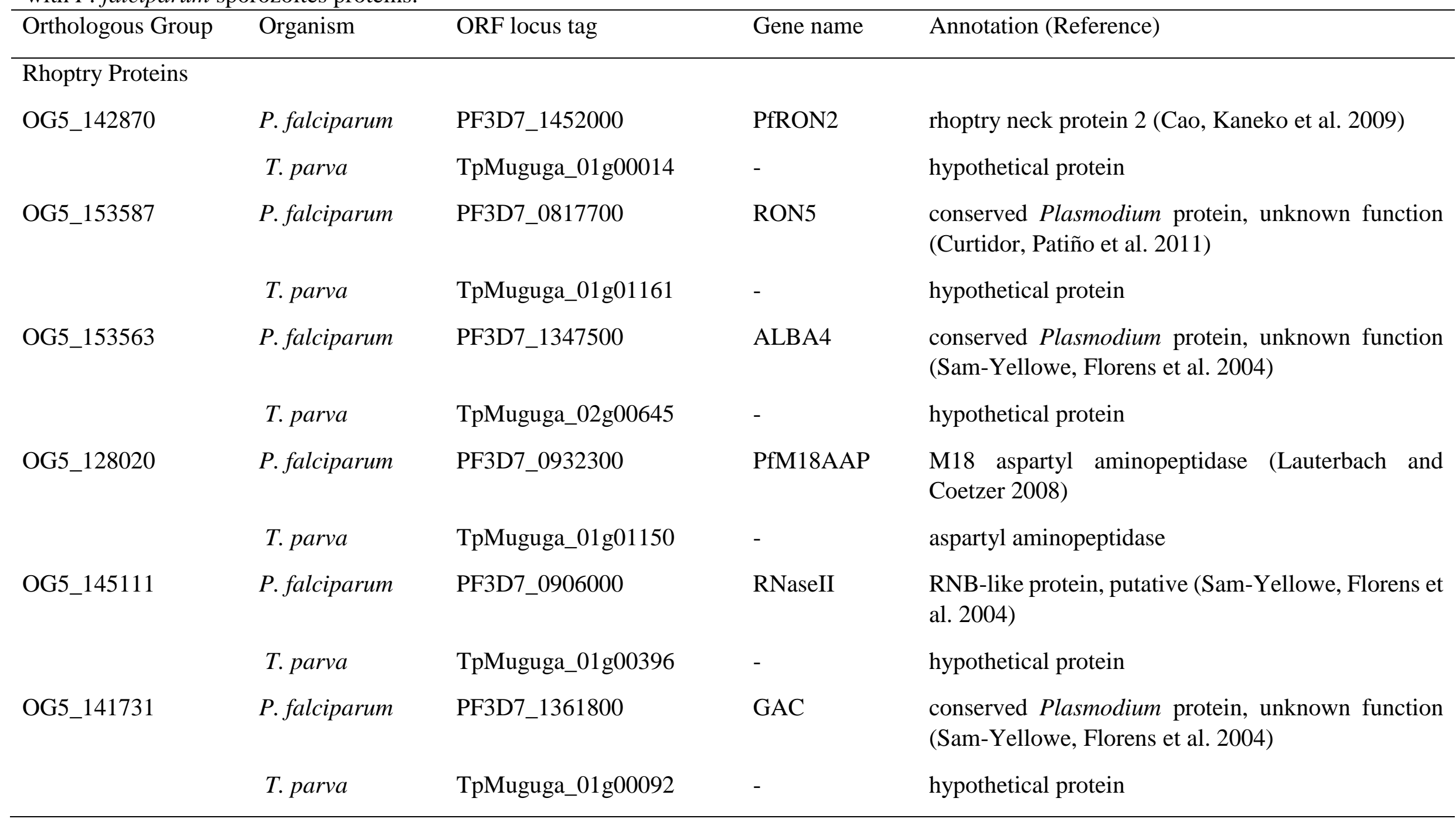




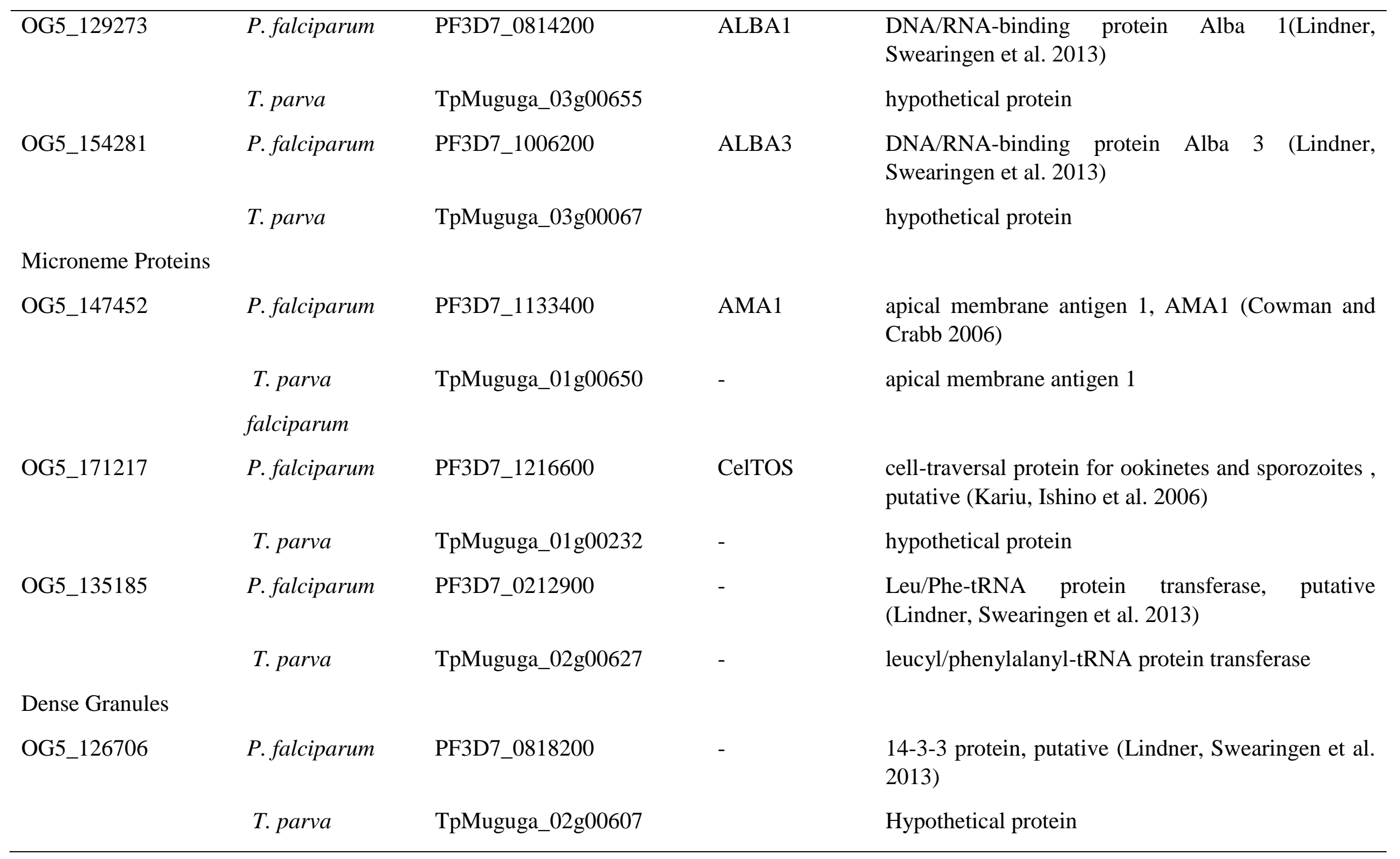


In T. parva, mobilization of $\mathrm{Ca}^{2+}$ is necessary for successful sporozoite invasion of bovine lymphocytes and reagents that prevent $\mathrm{Ca}^{2+}$ mobilization significantly curb zippering and internalization stages of the entry process (Shaw 1995). Table 3 shows 13 proteins identified in T. parva clustered with the Plasmodium proteins that play a role in calcium signaling, including calmodulin, an intracellular target for $\mathrm{Ca}^{2+}$ activation that acts on proteins such as guanylyl cyclases, protein kinases and phosphatases to aid in signal transduction.

\section{Putative T. parva surface proteins within the sporozoite proteome}

We used two methods to search for novel putative surface proteins. The first method was to use bioinformatics tools to predict the presence of GPI anchors and signal peptide (SP) in proteins expressed by sporozoites. Only 12 proteins of the 2007 sporozoite proteins were found in this category (Table 4). The list includes TpMuguga_01g00939 (gp34), a protein that undergoes GPI modification when expressed in mammalian cells and a schizont surface protein (Xue, von Schubert et al. 2010). Since there is no direct evidence for addition of GPI anchors to parasite expressed proteins, we searched for enzymes of the GPI biosynthesis pathway encoded by the $T$. parva genome. Eight genes are essential for GPI synthesis in P. falciparum (Delorenzi, Sexton et al. 2002). We found homologs of all eight genes in T. parva (TpMuguga_04g00759, TpMuguga_04g00881, TpMuguga_04g00525, TpMuguga_01g00169, TpMuguga_02g00201, TpMuguga_03g00397, TpMuguga_03g00846 and TpMuguga_02g00741) and identified that the latter four are expressed in the sporozoite proteome. This suggests the existence of GPI anchored proteins in T. parva, although this remains to be formally proven.

Secondly, we compiled from the literature a list of surface-exposed $P$. falciparum proteins and determined if orthologs exist within the T. parva sporozoite proteome. We identified orthologs of AMA-1 (TpMuguga_01g00650) and a hexose transporter (TpMuguga_01g01069) which were both identified by specific biotinylation of $P$. falciparum and Plasmodium yoelii surface proteins (Lindner, Swearingen et al. 2013). 
Table 3. Proteins involved with calcium signaling. Proteins detected from whole cell lysates of $T$. parva salivary gland sporozoites are aligned by orthology with $P$. falciparum sporozoites proteins.

\begin{tabular}{|c|c|c|c|c|}
\hline $\begin{array}{l}\text { Orthologous } \\
\text { Group }\end{array}$ & Organism & ORF locus tag & $\begin{array}{l}\text { Gene } \\
\text { name }\end{array}$ & Annotation (Reference) \\
\hline OG5_126800 & P. falciparum & PF3D7_1434200 & CAM & calmodulin \\
\hline \multirow[t]{2}{*}{ OG5_129380 } & P. falciparum & PF3D7_1027700 & PfCEN1 & centrin-1 (Khan, Franke-Fayard et al. 2005) \\
\hline & T. parva & TpMuguga_01g00227 & - & centrin \\
\hline OG5_152981 & T. parva & TpMuguga_02g00412 & - & hypothetical protein \\
\hline \multirow[t]{2}{*}{ OG5_126600 } & P. falciparum & PF3D7_0717500 & PfCDPK4 & $\begin{array}{l}\text { calcium-dependent protein kinase } 4 \text { (Holder, Mohd Ridzuan et al. } \\
\text { 2012) }\end{array}$ \\
\hline & T. parva & TpMuguga_01g01073 & - & calmodulin-domain protein kinase \\
\hline \multirow[t]{2}{*}{ OG5_131887 } & P. falciparum & PF3D7_1123100 & CDPK7 & $\begin{array}{l}\text { calcium-dependent protein kinase } 7 \text { (Lindner, Swearingen et al. } \\
\text { 2013) }\end{array}$ \\
\hline & T. parva & TpMuguga_04g00518 & & Protein tyrosine kinase \\
\hline \multirow[t]{2}{*}{ OG5_127599 } & P. falciparum & PF3D7_1436600 & PKG & cGMP-dependent protein kinase (Lindner, Swearingen et al. 2013) \\
\hline & T. parva & TpMuguga_03g00511 & & Protein tyrosine kinase \\
\hline OG5_133188 & P. falciparum & PF3D7_1138400 & GCalpha & guanylyl cyclase (Pradel 2007) \\
\hline
\end{tabular}




\begin{tabular}{|c|c|c|c|c|}
\hline & T. parva & TpMuguga_02g00848 & - & guanylyl cyclase \\
\hline \multirow[t]{2}{*}{ OG5_141757 } & P. falciparum & PF3D7_1246400 & MTIP & myosin A tail domain interacting protein (Jones, Kitson et al. 2006) \\
\hline & T. parva & TpMuguga_01g00513 & - & myosin light chain \\
\hline \multirow[t]{2}{*}{ OG5_126577 } & P. falciparum & PF3D7_1329100 & MyoC & Myosin C (Tyagi, Swapna et al. 2009) \\
\hline & T. parva & TpMuguga_01g00774 & - & Myosin C \\
\hline \multirow[t]{4}{*}{ OG5_126674 } & P. falciparum & PF3D7_1211900 & ATPase4 & $\begin{array}{l}\text { non-SERCA-type } \mathrm{Ca}^{2+} \text {-transporting P-ATPase (Budu and Garcia } \\
\text { 2012) }\end{array}$ \\
\hline & P. falciparum & PF3D7_0106300 & ATP6 & calcium-transporting ATPase, putative (Budu and Garcia 2012) \\
\hline & T. parva & TpMuguga_01g00720 & - & P-type ATPase \\
\hline & T. parva & TpMuguga_02g00524 & - & calcium-transporting ATPase \\
\hline \multirow[t]{2}{*}{ OG5_127599 } & P. falciparum & PF3D7_0934800 & PKAc & $\begin{array}{l}\text { cAMP-dependent protein kinase catalytic subunit (Lindner, } \\
\text { Swearingen et al. 2013) }\end{array}$ \\
\hline & $\begin{array}{l}\text { T. parva } \\
\text { falciparum }\end{array}$ & TpMuguga_02g00378 & - & cAMP-dependent protein kinase \\
\hline
\end{tabular}


Table 4. Potential sporozoite surface proteins.

\begin{tabular}{|c|c|c|c|c|c|c|}
\hline ORF locus tag & Annotation & $\begin{array}{l}\text { Unique } \\
\text { peptides }\end{array}$ & emPAI & TMD $^{\text {a }}$ & $\begin{array}{l}\text { GPI- } \\
\text { anchor b }\end{array}$ & $\mathbf{S P}^{\mathrm{c}}$ \\
\hline TpMuguga_01g00438 & $\begin{array}{l}\text { hypothetical } \\
\text { protein }\end{array}$ & 34 & 1.01 & 0 & 1 & 1 \\
\hline TpMuguga_01g00939 & $\begin{array}{l}\text { hypothetical } \\
\text { protein (gp34) }\end{array}$ & 12 & 3.65 & 1 & 1 & 1 \\
\hline TpMuguga_01g00939 & $\begin{array}{l}\text { hypothetical } \\
\text { protein }\end{array}$ & 12 & 3.65 & 1 & 1 & 1 \\
\hline TpMuguga_01g00972 & $\begin{array}{l}\text { hypothetical } \\
\text { protein }\end{array}$ & 4 & 0.45 & 1 & 1 & 1 \\
\hline TpMuguga_01g01056 & $\begin{array}{l}\text { Merozoite Antigen } \\
\text { (p32) }\end{array}$ & 12 & 6.78 & 0 & 1 & 1 \\
\hline TpMuguga_02g00412 & $\begin{array}{l}\text { hypothetical } \\
\text { protein }\end{array}$ & 5 & 0.3 & 0 & 1 & 1 \\
\hline TpMuguga_02g00538 & $\begin{array}{l}\text { hypothetical } \\
\text { protein }\end{array}$ & 31 & 1.34 & 1 & 1 & 1 \\
\hline TpMuguga_02g00553 & $\begin{array}{l}\text { hypothetical } \\
\text { protein }\end{array}$ & 6 & 2.95 & 1 & 1 & 1 \\
\hline TpMuguga_02g00950 & $\begin{array}{l}\text { hypothetical } \\
\text { protein }\end{array}$ & 2 & $<0.05$ & 1 & 1 & 1 \\
\hline TpMuguga_03g00287 & $\begin{array}{l}\text { Sporozoite p67 } \\
\text { surface antigen }\end{array}$ & 53 & 39.16 & 1 & 1 & 1 \\
\hline TpMuguga_04g00437 & $\begin{array}{l}104 \mathrm{kDa} \\
\text { microneme/rhoptry } \\
\text { antigen (p104) }\end{array}$ & 60 & 12.35 & 1 & 1 & 1 \\
\hline TpMuguga_04g00615 & $\begin{array}{l}\text { Probable N- } \\
\text { acetylglucosaminyl } \\
\text { - } \\
\text { phosphatidylinosit } \\
\text { ol de-N-acetylase }\end{array}$ & 2 & $<0.05$ & 0 & 1 & 1 \\
\hline
\end{tabular}

Proteins detected from whole cell lysates of $T$. parva salivary gland sporozoites predicted to contain GPI anchor and either transmembrane domain (TMD) or signal peptide (SP). Data presented include ORF locus tag, annotation, number of unique peptides identified for the protein and relative protein abundance in sample (emPAI). Hypothetical protein is of unknown function(s).

apredicted using the TMHMM Server v. 2.0 (http://www.cbs.dtu.dk/services/TMHMM/)

${ }^{b}$ Predicted using the GPI-SOM (http://gpi.unibe.ch/)

cPredicted using the SignalP 4.1 server (http://www.cbs.dtu.dk/services/SignalP/).

\section{T. parva proteins as candidate manipulators of host cell signaling leading to transformation}

Lymphocyte transformation characterized by cancer-like cell phenotypes is solely dependent on viable schizonts and requires the schizont proteins to interact with and manipulate pathways regulating lymphocyte apoptosis, proliferation and gene expression (Dobbelaere and Heussler 1999, Tretina, Gotia et al. 2015). We identified 17 proteins predicted to be manipulators of host cells (Shiels, Langsley et al. 2006) in the sporozoite stage, suggesting that these proteins may be required immediately upon host cell entry (Supplementary Table S 5). Transcripts for the genes encoding all 17 proteins are found in the RNAseq data from schizont- 
infected cells (see Materials and Methods), although to different levels (data not shown). Among the identified proteins are members of two multigene families, the Sub-telomereencoded Variable Secreted Protein (SVSP) gene family and the Theileria annulata schizont AT-hook (TashAT) gene family, or T. parva host nuclear (TpHN) gene family. TashAT proteins display a high degree of sequence conservation in their DNA-binding domains (AThook) in T. annulata but not in T. parva and contain an N-terminal signal sequence for transport across the parasite plasma membrane (reviewed in Tretina, Gotia et al. 2015). TashAT family proteins are implicated in regulation of host gene expression and as accessory factors for parasite transcription (Shiels, Langsley et al. 2006). Other families featured are DEAD-box RNA helicases with members implicated in alteration of RNA secondary structures and promotion of proto-oncogene c-myc expression (e.g., DDX6) (Abdelhaleem 2004), thioredoxin/glutaredoxin family that are redox regulators and influence important signaling pathways such as NF-kB and AP1 pathways that are both activated in Theileria-transformed cells (Shiels, Langsley et al. 2006). In addition, we also identified T. parva Schizont-derived Cytoskeleton-binding Protein (TpSCOP), a protein that activates host NF- $\kappa B$ and MAPK pathways, leading to resistance to programmed host cell death (Hayashida, Hattori et al. 2010) and a peptidyl-prolyl isomerase, which has been demonstrated to interact with and lead to degradation of host ubiquitin ligase FBW7, thereby stabilizing host c-JUN and promoting transformation of host cells (Marsolier, Perichon et al. 2015). Interestingly, the bulk schizont RNAseq data identified a high level of anti-sense transcription of the TpSCOP gene (data not shown), suggesting that expression of this gene in the schizont stage may be under differential control. Resolution of the significance of this observation will require analysis of cell-cycle synchronized samples.

\section{Sporozoite proteins involved in glycolysis and tricarboxylic acid (TCA) cycle}

Proteins of the glycolytic pathway are conserved in most eukaryotic organisms and 10 genes encoding glycolytic enzymes have been found in Theileria genomes (Gardner, Bishop et al. 2005, Pain, Renauld et al. 2005). We identified expression of all the 10 enzymes of the glycolytic pathway in this study (Figure 1) including lactate dehydrogenase, an enzyme that converts pyruvate, the last product of glycolysis, to lactate during low or no oxygen conditions. We also identified all the TCA cycle enzymes by mass spectrometry (Figure 1) with the exception that malate dehydrogenase is functionally replaced by malate-quinone oxidoreductase (Gardner, Bishop et al. 2005), and was identified in the proteome data. Glutamate dehydrogenase was also identified in the proteome and glutamate has been suggested to be a supplementary intermediate for the TCA cycle (Gardner, Bishop et al. 2005). The only functional link we have found between glycolysis and the TCA cycle is the presence of phosphoenolpyruvate carboxykinase. Neither glycerol kinase nor glycerol 3-phosphate dehydrogenase were identified, although $T$. parva encodes genes for both enzymes. These enzymes were identified with low levels in the schizont stage of T. annulata (Witschi, Xia et al. 2013). 


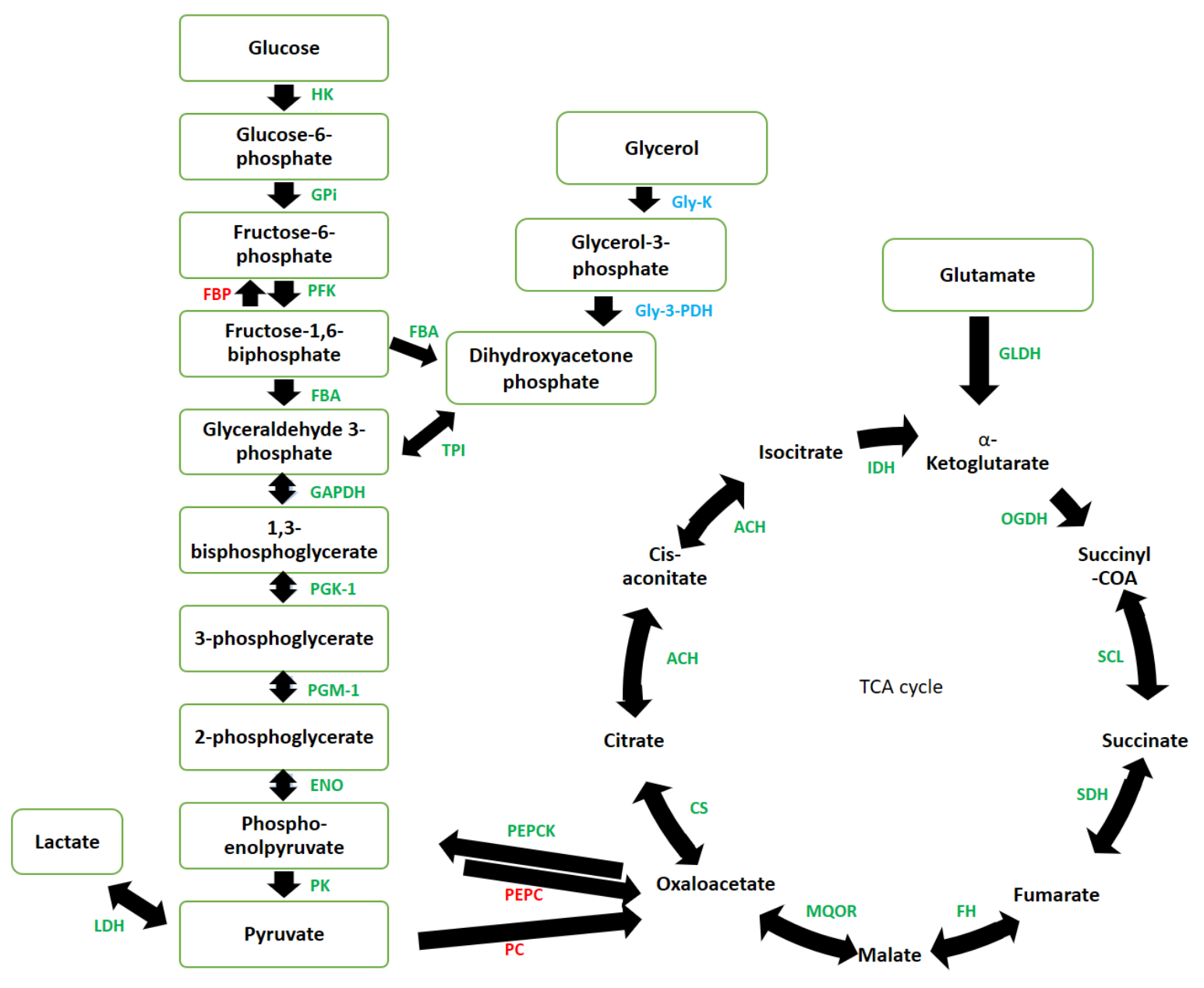

Figure 1. Most of T. parva proteins involved in glycolysis and tricarboxylic acid (TCA) cycle were identified in this study. The glycolysis pathway is shown on the left and TCA cycle is shown on the right. Color code for proteins: green indicates enzymes that we identified by mass spectrometry, blue shows enzymes encoded in the $T$. parva genome but not identified by mass spectrometry, and red shows enzymes not encoded by T. parva genome and not identified in this study. Enzymes identified by mass spectrometry have ORF locus tags included in brackets: HK, hexokinase (TpMuguga_01g00043); GPI, glucose 6-phosphate-isomerase (TpMuguga_03g00346); PFK, phosphofructokinase (TpMuguga_02g00577); FBP, fructose bisphosphatase; FBA, fructose bisphosphate aldolase (TpMuguga_01g00101); TPI, triosephosphate isomerase (TpMuguga_04g00464); Gly-3PDH, glycerol-3-phosphate dehydrogenase; Gly-K, glycerol kinase; GAPDH, glyceraldehyde phosphate dehydrogenase (TpMuguga_02g00858); PGK-1, phosphoglycerate kinase (TpMuguga_01g00965); PGM-1, phosphoglycerate mutase (TpMuguga_04g00690); ENO, enolase (TpMuguga_04g00700); PK, pyruvate kinase (TpMuguga_02g00134, TpMuguga_04g00607); LDH, lactate dehydrogenase (TpMuguga_01g01182); PC, pyruvate carboxylase; $\mathrm{ACH}$, aconitate hydratase-1 (TpMuguga_01g01050); IDH, isocitrate dehydrogenase (TpMuguga_04g00620); OGDH, oxoglutarate dehydrogenase (TpMuguga_01g00262); SCL, succinyl coenzyme A ligase (TpMuguga_04g00660); SDH, succinate dehydrogenase (TpMuguga_01g00210); FH, fumarate hydratase-1 (TpMuguga_03g00078); $\mathrm{MDH}$, malate dehydrogenase; MQOR, Malate: quionone oxidoreductase (TpMuguga_03g00758); CS, citrate synthase (TpMuguga_02g00666); PEPC, phosphoenolpyruvate carboxylase; PEPCK, phosphoenolpyruvate carboxykinase (TpMuguga_01g00495). 


\section{Tick proteins}

Searching the Uniprot database entries for $R$. appendiculatus with the LC MS/MS data led to identification of 2,773 tick proteins in addition to the T. parva proteins. The complete list of all the identified tick proteins is presented in Supplementary Table S 1, but a detailed analysis of vector proteins will be reported in Chapter 3. 


\section{Discussion}

In this study, we employed a DE-52 ion-exchange column purification method to semipurify $T$. parva sporozoites from infected tick salivary glands. Although tick proteins constituted 58\% (2773/4780) of the total number of proteins of all proteins identified by LCMS/MS and the Peaks and Mascot software packages, we were able to identify 2,007 T. parva proteins expressed in the sporozoite life-cycle stage. This represents $\sim 50 \%$ of the total predicted re-annotated T. parva proteome of 4084 proteins (see Materials and methods). About $40 \%$ of these proteins are annotated as hypothetical proteins. Hence, our data provides evidence that real genes encode these proteins, although their function remains unknown.

Studies on the proteome of $P$. falciparum sporozoite stages have reported identification of $\sim 13 \%$ (Lasonder, Janse et al. 2008), 19\% (Florens, Washburn et al. 2002) and 36\% (Lindner, Swearingen et al. 2013) of the 5,524 annotated $P$. falciparum genes using materials purified by DEAE-cellulose chromatography only (Florens, Washburn et al. 2002, Lasonder, Janse et al. 2008), and on 17\% w/v Accudenz cushion followed by DEAE-cellulose chromatography (Lindner, Swearingen et al. 2013). The range of vector contamination is an important component of such studies and varied depending on the method of parasite purification. Lasonder et al (2008) reported $65 \%$ to $89 \%$ mosquito protein contamination in the samples analyzed, while Lindner et al (2013) reported $60.1 \%$ mosquito proteins in the sample, but had to do double purification, initially on a $17 \% \mathrm{w} / \mathrm{v}$ Accudenz cushion then followed by DEAEcellulose chromatography to reduce mosquito protein contamination to $29 \%$ (Lasonder, Janse et al. 2008, Lindner, Swearingen et al. 2013). The presence of mosquito material in the sample was not discussed by Florens and colleagues (Florens, Washburn et al. 2002). We managed to achieve low levels of vector protein contamination with a single DE-52 column purification step.

Positive identification of proteins by mass spectrometry confers confidence in their presence, especially when the proteins are identified by more than one unique peptide hit. 1,708 of the 2,007 parasite proteins were identified by more than one hit, providing a high degree of confidence in $85 \%$ of the data. For the purposes of our current analyses we have, however, reported on the entire data set of 2007 proteins. Failure to identify T. parva proteins does not directly imply their absence in the sample. Peptides from proteins with low abundance may fall below the detection limit or are simply not sequenced by the mass spectrometer due to limited dynamic range and/or speed of instrument acquisition. Furthermore, unknown, complex, or amino acid modifications leading to alteration of the peptide mass can only be detected in some cases by the Peaks software. Finally, trypsin digestion of proteins with low or irregular arginine/lysine content can lead to very short and very long tryptic peptides that fall out of the acquired mass range and may therefore not be detected.

Identification of $T$. parva sporozoite proteins through mass spectrometry has allowed us to assess the proteomic component of the mammalian-infective stage of the parasite. We have also calculated the emPAI using Mascot to estimate the relative abundance ranking of proteins in the sample, which revealed a very high range of abundance with histones ranked with an emPAI of 60 7200 for the different histone subunits to an emPAI index of 39 for the major circumsporozoite p67 protein. Subunits of two enzymes within the glycolytic pathway, phosphoglycerate mutase and glyceraldehyde 3-phosphate dehydrogenase, are among the 20 most abundant sporozoite proteins detected (Table 1). A high abundance of histones is not unusual. Lindner et al (2013) reported histones as the third most abundant protein in 
Plasmodium sporozoite proteome after the circumsporozoite protein and mitochondrial ATP synthase, subunit beta (Lindner, Swearingen et al. 2013).

A number of known antigens were identified within the sporozoite proteome, including p67, a leading vaccine antigen, and previously described components of secretory organelles (e.g., p104 and p150) (Table 4). RAP-1, a rhoptry antigen protective against $P$. falciparum infection in Saimiri monkeys (Ridley, Takacs et al. 1990) was also identified (Table 1). Unexpectedly, the polymorphic immuno-dominant molecule (PIM), a well-known antigen (Toye, Goddeeris et al. 1991), was not identified in this study, even though p150, an antigen that is immunologically cross-reactive with PIM (Skilton, Bishop et al. 1998) was identified. The PIM protein sequence contains a large repetitive domain rich in glutamine and proline amino acid residues that is devoid of lysine and arginine residues (Toye, Goddeeris et al. 1991). An in silico digestion of PIM with trypsin leads to prediction of few detectable tryptic peptides (data not shown). This may explain why we did not detect it. All schizont proteins that have been identified as CTL antigens are also expressed in sporozoites (emPAI range of 0.76 to 31.69). Some of these antigens are encoded by housekeeping proteins (e.g., hsp90) and translation elongation initiation factor 1A, so expression by sporozoites of some CTL antigens is not unexpected. The finding that all the known CTL antigens are expressed by sporozoites raises the question of whether infection of dendritic cells by sporozoites results in direct presentation of antigen for priming CTL responses in vivo, provided the antigen load is sufficient.

A study on the proteome of $T$. annulata schizont stage, in which 798 proteins were identified, failed to identify any member of SVSP and TashAT families (Witschi, Xia et al. 2013). In contrast, we identified members of both families in the sporozoite stage (Supplementary Table S 5). There is increasing evidence pointing to a role of these proteins in host-parasite interaction, for instance SVSP epitope-tagged TpMuguga_03g00882 protein expressed in mammalian cells was found to translocate into the host nucleus pointing to potential role in transforming host cells (Schmuckli-Maurer, Casanova et al. 2009). In addition, we identified other predicted host manipulation proteins such as DEAD-box RNA helicases, peptidases and two proteins, namely a peptidyl prolyl-isomerase and TpSCOP, demonstrated to play role in host manipulation by stabilizing c-JUN and activation of NF-kB respectively (Shiels, Langsley et al. 2006, Hayashida, Hattori et al. 2010, Marsolier, Perichon et al. 2015). Host cell manipulation is known to occur at the schizont stage and the finding of these proteins in the sporozoite stage suggests early expression of these proteins may be required, or multifunctionality of the proteins.

Sporozoite invasion of lymphocytes begins with binding events that trigger the mobilization of $\mathrm{Ca}^{2+}$ within the sporozoites (Dobbelaere and Heussler 1999). The free intracellular $\mathrm{Ca}^{2+}$ can be utilized by calmodulin to remodel itself structurally so as to act on downstream effectors like CDPKs, which have been shown to be useful for parasite infectivity. We detected both calmodulin and CDPKs in this study (Table 3). We have also detected other calcium signaling proteins including guanylyl cyclases, cGMP-dependent protein kinases and cAMP-dependent protein kinases, all of which are important for downstream calcium signaling and have been shown to be essential for sporozoite invasion (reviewed in Dobbelaere and Heussler 1999).

In motile apicomplexans such as Plasmodium, free calcium induces microneme secretion by sporozoites to aid in gliding motility and host invasion (Lindner, Swearingen et al. 2013). Although, T. parva sporozoites are immotile (Shaw 2003), we identified orthologs of 
Plasmodium microneme components, including AMA-1, CelTOS and Leu/Phe-tRNA protein transferase (Cowman and Crabb 2006, Kariu, Ishino et al. 2006, Lindner, Swearingen et al. 2013). These proteins may be involved solely in invasion processes together with the detected rhoptry proteins (PfRON2, Conserved Plasmodium protein, PfM18AAP and RNB-like protein) and dense granules protein (14-3-3 protein) (Sam-Yellowe, Florens et al. 2004, Lauterbach and Coetzer 2008, Cao, Kaneko et al. 2009, Curtidor, Patiño et al. 2011, Lindner, Swearingen et al. 2013). Since most of these proteins are still classified as hypothetical in $T$. parva, they present an opportunity for further analysis in studies aiming to block parasite invasion of host cells.

In conclusion, these data establish the expression profile of $T$. parva sporozoite proteins, the only such profile available to date. One or more of the newly identified proteins, in particular putative surface proteins, may prove to be effective vaccine candidates and might be combined with the major surface protein $\mathrm{p} 67$ to induce broader anti-sporozoite immunity, and protection against ECF.

\section{Acknowledgement}

We are grateful to Stephen Mwaura and Milton Owido for providing the dissected tick salivary glands. We thank the CGIAR Research Program on Livestock and Fish, the Norman Borlaug Commemorative Research Initiative, an initiative between the Feed the Future program of USAID and USDA-ARS (58-5348-2-117F) and the Department for International Development of the United Kingdom and the Bill and Melinda Gates Foundation (OPP1078791) for financial support. Mass spectrometry analysis was performed in the Target Discovery Institute Mass Spectrometry Laboratory led by Benedikt M. Kessler.

\section{Conflicts of interest}

The authors declare no conflict of interest. 


\section{References}

Abdelhaleem, M., 2004. Do human RNA helicases have a role in cancer? Biochim. Biophys. Acta 1704, 37-46.

Anamika, Srinivasan, N., Krupa, A., 2005. A genomic perspective of protein kinases in Plasmodium falciparum. Proteins: Struct., Funct., Bioinf. 58, 180-189.

Aurrecoechea, C., Brestelli, J., Brunk, B.P., Fischer, S., Gajria, B., Gao, X., Gingle, A., Grant, G., Harb, O.S., Heiges, M., Innamorato, F., Iodice, J., Kissinger, J.C., Kraemer, E.T., Li, W., Miller, J.A., Nayak, V., Pennington, C., Pinney, D.F., Roos, D.S., Ross, C., Srinivasamoorthy, G., Stoeckert, J.C.J., Thibodeau, R., Treatman, C., Wang, H., 2010. EuPathDB: a portal to eukaryotic pathogen databases. Nucleic Acids Res. 38, D415-D419.

Ballingall, K.T., Mwangi, D.M., MacHugh, N.D., Taracha, E.L.N., Totte, P., McKeever, D.J., 2000. A highly sensitive, non-radioactive assay for $\mathrm{T}$ cell activation in cattle: applications in screening for antigens recognised by CD4+ and CD8+ T cells. J. Immunol. Methods 239, 8593.

Brown, W.C., McElwain, T.F., Palmer, G.H., Chantler, S.E., Estes, D.M., 1999. Bovine CD4+ T-Lymphocyte Clones Specific for Rhoptry-Associated Protein 1 of Babesia bigemina Stimulate Enhanced Immunoglobulin G1 (IgG1) and IgG2 Synthesis. Infect. Immun. 67, 155164.

Brown, W.C., Sugimoto, C., Grab, D.J., 1989. Theileria parva: Bovine helper T cell clones specific for both infected lymphocytes and schizont membrane antigens. Exp. Parasitol. 69, 234-248.

Brown, W.C., Zhao, S., Logan, K.S., Grab, D.J., Rice-Ficht, A.C., 1995. Identification of candidate vaccine antigens of bovine hemoparasites Theileria parva and Babesia bovis by use of helper T cell clones. Vet. Parasitol. 57, 189-203.

Budu, A., Garcia, C.R.S., 2012. Generation of second messengers in Plasmodium. Microb. Infect. 14, 787-795.

Büscher, G., Tangus, J., 1986. Quantitative studies on Theileria parva in the salivary glands of Rhipicephalus appendiculatus adults: Search for conditions for high infections. Int. J. Parasitol. $16,121-129$.

Cao, J., Kaneko, O., Thongkukiatkul, A., Tachibana, M., Otsuki, H., Gao, Q., Tsuboi, T., Torii, M., 2009. Rhoptry neck protein RON2 forms a complex with microneme protein AMA1 in Plasmodium falciparum merozoites. Parasitol. Int. 58, 29-35.

Cowman, A.F., Crabb, B.S., 2006. Invasion of Red Blood Cells by Malaria Parasites. Cell 124, 755-766. 
Curtidor, H., Patiño, L.C., Arévalo-Pinzón, G., Patarroyo, M.E., Patarroyo, M.A., 2011. Identification of the Plasmodium falciparum rhoptry neck protein 5 (PfRON5). Gene 474, 2228.

Delorenzi, M., Sexton, A., Shams-Eldin, H., Schwarz, R.T., Speed, T., Schofield, L., 2002. Genes for Glycosylphosphatidylinositol Toxin Biosynthesis in Plasmodium falciparum. Infect. Immun. 70, 4510-4522.

Dessauge, F., Lizundia, R., Baumgartner, M., Chaussepied, M., Langsley, G., 2005. Taking the Myc is bad for Theileria. Trends Parasitol. 21, 377-385.

Di Giulio, G., Lynen, G., Morzaria, S., Oura, C., Bishop, R., 2009. Live immunization against East Coast fever - current status. Trends Parasitol. 25, 85-92.

Dobbelaere, D., Heussler, V., 1999. Transformation of Leukocytes by Theileria parva and T. annulata. Annu. Rev. Microbiol. 53, 1-42.

Dobbelaere, D., Shapiro, S.Z., Webster, P., 1985. Identification of a surface antigen on Theileria parva sporozoites by monoclonal antibody. Proc. Natl. Acad. Sci. U. S. A. 82, 17711775.

Dobbelaere, D.A.E., Küenzi, P., 2004. The strategies of the Theileria parasite: a new twist in host-pathogen interactions. Curr. Opin. Immunol. 16, 524-530.

Dobbelaere, D.A.E., Spooner, P.R., Barry, W.C., Irvin, A.D., 1984. Monoclonal antibody neutralizes the sporozoite stage of different Theileria parva stocks. Parasite Immunol. 6, 361370 .

Dvorin, J.D., Martyn, D.C., Patel, S.D., Grimley, J.S., Collins, C.R., Hopp, C.S., Bright, A.T., Westenberger, S., Winzeler, E., Blackman, M.J., Baker, D.A., Wandless, T.J., Duraisingh, M.T., 2010. A Plant-Like Kinase in Plasmodium falciparum Regulates Parasite Egress from Erythrocytes. Science 328, 910-912.

Ebel, T., Gerhards, J., Binder, B.R., Lipp, J., 1999. Theileria parva 104 kDa micronemerhoptry protein is membrane-anchored by a non-cleaved amino-terminal signal sequence for entry into the endoplasmic reticulum. Mol. Biochem. Parasitol. 100, 19-26.

Emanuelsson, O., Nielsen, H., Brunak, S., von Heijne, G., 2000. Predicting Subcellular Localization of Proteins Based on their N-terminal Amino Acid Sequence. J. Mol. Biol. 300, 1005-1016.

Fankhauser, N., Mäser, P., 2005. Identification of GPI anchor attachment signals by a Kohonen self-organizing map. Bioinformatics 21, 1846-1852. 
Fawcett, D.W., Doxsey, S., Stagg, D.A., Young, A.S., 1982b. The entry of sporozoites of Theileria parva into bovine lymphocytes in vitro. Electron microscopic observations. Eur. J. Cell Biol. 27, 10-21.

Florens, L., Washburn, M.P., Raine, J.D., Anthony, R.M., Grainger, M., Haynes, J.D., Moch, J.K., Muster, N., Sacci, J.B., Tabb, D.L., Witney, A.A., Wolters, D., Wu, Y., Gardner, M.J., Holder, A.A., Sinden, R.E., Yates, J.R., Carucci, D.J., 2002. A proteomic view of the Plasmodium falciparum life cycle. Nature 419, 520-526.

Gardner, M.J., Bishop, R., Shah, T., de Villiers, E.P., Carlton, J.M., Hall, N., Ren, Q., Paulsen, I.T., Pain, A., Berriman, M., Wilson, R.J.M., Sato, S., Ralph, S.A., Mann, D.J., Xiong, Z., Shallom, S.J., Weidman, J., Jiang, L., Lynn, J., Weaver, B., Shoaibi, A., Domingo, A.R., Wasawo, D., Crabtree, J., Wortman, J.R., Haas, B., Angiuoli, S.V., Creasy, T.H., Lu, C., Suh, B., Silva, J.C., Utterback, T.R., Feldblyum, T.V., Pertea, M., Allen, J., Nierman, W.C., Taracha, E.L.N., Salzberg, S.L., White, O.R., Fitzhugh, H.A., Morzaria, S., Venter, J.C., Fraser, C.M., Nene, V., 2005. Genome Sequence of Theileria parva, a Bovine Pathogen That Transforms Lymphocytes. Science 309, 134-137.

Graham, S.P., Honda, Y., Pellé, R., Mwangi, D.M., Glew, E.J., de Villiers, E.P., Shah, T., Bishop, R., van der Bruggen, P., Nene, V., Taracha, E.L.N., 2007. A novel strategy for the identification of antigens that are recognised by bovine MHC class I restricted cytotoxic T cells in a protozoan infection using reverse vaccinology. Immunome Res 3, 2-2.

Graham, S.P., Pelle, R., Honda, Y., Mwangi, D.M., Tonukari, N.J., Yamage, M., Glew, E.J., de Villiers, E.P., Shah, T., Bishop, R., Abuya, E., Awino, E., Gachanja, J., Luyai, A.E., Mbwika, F., Muthiani, A.M., Ndegwa, D.M., Njahira, M., Nyanjui, J.K., Onono, F.O., Osaso, J., Saya, R.M., Wildmann, C., Fraser, C.M., Maudlin, I., Gardner, M.J., Morzaria, S.P., Loosmore, S., Gilbert, S.C., Audonnet, J.C., van der Bruggen, P., Nene, V., Taracha, E.L., 2006. Theileria parva candidate vaccine antigens recognized by immune bovine cytotoxic $\mathrm{T}$ lymphocytes. Proc. Natl. Acad. Sci. USA 103, 3286-3291.

Graham, S.P., Pellé, R., Yamage, M., Mwangi, D.M., Honda, Y., Mwakubambanya, R.S., de Villiers, E.P., Abuya, E., Awino, E., Gachanja, J., Mbwika, F., Muthiani, A.M., Muriuki, C., Nyanjui, J.K., Onono, F.O., Osaso, J., Riitho, V., Saya, R.M., Ellis, S.A., McKeever, D.J., MacHugh, N.D., Gilbert, S.C., Audonnet, J.-C., Morrison, W.I., van der Bruggen, P., Taracha, E.L.N., 2008. Characterization of the Fine Specificity of Bovine CD8 T-Cell Responses to Defined Antigens from the Protozoan Parasite Theileria parva. Infect. Immun. 76, 685-694.

Hayashida, K., Hara, Y., Abe, T., Yamasaki, C., Toyoda, A., Kosuge, T., Suzuki, Y., Sato, Y., Kawashima, S., Katayama, T., Wakaguri, H., Inoue, N., Homma, K., Tada-Umezaki, M., Yagi, Y., Fujii, Y., Habara, T., Kanehisa, M., Watanabe, H., Ito, K., Gojobori, T., Sugawara, H., Imanishi, T., Weir, W., Gardner, M., Pain, A., Shiels, B., Hattori, M., Nene, V., Sugimoto, C., 2012. Comparative Genome Analysis of Three Eukaryotic Parasites with Differing Abilities To Transform Leukocytes Reveals Key Mediators of Theileria-Induced Leukocyte Transformation. mBio 3. 
Hayashida, K., Hattori, M., Nakao, R., Tanaka, Y., Kim, J.-Y., Inoue, N., Nene, V., Sugimoto, C., 2010. A schizont-derived protein, TpSCOP, is involved in the activation of NF- $\kappa B$ in Theileria parva-infected lymphocytes. Mol. Biochem. Parasitol. 174, 8-17.

Holder, A.A., Mohd Ridzuan, M.A., Green, J.L., 2012. Calcium dependent protein kinase 1 and calcium fluxes in the malaria parasite. Microb. Infect. 14, 825-830.

Hopp, C.S., Bowyer, P.W., Baker, D.A., 2012. The role of cGMP signalling in regulating life cycle progression of Plasmodium. Microb. Infect. 14, 831-837.

Ishihama, Y., Oda, Y., Tabata, T., Sato, T., Nagasu, T., Rappsilber, J., Mann, M., 2005. Exponentially Modified Protein Abundance Index (emPAI) for Estimation of Absolute Protein Amount in Proteomics by the Number of Sequenced Peptides per Protein. Mol. Cell. Proteomics 4, 1265-1272.

Jones, M.L., Kitson, E.L., Rayner, J.C., 2006. Plasmodium falciparum erythrocyte invasion: A conserved myosin associated complex. Mol. Biochem. Parasitol. 147, 74-84.

Kariu, T., Ishino, T., Yano, K., Chinzei, Y., Yuda, M., 2006. CelTOS, a novel malarial protein that mediates transmission to mosquito and vertebrate hosts. Mol. Microbiol. 59, 1369-1379.

Khan, S.M., Franke-Fayard, B., Mair, G.R., Lasonder, E., Janse, C.J., Mann, M., Waters, A.P., 2005. Proteome Analysis of Separated Male and Female Gametocytes Reveals Novel SexSpecific Plasmodium Biology. Cell 121, 675-687.

Krogh, A., Larsson, B., von Heijne, G., Sonnhammer, E.L.L., 2001. Predicting transmembrane protein topology with a hidden markov model: application to complete genomes1. J. Mol. Biol. 305, 567-580.

Lasonder, E., Janse, C.J., van Gemert, G.-J., Mair, G.R., Vermunt, A.M.W., Douradinha, B.G., van Noort, V., Huynen, M.A., Luty, A.J.F., Kroeze, H., Khan, S.M., Sauerwein, R.W., Waters, A.P., Mann, M., Stunnenberg, H.G., 2008. Proteomic Profiling of Plasmodium Sporozoite Maturation Identifies New Proteins Essential for Parasite Development and Infectivity. PLoS Pathog 4, e1000195.

Lauterbach, S.B., Coetzer, T.L., 2008. The M18 aspartyl aminopeptidase of Plasmodium falciparum binds to human erythrocyte spectrin in vitro. Malaria Journal 7, 1-10.

Li, L., Stoeckert, C.J., Roos, D.S., 2003. OrthoMCL: Identification of Ortholog Groups for Eukaryotic Genomes. Genome Res. 13, 2178-2189.

Lindner, S.E., Swearingen, K.E., Harupa, A., Vaughan, A.M., Sinnis, P., Moritz, R.L., Kappe, S.H., 2013. Total and putative surface proteomics of malaria parasite salivary gland sporozoites. Mol. Cell. Proteomics 12, 1127-1143. 
Marsolier, J., Perichon, M., DeBarry, J.D., Villoutreix, B.O., Chluba, J., Lopez, T., Garrido, C., Zhou, X.Z., Lu, K.P., Fritsch, L., Ait-Si-Ali, S., Mhadhbi, M., Medjkane, S., Weitzman, J.B., 2015. Theileria parasites secrete a prolyl isomerase to maintain host leukocyte transformation. Nature 520, 378-382.

Morzaria, S., Nene, V., Bishop, R., Musoke, A., 2000. Vaccines against Theileria parva. Ann. N. Y. Acad. Sci. 916, 464-473.

Morzaria, S.P., Katende, J., Musoke, A., Nene, V., Skilton, R., Bishop, R., 1999. Development of sero-diagnostic and molecular tools for the control of important tick-borne pathogens of cattle in Africa. Parassitologia 41 Suppl 1, 73-80.

Musoke, A., Morzaria, S., Nkonge, C., Jones, E., Nene, V., 1992. A recombinant sporozoite surface antigen of Theileria parva induces protection in cattle. Proc. Natl. Acad. Sci. U. S. A. 89, 514-518.

Nene, V., Kiara, H., Lacasta, A., Pelle, R., Svitek, N., Steinaa, L., 2016. The biology of Theileria parva and control of East Coast fever - Current status and future trends. Ticks Tick Borne Dis 7, 549-564.

Nene, V., Morrison, W.I., 2016. Approaches to vaccination against Theileria parva and Theileria annulata. Parasite Immunol. 38, 724-734.

Norval, R.A.I., Perry, B.D., Young, A., 1992. The epidemiology of theileriosis in Africa. ILRI (aka ILCA and ILRAD).

Odongo, D.O., Sunter, J.D., Kiara, H.K., Skilton, R.A., Bishop, R.P., 2010. A nested PCR assay exhibits enhanced sensitivity for detection of Theileria parva infections in bovine blood samples from carrier animals. Parasitol. Res. 106, 357-365.

Pain, A., Renauld, H., Berriman, M., Murphy, L., Yeats, C.A., Weir, W., Kerhornou, A., Aslett, M., Bishop, R., Bouchier, C., Cochet, M., Coulson, R.M.R., Cronin, A., de Villiers, E.P., Fraser, A., Fosker, N., Gardner, M., Goble, A., Griffiths-Jones, S., Harris, D.E., Katzer, F., Larke, N., Lord, A., Maser, P., McKellar, S., Mooney, P., Morton, F., Nene, V., Neil, S., Price, C., Quail, M.A., Rabbinowitsch, E., Rawlings, N.D., Rutter, S., Saunders, D., Seeger, K., Shah, T., Squares, R., Squares, S., Tivey, A., Walker, A.R., Woodward, J., Dobbelaere, D.A.E., Langsley, G., Rajandream, M.-A., McKeever, D., Shiels, B., Tait, A., Barrell, B., Hall, N., 2005. Genome of the Host-Cell Transforming Parasite Theileria annulata Compared with $T$. parva. Science 309, 131.

Patarroyo, M.E., Alba, M.P., Curtidor, H., 2011. Biological and structural characteristics of the binding peptides from the sporozoite proteins essential for cell traversal (SPECT)-1 and -2. Peptides 32, 154-160.

Patel, E., Mwaura, S., Kiara, H., Morzaria, S., Peters, A., Toye, P., 2016. Production and dose determination of the Infection and Treatment Method (ITM) Muguga cocktail vaccine used to control East Coast fever in cattle. Ticks Tick Borne Dis 7, 306-314. 
Petersen, T.N., Brunak, S., von Heijne, G., Nielsen, H., 2011. SignalP 4.0: discriminating signal peptides from transmembrane regions. Nat Meth 8, 785-786.

Pradel, G., 2007. Proteins of the malaria parasite sexual stages: expression, function and potential for transmission blocking strategies. Parasitology 134, 1911-1929.

Radley, D.E., Brown, C.G.D., Burridge, M.J., Cunningham, M.P., Kirimi, I.M., Purnell, R.E., Young, A.S., 1975a. East coast fever: 1. Chemoprophylactic immunization of cattle against Theileria parva (Muguga) and five theilerial strains. Vet. Parasitol. 1, 35-41.

Remarque, E.J., Faber, B.W., Kocken, C.H.M., Thomas, A.W., 2008. Apical membrane antigen 1: a malaria vaccine candidate in review. Trends Parasitol. 24, 74-84.

Ridley, R.G., Takacs, B., Etlinger, H., Scaife, J.G., 1990. A rhoptry antigen of Plasmodium falciparum is protective in Saimiri monkeys. Parasitology 101, 187-192.

Sam-Yellowe, T.Y., Florens, L., Wang, T., Raine, J.D., Carucci, D.J., Sinden, R., Yates, J.R., 2004. Proteome Analysis of Rhoptry-Enriched Fractions Isolated from Plasmodium Merozoites. J. Proteome Res. 3, 995-1001.

Schirmer, E.C., Yates, J.R., 3rd, Gerace, L., 2003. MudPIT: A powerful proteomics tool for discovery. Discov Med 3, 38-39.

Schmuckli-Maurer, J., Casanova, C., Schmied, S., Affentranger, S., Parvanova, I., Kang'a, S., Nene, V., Katzer, F., McKeever, D., Müller, J., Bishop, R., Pain, A., Dobbelaere, D.A.E., 2009. Expression Analysis of the Theileria parva Subtelomere-Encoded Variable Secreted Protein Gene Family. PLoS ONE 4, e4839.

Shapiro, S.Z., Fujisaki, K., Morzaria, S.P., Webster, P., Fujinaga, T., Spooner, P.R., Irvin, A.D., 1987. A life-cycle stage-specific antigen of Theileria parva recognized by antimacroschizont monoclonal antibodies. Parasitology 94, 29-37.

Shaw, M.K., 1995. Mobilization of intrasporozoite $\mathrm{Ca} 2+$ is essential for Theileria parva sporozoite invasion of bovine lymphocytes. Eur. J. Cell Biol. 68, 78-87.

Shaw, M.K., 2003. Cell invasion by Theileria sporozoites. Trends Parasitol. 19, 2-6.

Shaw, M.K., Tilney, L.G., McKeever, D.J., 1993. Tick salivary gland extract and interleukin2 stimulation enhance susceptibility of lymphocytes to infection by Theileria parva sporozoites. Infect. Immun. 61, 1486-1495.

Shiels, B., Langsley, G., Weir, W., Pain, A., McKellar, S., Dobbelaere, D., 2006. Alteration of host cell phenotype by Theileria annulata and Theileria parva: mining for manipulators in the parasite genomes. Int. J. Parasitol. 36, 9-21. 
Skilton, R.A., Bishop, R.P., Wells, C.W., Spooner, P.R., Gobright, E., Nkonge, C., Musoke, A.J., Macklin, M., Iams, K.P., 1998. Cloning and characterization of a $150 \mathrm{kDa}$ microsphere antigen of Theileria parva that is immunologically cross-reactive with the polymorphic immunodominant molecule (PIM). Parasitology 117 ( Pt 4), 321-330.

Skilton, R.A., Musoke, A.J., Wells, C.W., Yagi, Y., Nene, V., Spooner, P.R., Gachanja, J., Osaso, J., Bishop, R.P., Morzaria, S.P., 2000. A $32 \mathrm{kDa}$ surface antigen of Theileria parva: characterization and immunization studies. Parasitology 120 ( Pt 6), 553-564.

Toye, P.G., Goddeeris, B.M., Iams, K., Musoke, A.J., Morrison, W.I., 1991. Characterization of a polymorphic immunodominant molecule in sporozoites and schizonts of Theileria parva. Parasite Immunol. 13, 49-62.

Treeck, M., Zacherl, S., Herrmann, S., Cabrera, A., Kono, M., Struck, N.S., Engelberg, K., Haase, S., Frischknecht, F., Miura, K., Spielmann, T., Gilberger, T.W., 2009. Functional Analysis of the Leading Malaria Vaccine Candidate AMA-1 Reveals an Essential Role for the Cytoplasmic Domain in the Invasion Process. PLoS Pathog 5, e1000322.

Tretina, K., Gotia, H.T., Mann, D.J., Silva, J.C., 2015. Theileria-transformed bovine leukocytes have cancer hallmarks. Trends Parasitol. 31, 306-314.

Tretina, K., Pelle, R., Silva, J.C., 2016. Cis regulatory motifs and antisense transcriptional control in the apicomplexan Theileria parva. BMC Genomics 17, 128.

Tyagi, N., Swapna, L.S., Mohanty, S., Agarwal, G., Gowri, V.S., Anamika, K., Priya, M.L., Krishnadev, O., Srinivasan, N., 2009. Evolutionary Divergence of Plasmodium falciparum: Sequences, Protein- Protein Interactions, Pathways and Processes. Infect Disord Drug Targets $9,257-271$.

Witschi, M., Xia, D., Sanderson, S., Baumgartner, M., Wastling, J.M., Dobbelaere, D.A.E., 2013. Proteomic analysis of the Theileria annulata schizont. Int. J. Parasitol. 43, 173-180.

Xue, G., von Schubert, C., Hermann, P., Peyer, M., Maushagen, R., Schmuckli-Maurer, J., Bütikofer, P., Langsley, G., Dobbelaere, D.A.E., 2010. Characterisation of gp34, a GPIanchored protein expressed by schizonts of Theileria parva and T. annulata. Mol. Biochem. Parasitol. 172, 113-120.

Zhang, H., Compaore, M.K., Lee, E.-g., Liao, M., Zhang, G., Sugimoto, C., Fujisaki, K., Nishikawa, Y., Xuan, X., 2007. Apical membrane antigen 1 is a cross-reactive antigen between Neospora caninum and Toxoplasma gondii, and the anti-NcAMA1 antibody inhibits host cell invasion by both parasites. Mol. Biochem. Parasitol. 151, 205-212. 
CHAPTER

3

Characterization of Rhipicephalus appendiculatus salivary glands proteins co-purified with Theileria parva sporozoites

James Nyagwange

Edwin Tijhaar

Nicola Ternette

Milcah Kigoni

Roger Pelle

Vishvanath Nene 


\begin{abstract}
Ticks are obligate hematophagous arthropods and are vectors of many pathogens including parasites, viruses and bacteria. The brown ear tick Rhipicephalus appendiculatus is the major vector of Theileria parva, an apicomplexan parasite that causes a lymphoproliferative disease in cattle known as East Coast fever (ECF). Sporozoites, the bovine infective stage of $T$. parva, are harbored in the salivary glands of $R$. appendiculatus and are transmitted to the bovine host during tick feeding. Tick salivary glands and saliva contain proteins that facilitate tick feeding by enhancing attachment and dampening of bovine host defenses. Therefore, these proteins are targets for development of anti-tick vaccines, which block attachment or compromise tick feeding, which subsequently results in poor reproductive fitness and limited or no pathogen transmission. We have characterized the salivary gland proteome of $R$. appendiculatus ticks infected by T. parva sporozoites using LC-MS/MS. In total 4,780 proteins were identified, of which 2,773 were $R$. appendiculatus proteins and 2,007 were of parasite origin. The $R$. appendiculatus proteins identified include known $R$. appendiculatus salivary glands antigens such as Rhipicephalus Immuno-dominant Molecule 36 (RIM 36) and orthologs of proteins playing roles in host defense modulation including, calreticulins, ixodegrins and histamine binding proteins, among others. Some of the novel tick proteins identified that are associated or attached to the sporozoites could induce antibodies which opsonize the sporozoites leading to destruction of the parasite through phagocytosis or complement lysis.
\end{abstract}

Keywords:

Rhipicephalus appendiculatus, salivary glands, proteomics, vaccine antigens 


\section{Introduction}

Ticks are obligate blood sucking arachnids and vectors of viruses, bacteria and protozoa which, when transmitted to vertebrate hosts, may cause disease (Cupp 1991). Ticks acquire pathogens from infected blood and pathogens are transmitted by a trans-stadial route, i.e., where infection is acquired by one life-cycle stage and transmitted by the next tick instar, or a trans-ovarial route, which gives rise to infectious larvae upon hatching of infected eggs (Norval, Perry et al. 1992) Tick infection is usually followed by pathogen replication, although passive transfer of pathogens can also occur (Norval, Perry et al. 1992). Tick saliva is the major route for pathogen transmission and release of pathogens from infected salivary glands coincides with excretion of excess water acquired during feeding (Sauer, Essenberg et al. 2000). Components of the tick saliva may enhance infectivity of the pathogens by regulating host hemostasis, immune and inflammatory responses (Sauer, Essenberg et al. 2000). Furthermore tick proteins bound to the surface of the sporozoite might induce protective antibodies resulting in activation of complement and enhanced phagocytosis and destruction by macrophages. Thus, understanding the proteins involved in these processes, may be useful, for example, in designing anti-sporozoite vaccines, transmission blocking vaccines, and gaining a better understanding of tick biology.

Rhipicephalus appendiculatus is a three-host tick and the principal vector for the transmission of Theileria parva, an apicomplexan parasite causing, a lymphoproliferative cattle disease known as East Coast fever (ECF) (Theiler 1912). Transmission of T. parva occurs trans-stadially by the nymph and the adult ticks after acquiring infections as either larvae or nymphs (reviewed by Norval, Perry et al. 1992). After a blood meal the ticks are infected by T. parva piroplasms, a life cycle stage of the parasite that resides inside red blood cells (reviewed by Norval, Perry et al. 1992). The piroplasms differentiates into gametes in the tick gut post-ingestion. The macro- and micro-gametes then fuse forming zygotes, which enters the gut epithelial cells and differentiates into motile kinetes, that are subsequently released into the tick hemocoel (reviewed in Nene, Lee et al. 2004). The kinetes invade e-cells of type III acini of the salivary glands and goes through final differentiation, with complete sporogony occurring only after the tick molts into the next instar, a process essentially triggered by blood feeding (Fawcett, Büscher et al. 1982). Release of mature mammalian infective sporozoites from the salivary glands occurs as a trickle between day 4-8, with peak production on day 4 and 5, after initiation of feeding (reviewed in Nene, Lee et al. 2004, Shaw and Young 2009).

Control of ECF includes killing of $R$. appendiculatus by acaricide treatment and by chemotherapy using drugs such as buparvaquone. However, both strategies have serious limitations ranging from resistance of ticks to acaricides to concerns of $T$. parva developing resistance to buparvaquone following resistance in Theileria annulata. There are also concerns of toxic residues in food and in the environment following acaricide use. A live vaccine is available and involves deliberate infection with sporozoites, followed by treatment with long acting oxytetracycline (Radley, Brown et al. 1975). There are ongoing efforts to develop next generation subunit vaccines based on what is known about the mechanism of immunity of this live vaccine, including characterization of the sporozoite proteome for identification of antigens and testing of novel and known antigens in different formulations for both humoral and cellular immune responses (Nene, Kiara et al. 2016). Another area of research attracting attention is the development of novel transmission blocking vaccines, which can be integrated with the other methods to control ECF. Therefore, there is still need for identification of tick antigens with cross-protective epitopes.

As an initiative to improve the understanding of the biology of T. parva, we recently undertook a Multidimensional Protein Identification Technology (MudPIT) mass spectrometry-based approach (reviewed in Schirmer, Yates et al. 2003) to characterize the 
proteome of $T$. parva sporozoites purified from tick salivary glands by ion-exchange chromatography and precipitation (Nyagwange, Tijhaar et al. 2018), where we identified 2,007 parasite proteins. In the process, we also identified 2,773 $R$. appendiculatus proteins. Here, we have employed bioinformatics tools to analyze these $R$. appendiculatus proteins to identify tick salivary glands proteins associated with or bound to sporozoites as they may be involved in infectivity and/ or transmission of the parasites. Moreover, the tick proteins bound to sporozoites could be targets for opsonizing antibodies that may aid in the destruction of the sporozoite.Therefore some of these tick proteins could represent potential ECF vaccine candidates. 


\section{Materials and methods}

\section{DE-52 column purification and LC-MS/MS analysis}

The procedure for production of T. parva infected ticks has been described before (Patel, Mwaura et al. 2016) and we have recently described the DE-52 column purification method used for purification of sporozoites (Nyagwange, Tijhaar et al. 2018). Briefly, sporozoite infected tick salivary glands were dissected, homogenized and lysate centrifugated at 1000 $\mathrm{rpm}, 5 \mathrm{~min}, 4^{\circ} \mathrm{C}$, in a pre-chilled centrifuge before the resulting supernatant added onto the DE52 column bed and the sporozoites eluted by SP buffer $(0.16 \mathrm{M} \mathrm{NaCl}, 0.16 \mathrm{M}$ D-glucose, $0.16 \mathrm{M}$ $\mathrm{Na}_{2} \mathrm{HPO}_{4}, 0.16 \mathrm{M}$ Trisbase, $\mathrm{pH}$ 8.2). The resulting cloudy suspension was centrifuged and the resulting pellet re-suspended in SDS-PAGE sample buffer and denatured at $100^{\circ} \mathrm{C}$ for 5 min then fractionated on $10 \%$ one-dimensional SDS-PAGE and stained with Coomassie Blue. Trypsin digestion was performed in-gel and tryptic peptides analyzed by LC-MS/MS (Nyagwange, Tijhaar et al. 2018).

\section{Data Analysis}

\section{Protein identification and relative abundance}

Raw MS/MS data files were analysed with the Peaks software (Bioinformatics solutions) as described in (Nyagwange, Tijhaar et al. 2018). Briefly, a database containing the reannotated proteome of $T$. parva (4,084 proteins) and all Uniprot database entries for $R$. appendiculatus (12,884 proteins, July 2016) was used for analysis and a peptide false discovery rate (FDR) of $1.2 \%$ was applied.

Exponentially Modified Protein Abundance Index (emPAI) was calculated using Mascot (Matrix Science) (Ishihama, Oda et al. 2005) and was used to rank the identified proteins by their abundance in the sample.

\section{Classification of the identified $R$. appendiculatus proteins by orthology}

We clustered all protein coding sequences of $R$. appendiculatus with the predicted salivary gland proteomes of Rhipicephalus microplus, Ambylomma variegatum, Rhipicephalus pulchellus, Ixodes scapularis and Ixodes ricinus (Ribeiro, Alarcon-Chaidez et al. 2006, Ribeiro, Anderson et al. 2011, Tan, Francischetti et al. 2015) into putative orthologous groups using the OrthoMCL standalone software Version 2.0.2 (Li, Stoeckert et al. 2003). The blast step of OrthoMCL was performed using an E-value cut-off of 1e-10, and minimum $70 \%$ sequence identity over $75 \%$ sequence coverage. 


\section{Results}

\section{Determination and relative quantification of tick salivary gland proteins}

LC-MS/MS was used to identify 4,780 proteins purified by DE-52 column, of which 2,773 proteins originated from $R$. appendiculatus and 2007 from $T$. parva. Most proteins $(3,780)$ were identified with 2 or more unique peptide identifications, while 1,000 protein identifications were based on a single unique peptide match, which includes $437 R$. appendiculatus proteins. Thus, there is a higher confidence in the identification of 2,336 tick proteins. A sequence coverage of over $70 \%$ was achieved for some of the $R$. appendiculatus proteins with others identified by as many as 150 unique peptide identifications.

It was only possible to rank 1,319 proteins of the 2,773 identified proteins by calculation of relative abundance in the sample using emPAI values (Supplementary Table S2). The emPAI parameter is useful for obtaining an overview of proteome profiles with a wide dynamic range of concentrations ( $30 \mathrm{fmol}$ to $1.8 \mathrm{pmol} / \mu \mathrm{l}$ ) (Ishihama, Oda et al. 2005), and the 20 most abundant $R$. appendiculatus salivary gland proteins are shown in Table 1. Even within this data set, there is a considerable range in the abundance of tick proteins with NADH dehydrogenase (Ubiquinone) 1 alpha subcomplex subunit 4 being the most abundant. Other housekeeping proteins, e.g., cytochromes, ATPases, heat shock protein 70, actin and Thioredoxin, feature in this list.

\section{Known $R$. appendiculatus salivary antigens relevant for $T$. parva transmission}

Rhipicephalus Immuno-dominant Molecule 36 (RIM36), expressed predominantly in the e cells of the type III salivary gland acinus (Bishop, Lambson et al. 2002) and a candidate antigen for anti-tick vaccine development is among the known antigens identified in the salivary glands by MS. Additional vaccine candidate antigens that had been previously characterized were identified in this study e.g. serine protease inhibitors (serpins), proteins used by ticks to disrupt host defensive processes and to sustain tick homeostasis (Imamura, Namangala et al. 2006, Imamura, Konnai et al. 2008) and Glutathione S-transferase (GST), a protein used by ticks for detoxification by catalyzing a nucleophilic conjugation reaction of the toxic compound with reduced glutathione (Sabadin, Parizi et al. 2017). A 20/24 kDa immunodominant saliva protein was also identified (Nene, Lee et al. 2004).

Protein 64TRP expressed in the salivary glands and functioning in anchoring tick mouthparts to the host during feeding and a vaccine candidate antigen (Havlíková, Roller et al. 2009), was not identified, suggesting that the protein is involved in the feeding of the tick but may not be associated with the sporozoites. 
Table 1. Abundant R. appendiculatus salivary glands proteins

\begin{tabular}{|c|c|c|c|}
\hline ORF locus tag & Annotation & Mass (Da) & emPAI \\
\hline A0A131YIK5 & $\begin{array}{l}\text { NADH dehydrogenase (Ubiquinone) } 1 \text { alpha } \\
\text { subcomplex subunit } 4\end{array}$ & 9301 & 137.99 \\
\hline A0A131Z701 & Cytochrome c & 12159 & 93.99 \\
\hline A0A131Z7X1 & Cytochrome c oxidase subunit 4 & 20758 & 89.65 \\
\hline A0A131YGU7 & F-type $\mathrm{H}+$-transporting ATPase subunit $\mathrm{O}$ & 22974 & 87.64 \\
\hline A0A131YXJ2 & $\begin{array}{l}\text { Capping protein (Actin filament) muscle Z- } \\
\text { line, beta }\end{array}$ & 11515 & 81.21 \\
\hline A0A131YYS7 & ATP synthase subunit beta & 56382 & 70.33 \\
\hline A0A131YUP7 & Peptidyl-prolyl cis-trans isomerase & 21922 & 57.39 \\
\hline A0A131YWH5 & Heat shock $70 \mathrm{kDa}$ protein $1 / 8$ & 71203 & 46 \\
\hline A0A131Z5N9 & Cytochrome c oxidase subunit $5 \mathrm{~b}$ & 14618 & 44.12 \\
\hline A0A131Z614 & ATP synthase subunit alpha & 60187 & 42.19 \\
\hline Q6X4W2 & Actin & 42180 & 34.64 \\
\hline A0A131YU54 & Chaperonin GroES & 17149 & 33.71 \\
\hline A0A131YNP5 & $\begin{array}{l}\text { Solute carrier family } 25 \text { (Mitochondrial } \\
\text { adenine nucleotide translocator), member } \\
4 / 5 / 6 / 31\end{array}$ & 33252 & 33.12 \\
\hline $\mathrm{A} 0 \mathrm{~A} 131 \mathrm{Z} 2 \mathrm{~K} 0$ & Nucleoside diphosphate kinase & 17342 & 32.19 \\
\hline A0A131YRI2 & Chaperonin GroEL & 61200 & 31.23 \\
\hline A0A131Z1V0 & Thioredoxin & 16203 & 30.51 \\
\hline A0A131Z6D0 & Large subunit ribosomal protein $\mathrm{L} 23 \mathrm{e}$ & 14882 & 30.21 \\
\hline A0A131YWW0 & Ras-related protein Rab-1A & 23281 & 29.46 \\
\hline A0A131Z560 & Enolase & 47651 & 27.95 \\
\hline A0A131YTE0 & Small subunit ribosomal protein $\mathrm{S} 3 \mathrm{e}$ & 26764 & 27.01 \\
\hline
\end{tabular}




\section{Tick proteins involved in modulation of host defense responses}

During feeding, ticks cause injury to the host and face challenges of host hemostasis (mechanisms that prevent loss of host blood), inflammation (mechanisms producing itching and pain and initiating host defense responses) and immunity (humoral and cellular defense responses). Ticks have evolved pharmacological active compounds to counter host defense and assist in tick feeding. Many of these compounds have been identified and they involve several families of proteins (Ribeiro, Anderson et al. 2011, Šimo, Kazimirova et al. 2017). We have identified some members of these families in the MS data and indicated host processes targeted for inhibition by these proteins (table 2). The list features ixodegrins, nucleotidases and lipocalins. Ixodegrin family have members with a conserved Arg-Gly-Asp (RGD) domain and are implicated in disruption of fibrinogen binding to platelets (Francischetti, My Pham et al. 2005, reviewed in Ribeiro, Anderson et al. 2011). Nucleotidases also known as apyrases hydrolyze tri- and di-phosphonucleotides (such as ATP and ADP) to their monophosphate esters plus inorganic phosphate. ATP and ADP are important agonists of neutrophil (O'Flaherty and Cordes 1994) and platelet aggregation (Gachet 2008). Lipocalins are proteins that not only bind lipophylic compounds such as leukotrienes and thromboxane A2 but also serotonin and histamine, which are agonists of inflammation (Beaufays, Adam et al. 2008). 
Table 2. Identified tick proteins involved in modulation of host defense responses

\begin{tabular}{|c|c|c|c|c|}
\hline OG group & Organism & ORF locus tag & Annotation & $\begin{array}{l}\text { Mechanism } \\
\text { targeted for } \\
\text { inhibition } \\
\text { (reference) }\end{array}$ \\
\hline \multicolumn{5}{|c|}{ Calreticulins } \\
\hline \multirow[t]{2}{*}{ OG_430 } & Amblyomma & F0JA25 & Calreticulin & \multirow[b]{2}{*}{$\begin{array}{l}\text { Blood } \\
\text { coagulation } \\
\text { (Jaworski, } \\
\text { Simmen et al. } \\
1995 \text { ) }\end{array}$} \\
\hline & $\begin{array}{l}R . \\
\text { appendiculatus }\end{array}$ & A0A131Z2S4 & Calreticulin & \\
\hline \multicolumn{5}{|c|}{ Metalloproteases } \\
\hline \multirow[t]{6}{*}{ OG_614 } & $\begin{array}{l}\text { Ixodes } \\
\text { sanguineus }\end{array}$ & A0A068LGB8 & Metalloprotease 1 & \multirow[b]{6}{*}{$\begin{array}{l}\text { Wound healing/ } \\
\text { angiogenesis }\end{array}$} \\
\hline & I. sanguineus & A0A068LE08 & Metalloprotease 1 & \\
\hline & $\begin{array}{l}R . \\
\text { appendiculatus }\end{array}$ & A0A131YXN8 & Reprolysin & \\
\hline & $\begin{array}{l}R \text {. } \\
\text { appendiculatus }\end{array}$ & A0A131YMV3 & Reprolysin & \\
\hline & I. ricinus & A0A0K8RKL9 & $\begin{array}{l}\text { Putative } \\
\text { metalloprotease }\end{array}$ & \\
\hline & $\begin{array}{l}R . \\
\text { appendiculatus }\end{array}$ & A0A131YJK3 & Reprolysin & \\
\hline \multirow[t]{4}{*}{ OG_1653 } & I. sanguineus & A0A068LER5 & Metalloprotease 5 & \multirow{4}{*}{$\begin{array}{l}\text { (Ribeiro and } \\
\text { Mather 1998, } \\
\text { Decrem, } \\
\text { Beaufays et al. } \\
\text { 2008) Blood } \\
\text { coagulation and } \\
\text { Innate immune }\end{array}$} \\
\hline & $\begin{array}{l}\text { Rhipicephalus } \\
\text { microplus }\end{array}$ & A0A068LEA0 & Metalloprotease 5 & \\
\hline & $\begin{array}{l}R \text {. } \\
\text { appendiculatus }\end{array}$ & A0A131Z4U4 & Reprolysin & \\
\hline & $\begin{array}{l}R \text {. } \\
\text { appendiculatus }\end{array}$ & A0A131YFM5 & Reprolysin & \\
\hline \multirow[t]{2}{*}{ OG_6106 } & A. variegatum & F0J8I5 & $\begin{array}{l}\text { Salivary gland } \\
\text { metalloprotease } \\
\text { (Fragment) }\end{array}$ & \multirow[t]{2}{*}{ responses } \\
\hline & $\begin{array}{l}R . \\
\text { appendiculatus }\end{array}$ & A0A131YWB8 & Reprolysin & \\
\hline \multicolumn{5}{|l|}{ Ixodegrins } \\
\hline \multirow[t]{2}{*}{ OG_1591 } & I. ricinus & A0A0K8RFW7 & $\begin{array}{l}\text { Putative secreted } \\
\text { stromal cell-derived } \\
\text { factor } 2\end{array}$ & \multirow{4}{*}{$\begin{array}{l}\text { Platelet } \\
\text { aggregation } \\
\text { (Francischetti, } \\
\text { My Pham et al. } \\
\text { 2005, Gachet } \\
\text { 2008) }\end{array}$} \\
\hline & $\begin{array}{l}R . \\
\text { appendiculatus }\end{array}$ & A0A131ZBX5 & $\begin{array}{l}\text { Ixodegrin } \\
\text { (Fragment) }\end{array}$ & \\
\hline OG_145 & I. ricinus & A0A0K8R9T6 & $\begin{array}{l}\text { Putative 5'- } \\
\text { nucleotidase/apyrase }\end{array}$ & \\
\hline & $\begin{array}{l}R . \\
\text { appendiculatus }\end{array}$ & A0A131Z1W4 & 5'-Nucleotidase & \\
\hline
\end{tabular}




\begin{tabular}{|c|c|c|c|c|}
\hline \multirow[t]{2}{*}{ OG_250 } & I. scapularis & Q4PMH4 & $\begin{array}{l}\text { Histamine binding } \\
\text { protein }\end{array}$ & \multirow{6}{*}{$\begin{array}{l}\text { Innate immune } \\
\text { responses } \\
\text { (Paesen, Adams } \\
\text { et al. 1999) } \\
\text { (Beaufays, } \\
\text { Adam et al. } \\
\text { 2008) }\end{array}$} \\
\hline & $\begin{array}{l}R . \\
\text { appendiculatus }\end{array}$ & A0A131Z256 & Lipocalin & \\
\hline \multirow[t]{4}{*}{ OG_11545 } & $\begin{array}{l}\text { Rhipicephalus } \\
\text { pulchellus }\end{array}$ & L7MA16 & $\begin{array}{l}\text { Putative group viii } \\
\text { salivary lipocalin }\end{array}$ & \\
\hline & R. pulchellus & L7M9J3 & $\begin{array}{l}\text { Putative group viii } \\
\text { salivary lipocalin }\end{array}$ & \\
\hline & $\begin{array}{l}R . \\
\text { appendiculatus }\end{array}$ & A0A131YT83 & lipocalin & \\
\hline & $\begin{array}{l}R \text {. } \\
\text { appendiculatus }\end{array}$ & M1NKV5 & Japanin-like-RA2 & \\
\hline \multicolumn{5}{|l|}{ Cystatins } \\
\hline \multirow[t]{2}{*}{ OG_12859 } & R. pulchellus & L7LRB4 & $\begin{array}{l}\text { Putative tick salivary } \\
\text { cystatin }\end{array}$ & \multirow{2}{*}{$\begin{array}{l}\text { Inflammation } \\
\text { and innate } \\
\text { immune } \\
\text { responses } \\
\text { (Ribeiro, } \\
\text { Anderson et al. } \\
\text { 2011) }\end{array}$} \\
\hline & $\begin{array}{l}R . \\
\text { appendiculatus }\end{array}$ & A0A131Z1J2 & Cystatin & \\
\hline \multirow[t]{2}{*}{ OG_7257 } & $\begin{array}{l}\text { Amblyomma } \\
\text { cajennense }\end{array}$ & A0A023FRE6 & \multirow{2}{*}{\multicolumn{2}{|c|}{$\begin{array}{l}\text { fed tick salivary } \\
\text { protein } \\
\text { Fed tick salivary } \\
\text { protein } 7\end{array}$}} \\
\hline & $\begin{array}{l}R . \\
\text { appendiculatus }\end{array}$ & A0A131Z0K9 & & \\
\hline \multicolumn{5}{|l|}{ Serpins } \\
\hline \multirow[t]{2}{*}{ OG_8521 } & R. microplus & V9VP22 & $\begin{array}{l}\text { Serine protease } \\
\text { inhibitor } 15 \mathrm{RmS} 15\end{array}$ & \multirow{2}{*}{$\begin{array}{l}\text { Blood } \\
\text { coagulation } \\
\text { (Xu, Lew-Tabor } \\
\text { et al. 2016) }\end{array}$} \\
\hline & $\begin{array}{l}R . \\
\text { appendiculatus }\end{array}$ & A0A131YYG3 & Serpin B & \\
\hline \multicolumn{5}{|c|}{ Da-p36 immunosuppressant } \\
\hline \multirow[t]{2}{*}{ OG_11462 } & R. pulchellus & L7LTD7 & $\begin{array}{l}\text { Putative da-p36 } \\
\text { protein }\end{array}$ & \multirow{2}{*}{$\begin{array}{l}\text { Immune } \\
\text { responses } \\
\text { (reviewed in } \\
\text { Ribeiro, } \\
\text { Anderson et al. } \\
\text { 2011) }\end{array}$} \\
\hline & $\begin{array}{l}R . \\
\text { appendiculatus }\end{array}$ & A0A131YVJ3 & $\begin{array}{l}\text { DA-P36 family } \\
\text { member }\end{array}$ & \\
\hline
\end{tabular}




\section{Discussion}

The current study reports on $R$. appendiculatus proteins co-purified with $T$. parva sporozoites. Although our initial aim was to identify $T$. parva sporozoites proteins from infected tick salivary glands, tick proteins constituted 58\% (2773/4780) of all the proteins identified by LC-MS/MS and Peaks and Mascot software packages, in addition to the identified 2,007 parasite proteins which we have reported on elsewhere. Ideally the DE-52 is a positively charged resin that should trap the negatively charged proteins and allow the positively charged sporozoite cells to elute in the SP buffer used. However, abundant tick proteins, proteins that are not negatively charged or those tightly associated with sporozoites can still end up in the flow-through fraction. The following centrifugation of the flow through fraction should eliminate the soluble tick proteins from the sporozoite fraction leaving tick proteins bound to sporozoites, insoluble uncharged and positively charged tick proteins. We have searched this list of tick proteins co-purified with the sporozoites to identify proteins that are likely to play a role in sporozoite infection.

Positive identification of proteins by MS especially, by multiple unique peptides, confers confidence in the presence of such proteins. A total of 2,088 of the 2,773 tick proteins identified with more than a single unique peptide, giving confidence in $75 \%$ of the data. We have however reported on the complete set of the 2,773 proteins. Although positive identification confer confidence in the presence of the protein, failure to identify a protein does not necessarily imply their absence in the sample.

We have calculated the emPAI using Mascot to estimate the relative abundance of proteins in the sample. Although the list consisted of many housekeeping genes, such as NADH dehydrogenase (Ubiquinone) 1 alpha subcomplex subunit 4, Cytochrome c oxidase subunit 4, ATP synthases (alpha and beta subunits) and solute carrier family 25 (mitochondrial adenine nucleotide translocator), member 4/5/6/31 (table 1), some proteins were identified that are involved in immune modulation and therefore might be useful for sporozoite infection (table 2 and supplementary table $\mathrm{S} 1$ ). The salivary glands is a highly active organ requiring energy for its functions such as maintenance of water and ion balance during blood feeding, formation of cement for tick attachment to the host and secretion of pharmacological armament modulating host processes (reviewed in Šimo, Kazimirova et al. 2017) and so high expression of mitochondrial proteins is not surprising.

Targeting salivary proteins involved in tick feeding as vaccine antigens, is expected to either lead to tick rejection, blocking/ limiting pathogen transmission or interfere with completion of blood meal and compromising tick reproductive fitness (Šimo, Kazimirova et al. 2017). Since tick proteins can induce host immune responses, tick proteins associated with sporozoites can also be targeted as anti-sporozoite vaccines. Such a vaccine would function on the basis of antibodies induced by the respective sporozoite bound tick antigen leading to opsonization of the sporozoites, increased phagocytosis by macrophages and complement dependent lysis. A number of known antigens were identified within the $R$. appendiculatus salivary glands proteome including serpins, anti-tick vaccine candidates targeted for their role in disrupting host haemostasis thereby facilitating tick feeding (Imamura, Namangala et al. 2006, Imamura, Konnai et al. 2008) and RIM36, a salivary gland protein and a component of tick cement targeted for its role in tick attachment and protecting the tick hypostome during feeding (Bishop, Lambson et al. 2002). However, a vaccine candidate antigen, 64TRP protein expressed in the salivary glands (Havlíková, Roller et al. 2009) was not identified. Although, an in silico 64TRP tryptic digestion leads to only few detectable peptides (data not shown), it is also possible that this protein was efficiently bound by the column or is not bound to sporozoites, hence not identified.

Hard ticks such as $R$. appendiculatus require extended periods of between 10 to 14 days to feed to repletion (Cupp 1991). During the feeding process, the ticks inflict injuries to the host 
which triggers host defense and repair reactions including; platelet activation and aggregation, blood clotting and vasocontraction (Ribeiro 1987). All these processes are aimed at expelling the intruding tick. The intruding ticks respond by secreting numerous active substances in their saliva to promote feeding by countering the host hemostatic and immune effector mechanisms to maintain a steady blood flow to the feeding site (Ribeiro 1987). Host animals can naturally acquire resistance to these salivary glands associated molecules following multiple tick infestations or active immunization with crude tick extracts (reviewed in Mulenga, Sugimoto et al. 2000). Therefore, tick salivary gland molecules are potential vaccine candidate antigens. Many tick proteins inhibiting host coagulation cascade and modulating host immune responses have been described but their molecular identities have not been elucidated (Mulenga, Sugimoto et al. 2000). However, some have been characterized and have molecular identities (Parizi, Githaka et al. 2012, Šimo, Kazimirova et al. 2017). We have identified known $R$. appendiculatus antigens (section 3.2) and orthologs of other tick antigens known to modulate host defenses (Table 2). The list features calreticulin, histamine binding proteins and metalloproteases. Whereas calreticulin is implicated in inhibiting blood coagulation by sequestering calcium ions which act as cofactors of the coagulation enzymes (Jaworski, Simmen et al. 1995), histamine binding proteins and salivary metalloproteases bind histamine and hydrolyze bradykinins respectively (Ribeiro and Mather 1998, Paesen, Adams et al. 1999). Histamines and bradykinins produced by mast cells in the skin promote inflammation, pain and itching at the site of tick intrusion and prevention of these processes interferes with downstream recruitment of host immune cells against the invading tick (Šimo, Kazimirova et al. 2017).

In conclusion, these data confirm the expression of 2,773 proteins of $R$. appendiculatus salivary glands infected by $T$. parva, the only such profile available to date. Although known vaccine antigens targeting transmission blocking were identified, determining the specific sporozoite bound proteins was not possible owing to the large number of tick proteins still present. A method for further isolation of sporozoites from the mixture of tick proteins might help in identifying the specific sporozoite bound proteins. Labelling sporozoites by monoclonal antibodies against p67 followed by FACS sorting before LC-MS/MS can increase the likelihood that the identified vector proteins are truly bound to the sporozoites. Nevertheless, we have confirmed the expression and abundance of some of the previously identified transmission blocking vaccine candidates and identified many orthologs of $R$. appendiculatus antigens implicated in modulating host defenses in other ticks. Some of the latter may represent novel antigens that could be used in transmission blocking anti-tick vaccines. 


\section{References}

Beaufays, J., B. Adam, C. Menten-Dedoyart, L. Fievez, A. Grosjean, Y. Decrem, P. P. Prevot, S. Santini, R. Brasseur, M. Brossard, M. Vanhaeverbeek, F. Bureau, E. Heinen, L. Lins, L. Vanhamme and E. Godfroid (2008). "Ir-LBP, an ixodes ricinus tick salivary LTB4-binding lipocalin, interferes with host neutrophil function." PLoS One 3(12): e3987.

Bishop, R., B. Lambson, C. Wells, P. Pandit, J. Osaso, C. Nkonge, S. Morzaria, A. Musoke and V. Nene (2002). "A cement protein of the tick Rhipicephalus appendiculatus, located in the secretory e cell granules of the type III salivary gland acini, induces strong antibody responses in cattle." International Journal for Parasitology 32(7): 833-842.

Cupp, E. W. (1991). "Biology of Ticks." Veterinary Clinics of North America: Small Animal Practice 21(1): 1-26.

Decrem, Y., J. Beaufays, V. Blasioli, K. Lahaye, M. Brossard, L. Vanhamme and E. Godfroid (2008). "A family of putative metalloproteases in the salivary glands of the tick Ixodes ricinus." Febs j 275(7): 1485-1499.

Fawcett, D. W., G. Büscher and S. Doxsey (1982). "Salivary gland of the tick vector of east coast fever. IV. Cell type selectivity and host cell responses to Theileria parva." Tissue and Cell 14(2): 397-414.

Francischetti, I. M. B., V. My Pham, B. J. Mans, J. F. Andersen, T. N. Mather, R. S. Lane and J. M. C. Ribeiro (2005). "The transcriptome of the salivary glands of the female western blacklegged tick Ixodes pacificus (Acari: Ixodidae)." Insect Biochemistry and Molecular Biology 35(10): 1142-1161.

Gachet, C. (2008). "P2 receptors, platelet function and pharmacological implications." Thromb Haemost 99(3): 466-472.

Havlíková, S., L. Roller, J. Koči, A. R. Trimnell, M. Kazimírová, B. Klempa and P. A. Nuttall (2009). "Functional role of 64P, the candidate transmission-blocking vaccine antigen from the tick, Rhipicephalus appendiculatus." International Journal for Parasitology 39(13): 1485-1494.

Imamura, S., S. Konnai, S. Vaz Ida, S. Yamada, C. Nakajima, Y. Ito, T. Tajima, J. Yasuda, M. Simuunza, M. Onuma and K. Ohashi (2008). "Effects of anti-tick cocktail vaccine against Rhipicephalus appendiculatus." Jpn J Vet Res 56(2): 85-98.

Imamura, S., B. Namangala, T. Tajima, M. E. Tembo, J. Yasuda, K. Ohashi and M. Onuma (2006). "Two serine protease inhibitors (serpins) that induce a bovine protective immune response against Rhipicephalus appendiculatus ticks." Vaccine 24(13): 2230-2237.

Ishihama, Y., Y. Oda, T. Tabata, T. Sato, T. Nagasu, J. Rappsilber and M. Mann (2005). "Exponentially Modified Protein Abundance Index (emPAI) for Estimation of Absolute Protein Amount in Proteomics by the Number of Sequenced Peptides per Protein." Molecular \& Cellular Proteomics 4(9): 1265-1272. 
Jaworski, D. C., F. A. Simmen, W. Lamoreaux, L. B. Coons, M. T. Muller and G. R. Needham (1995). "A secreted calreticulin protein in ixodid tick (Amblyomma americanum) saliva." Journal of Insect Physiology 41(4): 369-375.

Li, L., C. J. Stoeckert and D. S. Roos (2003). "OrthoMCL: Identification of Ortholog Groups for Eukaryotic Genomes." Genome Research 13(9): 2178-2189.

Mulenga, A., C. Sugimoto and M. Onuma (2000). "Issues in tick vaccine development: identification and characterization of potential candidate vaccine antigens." Microbes and Infection 2(11): 1353-1361.

Nene, V., H. Kiara, A. Lacasta, R. Pelle, N. Svitek and L. Steinaa (2016). "The biology of Theileria parva and control of East Coast fever - Current status and future trends." Ticks and Tick-borne Diseases 7(4): 549-564.

Nene, V., D. Lee, S. Kang'a, R. Skilton, T. Shah, E. de Villiers, S. Mwaura, D. Taylor, J. Quackenbush and R. Bishop (2004). "Genes transcribed in the salivary glands of female Rhipicephalus appendiculatus ticks infected with Theileria parva." Insect Biochemistry and Molecular Biology 34(10): 1117-1128.

Norval, R. A. I., B. D. Perry and A. Young (1992). The epidemiology of theileriosis in Africa, Academic press, London.

Nyagwange, J., E. Tijhaar, N. Ternette, F. Mobegi, K. Tretina, J. C. Silva, R. Pelle and V. Nene (2018). "Characterization of the Theileria parva sporozoite proteome." International Journal for Parasitology 48(3): 265-273.

O'Flaherty, J. T. and J. F. Cordes (1994). "Human neutrophil degranulation responses to nucleotides." Lab Invest 70(6): 816-821.

Paesen, G. C., P. L. Adams, K. Harlos, P. A. Nuttall and D. I. Stuart (1999). "Tick histaminebinding proteins: isolation, cloning, and three-dimensional structure." Mol Cell 3(5): 661-671.

Parizi, L. F., N. W. Githaka, C. Logullo, S. Konnai, A. Masuda, K. Ohashi and I. da Silva Vaz (2012). "The quest for a universal vaccine against ticks: Cross-immunity insights." The Veterinary Journal 194(2): 158-165.

Patel, E., S. Mwaura, H. Kiara, S. Morzaria, A. Peters and P. Toye (2016). "Production and dose determination of the Infection and Treatment Method (ITM) Muguga cocktail vaccine used to control East Coast fever in cattle." Ticks and Tick-borne Diseases 7(2): 306-314.

Radley, D. E., C. G. D. Brown, M. J. Burridge, M. P. Cunningham, I. M. Kirimi, R. E. Purnell and A. S. Young (1975). "East coast fever: 1. Chemoprophylactic immunization of cattle against Theileria parva (Muguga) and five theilerial strains." Veterinary Parasitology 1(1): 3541. 
Ribeiro, J. M., J. M. Anderson, N. C. Manoukis, Z. Meng and I. M. Francischetti (2011). "A further insight into the sialome of the tropical bont tick, Amblyomma variegatum." BMC Genomics 12(1): 136.

Ribeiro, J. M. and T. N. Mather (1998). "Ixodes scapularis: salivary kininase activity is a metallo dipeptidyl carboxypeptidase." Exp Parasitol 89(2): 213-221.

Ribeiro, J. M. C. (1987). "Role of Saliva in Blood-Feeding by Arthropods." Annual Review of Entomology 32(1): 463-478.

Sabadin, G. A., L. F. Parizi, I. Kiio, M. A. Xavier, R. da Silva Matos, M. I. Camargo-Mathias, N. W. o. Githaka, V. Nene and I. da Silva Vaz (2017). "Effect of recombinant glutathione Stransferase as vaccine antigen against Rhipicephalus appendiculatus and Rhipicephalus sanguineus infestation." Vaccine.

Sauer, J. R., R. C. Essenberg and A. S. Bowman (2000). "Salivary glands in ixodid ticks: control and mechanism of secretion." Journal of Insect Physiology 46(7): 1069-1078.

Schirmer, E. C., J. R. Yates, 3rd and L. Gerace (2003). "MudPIT: A powerful proteomics tool for discovery." Discov Med 3(18): 38-39.

Shaw, M. K. and A. S. Young (2009). "Differential development and emission of Theileria parva sporozoites from the salivary gland of Rhipicephalus appendiculatus." Parasitology 111(2): 153-160.

Šimo, L., M. Kazimirova, J. Richardson and S. I. Bonnet (2017). "The Essential Role of Tick Salivary Glands and Saliva in Tick Feeding and Pathogen Transmission." Frontiers in Cellular and Infection Microbiology 7(281).

Theiler, A. (1912). "The immunisation of cattle against East Coast fever." Second Rep. Dir. Vet. Res. 1912: 216-314.

Xu, T., A. Lew-Tabor and M. Rodriguez-Valle (2016). "Effective inhibition of thrombin by Rhipicephalus microplus serpin-15 (RmS-15) obtained in the yeast Pichia pastoris." Ticks and Tick-borne Diseases 7(1): 180-187. 
80 l Chapter 3 
CHAPTER

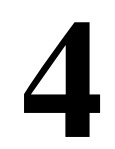

\section{Antibodies to in silico selected GPI-anchored Theileria parva proteins neutralize sporozoite infection in vitro}

James Nyagwange

Vishvanath Nene

Stephen Mwalimu

Sonal Henson

Lucilla Steinaa

Benjamin Nzau

Edwin Tijhaar

Roger Pelle

Published in Veterinary Immunology and Immunopathology, 2018; 199: 8-14 


\begin{abstract}
East Coast fever (ECF) caused by Theileria parva kills cattle in East, Central and Southern Africa leading to significant economic losses. Vaccination is used as a control strategy against ECF and is presently dependent on deliberate infection with live sporozoites and simultaneous treatment with a long-acting oxytetracycline. Although effective, this method has serious limitations; the immunity is parasite strain specific and immunized cattle can become life-long asymptomatic carriers of the parasite, posing risk for the spread of the disease. In efforts to develop a subunit vaccine, the role of antibodies in the neutralization of $T$. parva sporozoites infection of host cells has been investigated and a circumsporozoite protein, p67, is able to induce such neutralizing antibodies. However, the p67 protein only protects a proportion of immunized cattle against $T$. parva challenge and such protection might be improved by inclusion of additional parasite antigens that neutralize sporozoite infection. In an attempt to identify such antigens, we searched the re-annotated $T$. parva genome for genes predicted to contain GPI anchor signals, since they are likely to be located on the cell surface, and expressed fragments of six of the selected genes in E. coli. The recombinant proteins were used to raise antisera in mice. Antisera to two proteins, TpMuguga_01g00876 and TpMuguga_01g00939, neutralized sporozoite infectivity to a high degree, while antisera to two additional proteins, TpMuguga_01g00095 and TpMuguga_04g00437, exhibited moderate neutralizing capacity. We conclude that these four antigens are potential vaccine candidates, which should be evaluated further in cattle.
\end{abstract}

\title{
Key words
}

Theileria, sporozoites, antigens, neutralising antibodies, vaccine 


\section{Introduction}

East Coast fever (ECF) caused by Theileria parva is prevalent in East, Central and Southern Africa where it causes significant losses by reducing cattle productivity and kills a large number of them (Nene, Kiara et al. 2016). The disease is of major economic importance because of the high mortality it causes, and the expensive measures used to control the tick vector. In the 1900s, Dr. Arnold Theiler identified the three-host life cycle tick, Rhipicephalus appendiculatus, as the chief vector for transmission of $T$. parva, which occurs transstadially (Norval, Perry et al. 1992). The sporozoites, which are the mammalian infective stage of the parasite develop in the tick salivary glands and are introduced into the bovine host during tick feeding (Shaw 1996). The sporozoites enter the host lymphocytes rapidly by a zippering process of the host and sporozoite cell membranes (Fawcett, Doxsey et al. 1982b, Shaw 1996). Once inside the lymphocytes, the sporozoites differentiate into schizonts that undergo several multiplication cycles (Shaw 2003). A proportion of the schizonts undergo merogony resulting in the production of merozoites that invade erythrocytes and develop into piroplasms. These piroplasms are the tick infective stage and after uptake during blood feeding they will restart the life cycle of the parasite (Shaw 2003). Blocking sporozoite proteins involved in the lymphocyte invasion process, such as $\mathrm{p} 67$, presents a vaccine control strategy for ECF. The p67 protein, named for its size $\sim 67 \mathrm{kDa}$ protein, is the major surface antigen of sporozoites and the primary target of monoclonal antibodies that neutralize sporozoite infectivity in in vitro assays (Dobbelaere, Spooner et al. 1984, Musoke, Nantulya et al. 1984, Dobbelaere, Shapiro et al. 1985)

Apart from controlling the tick vectors by acaricides, infected cattle can be treated and burpavaquone has remained the commercial drug of choice three decades after its discovery (McHardy, Wekesa et al. 1985). However, the drug needs to be administered early in infection in order to be effective (Babo Martins, Di Giulio et al. 2010) and resistance has been reported in Theileria annulata (Mhadhbi, Naouach et al. 2010), which raises concerns for future ECF control as resistance could occur in T. parva. A live vaccine, based on an infection and treatment method (ITM) is also used to control ECF (Radley, Brown et al. 1975, Radley, Brown et al. 1975b). It involves infection with live sporozoites and simultaneous treatment with a long-acting oxytetracycline (Radley, Brown et al. 1975b). The drug controls but does not kill the parasite allowing generation of protective acquired immunity (reviewed in Nene, Kiara et al. 2016). However, the generated immunity is strain specific and animals vaccinated using the ITM can become life-long carries of the parasite, posing risk for spread of the disease (Uilenberg 1999). Production of the vaccine from infected ticks is also very laborious and the vaccine requires a liquid nitrogen cold chain for delivery making it expensive (Uilenberg 1999).

The protection conferred by the ITM vaccination is mediated by major histocompatibility complex (MHC) class I-restricted cytotoxic $\mathrm{T}$ lymphocytes (CTL) (Morrison and Goddeeris 1990, Morrison 2009). The sporozoites injected in the animal differentiate into schizonts and produces a transient parasitosis resulting in induction of specific MHC class I-restricted CTL that are directed against the schizont infected lymphoblasts (Morrison and Goddeeris 1990). These cellular responses were established in experiments that passively transferred immunity from immune animals to their naïve twins by transferring thoracic duct leukocytes from the former to the latter (Emery 1981). It was later determined that immunity was related to $\mathrm{CD} 8^{+}$cells as demonstrated by transfer of efferent lymph $\mathrm{CD} 8^{+}$ cells enriched by monoclonal antibody mediated complement lysis of $\mathrm{CD}^{+}$cells, $\gamma \delta \mathrm{T}$-cells and B-cells (McKeever, Taracha et al. 1994). However, there is indirect evidence for a role of antibodies in mediating immunity to ECF derived from observations that animals that survive repetitive challenge with infected ticks either in the field or experimentally develop sporozoite 
neutralizing antibodies (Musoke, Nantulya et al. 1982). Monoclonal antibodies against p67, a circumsporozoite protein, also neutralizes sporozoite infection in vitro (Dobbelaere, Spooner et al. 1984, Musoke, Nantulya et al. 1984) and experimental vaccines based on this protein has shown partial protection (Musoke, Morzaria et al. 1992, Hall, Boulter et al. 2000, Bishop, Nene et al. 2003). The p67 based vaccine might be improved by including additional sporozoite antigens.

In order to identify vaccine candidate antigens that might neutralize sporozoite infectivity, we performed a bioinformatics search of the re-annotated T. parva genome ( cited in Tretina, Pelle et al. 2016) for proteins predicted to contain a C-terminal Glycosylphosphatidylinositol (GPI) anchor signal and /or N-terminal signal peptide. GPIanchored proteins are usually expressed on the cell surface where they are involved in extracellular interaction (Ferguson 1999). Proteins with signal peptides are usually destined to the secretory pathway (von Heijne 1990). Therefore, proteins with these features are likely to be located on the cell surface and are likely vaccine candidates to induce sporozoite neutralizing antibodies. Structurally, the proteins are linked via the C-terminal to ethanolamine with a phosphodiester bond linking the core glycan (tri-mannoside glucosamine), which in turn is linked to inositol phospholipid (Ikezawa 2002). GPI-anchored proteins are ubiquitous among eukaryotic species and play different roles including infection (Tachado, Gerold et al. 1996, Delorenzi, Sexton et al. 2002) and can elicit strong immune responses, making them targets of vaccine development (Gilson, Nebl et al. 2006). We report on the expression of six of the in silico selected GPI anchored proteins and neutralization of sporozoite infection by antisera raised against four of the recombinant proteins.

\section{Materials and methods}

\section{In silico analysis and selection of genes encoding GPI-anchored protein}

We performed a bioinformatics search of the re-annotated $T$. parva genome (cited in Tretina, Pelle et al. 2016) for proteins predicted to contain a C-terminal GPI anchor signal and/or an N-terminal signal peptide using PredGPI (Pierleoni, Martelli et al. 2008) and SignalP 4.1 (Petersen, Brunak et al. 2011), respectively. Following PredGPI analysis, GPI-proteins were sorted based on their Hidden Markov Model (HMM) scores in decreasing order of prediction accuracy, from highly probable, probable and weakly probable. The selected proteins were further analyzed for the presence of predicted $\mathrm{N}$-terminal signal peptide.

To determine if the selected genes are conserved across various isolates of T. parva, DNA sequence reads for the genomes of $16 \mathrm{~T}$. parva isolates for which data is available in the European Nucleotide Archive (ENA) were mapped to the re-annotated T. parva Muguga reference genome (cited in Tretina, Pelle et al. 2016) using the smalt short read aligner (www.sanger.ac.uk/resources/software/smalt) set at default settings. Duplicates were marked using Picard Tools (http://broadinstitute.github.io/picard) set at default parameters. FreeBayes (Garrison and Marth 2012) was used for calling single nucleotide polymorphisms (parameters: -K -i -X -u -q 20 --min-coverage 6). SNPs were annotated using snpEff (Cingolani, Platts et al. 2012).

\section{Sporozoite RNA preparation and cloning of gene fragments}

The procedure for sporozoites production has been described before (Patel, Mwaura et al. 2016) and we have recently reported on DE-52 column purification of $T$. parva sporozoites (Nyagwange, Tijhaar et al. 2018). RNA was extracted from the sporozoites using high pure RNA isolation kit (cat no. 11828665001; Roche) and primers used in RT-PCR reaction (one step RT of 3 mins at $95{ }^{\circ} \mathrm{C}, 30$ cycles of 30 s at $95{ }^{\circ} \mathrm{C}, 60$ s at $60{ }^{\circ} \mathrm{C}, 60 \mathrm{~s}$ at $72{ }^{\circ} \mathrm{C}$ and final elongation of 5 mins at $72{ }^{\circ} \mathrm{C}$ ). We designed primers (Supplementary Table S1b) to amplify 
not the whole predicted protein, but fragments from the highly-conserved regions of the selected genes. The fragments would also reduce expression and solubility problems associated with full length recombinant proteins. The resulting PCR products were run on $2 \%$ agarose gel and purified with Qiaquick gel extraction kit (cat no. 28704; Qiagen) according to the manufacturers' protocol. The gel-extracted products were cloned in pJET1.2 vector (cat no. K1231; Thermo Fisher Scientific) using the CloneJET PCR cloning kit's protocol.

\section{Expression and purification of recombinant proteins}

The gene fragments were digested with BamHI (site designed in the forward primer) and NotI from pJET1.2 vector and ligated in pET28a expression vector, which was used to transform BL21 (DE3) star and/or JM109 (DE3) E. coli strains. An overnight culture was generated by inoculating $50 \mathrm{ml}$ of $2 \mathrm{x}$ YT medium (tryptone $16 \mathrm{~g} /$ liter; yeast extract, $10 \mathrm{~g} / \mathrm{liter}$; $\mathrm{NaCl}, 5.0 \mathrm{~g} / \mathrm{liter}$ ) containing $50 \mu \mathrm{g} / \mathrm{ml}$ kanamycin monosulphate (kanamycin A), with a loop of $E$. coli cells containing pET-28a with the cloned $T$. parva gene fragments and incubated at $37^{\circ} \mathrm{C}$ with shaking. The next morning, $5 \mathrm{ml}$ of this overnight culture was added to $500 \mathrm{ml}$ of $2 \mathrm{x}$ YT containing $50 \mu \mathrm{g} / \mathrm{ml}$ kanamycin and incubated at $37{ }^{\circ} \mathrm{C}$ with shaking until the cells reached A600 between 0.5 and 0.7 then isopropyl-1-thio-b-D-galactopyranoside (IPTG) added to a final concentration of $2 \mathrm{mM}$. Samples of $2 \mathrm{ml}$ were taken just before induction (non-induced control), 4hrs post induction and overnight post induction and were used to screen expression levels. Cells were harvested by centrifugation and then sonicated in buffer B (100 mM NaH $2 \mathrm{PO}_{4}, 10 \mathrm{mM}$ Tris. $\mathrm{Cl}, 8 \mathrm{M}$ urea, $\mathrm{pH}$ 8.0). The resulting supernatant was bound to Ni-sepharose (GE Healthcare Life Sciences, cat no. 17-5318-01) overnight and column purified. The column was washed with buffer $\mathrm{C}$ (buffer $\mathrm{B}$ at $\mathrm{pH}$ 6.3) and protein eluted in elution buffer $\left(0.1 \mathrm{M} \mathrm{NaH} \mathrm{PO}_{4}, 0.3 \mathrm{M} \mathrm{NaCl}, 10 \%\right.$ glycerol, $\left.\mathrm{pH} 3\right)$ and dialyzed extensively in PBS. Two proteins (TpMuguga_01g00972 and TpMuguga_01g00095) could not be eluted successfully from the resin. These resin bound proteins were denatured, run on SDS-PAGE gels and stained with Nile Red $(8 \mu \mathrm{g} / \mathrm{ml}$ final concentration in deionized water) as described in (Daban, Bartolomé et al. 1996). The proteins were visualized by UV transilluminator and cut from the gel. The gel pieces with the proteins were ground using mortar and pestle, dissolved in PBS, vortexed briefly then centrifuged and the supernatants containing the were proteins retained.

\section{Generation of murine antibodies to purified recombinant protein}

All animal procedures described in this article were approved by ILRI's Institute Animal Care and Use Committee (IACUC File Number 2015.16). The mice used for production of polyclonal antibodies were Swiss mice, 6-8 weeks old and each recombinant antigen was used for immunization of two mice. Blood was collected from the tails of the mice (pre-immunization control) and each mouse inoculated intraperitoneally with $75 \mu \mathrm{g}$ recombinant protein (in PBS) and Freund's adjuvant, Incomplete (cat no. F5506) mixture. Antigen and adjuvant were mixed on equal volume basis. Boosting was performed bi-weekly until day 42. Blood was collected by cardiac puncture after cervical dislocation at the end of the experiment.

\section{Assessment of immune responses via ELISA}

ELISA was performed by coating the Nunc Maxisorp 96 well plates (cat no.439454) with $100 \mu \mathrm{l} /$ well recombinant protein $(500 \mathrm{ng} / \mathrm{ml})$ in PBS and incubated overnight at $4{ }^{\circ} \mathrm{C}$. The coating solution was flicked out and the inverted plates slapped onto paper towels and washed with $150 \mu 1$ of PBS-T20 ( $0.1 \%$ tween 20 in PBS) four times. Blocking was then done by adding $150 \mu \mathrm{l}$ of blocking buffer $\left(0.2 \%\right.$ casein in PBS-T20) per well and incubated for $1 \mathrm{hr}$. at $37^{\circ} \mathrm{C}$. The blocking buffer was flicked out and washed as before, four times with $150 \mu 1$ of PBS-T20. Corresponding sera diluted from $1 / 33$ to $1 / 72900$ were added to the wells at $100 \mu 1$ per well 
and incubated for $1.5 \mathrm{hr}$ at $37^{\circ} \mathrm{C}$. The sera were flicked out and washed four times as before with $150 \mu$ l of PBS-T20. Secondary antibody, anti-mouse IgG peroxidase produced in rabbit (Sigma A9044), was added at 1/1000 dilution, $100 \mu \mathrm{l} /$ well. The reactions were revealed using the substrate 2, 2'-azino-di-[3-ethyl-benzothiazoline-6 sulfonic acid] diammonium salt (ABTS). Optical density was read at $405 \mathrm{~nm}$ on a microplate reader (Labsystems Multiskan MCC 340, Helsinki, Finland).

\section{Sporozoite neutralization assays}

The neutralization of sporozoite infectivity was performed using a slight modification of a previously described method (Musoke, Morzaria et al. 1992). The procedure for sporozoites production and infection rates assessment has been described before (Patel, Mwaura et al. 2016). In each well of a 96-well microtiter plate, $5 \times 10^{5}$ bovine peripheral blood mononuclear cells isolated from uninfected bovine blood by Ficoll-Paque density gradient centrifugation were added and incubated for $2 \mathrm{hr}$ at $37{ }^{\circ} \mathrm{C}, 5 \% \mathrm{C} 02$. A sporozoite suspension obtained from 1050 infected acini (approximately $3.7 \times 10^{7}$ sporozoites, mean infection rate of 28,570 sporozoites/acinus) in $100 \mu$ l RPMI 1640 medium with $7.5 \%$ fetal bovine serum and 5\% DMSO was diluted 100 times and $100 \mu 1$ with approximately $3.7 \times 10^{5}$ sporozoites/well added to various dilutions $(1 / 10,1 / 100$ and 1/1000) of pre- and day 56 post-immunization sera (poled for each antigen, heat inactivated at $56{ }^{\circ} \mathrm{C}$ for $30 \mathrm{~min}$ ) and positive control monoclonal antibody (ARIV21.4) with neat concentration of $670 \mu \mathrm{g} / \mathrm{ml}$, previously generated against the major sporozoite protein p67 and incubated for $10 \mathrm{~min}$ at $37{ }^{\circ} \mathrm{C}, 5 \% \mathrm{C}_{2}$. Giemsa-stained cytospin smears prepared from each well were examined for the presence of schizonts at day 14. One hundred cells from each well were counted and the percentage of cells containing schizonts was determined. Percent reduction in infection intensity were calculated relative to the control (PBMCs incubated with sporozoites only). The assays were performed in triplicate and scored by a blinded operator. All analyses were performed using GraphPad PRISM® version 7.01 with alpha $=0.05$. For each antiserum, the Mann-Whitney $U$ test was used to assess the differences in neutralizing ability of the recombinant antisera in relation to positive control monoclonal antibody, antip67c. 


\section{Results}

\section{Selection and in silico analysis of proteins}

Sequence analysis of the predicted T. parva proteome of 4085 genes with PredGPI (Pierleoni, Martelli et al. 2008) revealed 21 highly probable GPI anchored proteins. The top 10 highly probable proteins were selected for this study. Analysis of these 10 proteins with SignalP 4.1 (Petersen, Brunak et al. 2011) revealed signal peptides for all the proteins except one, TpMuguga_04g02375 (Table 1).

Table 1. The 10-selected putative T. parva surface proteins

\begin{tabular}{|c|c|c|c|c|c|}
\hline ORF locus tag (antisera) & Annotation & $\begin{array}{l}\text { cDNA } \\
\text { amplicon } \\
\text { size (bp) }\end{array}$ & $\begin{array}{l}\text { Expressed } \\
\text { protein } \\
\text { size } \\
(\mathrm{kDa}) * *\end{array}$ & $\begin{array}{l}\text { Full } \\
\text { protein } \\
\text { size } \\
(\mathrm{kDa})\end{array}$ & $\begin{array}{l}\text { Identifie } \\
\text { d by LC- } \\
\text { MS/MS }\end{array}$ \\
\hline TpMuguga_04g00437 (anti437) & $\begin{array}{l}104 \mathrm{kDa} \\
\text { antigen (p104) }\end{array}$ & 312 & 12 & 104 & Yes \\
\hline TpMuguga_01g00939 (anti939) & $\begin{array}{l}\text { hypothetical } \\
\text { protein (gp34) }\end{array}$ & 375 & 15 & 34 & Yes \\
\hline TpMuguga_01g00876 (anti876) & $\begin{array}{l}\text { hypothetical } \\
\text { protein }\end{array}$ & 274 & 10 & 13 & Yes \\
\hline TpMuguga_01g00095 (anti095) & $\begin{array}{l}\text { hypothetical } \\
\text { protein }\end{array}$ & 331 & 12 & 28.6 & No \\
\hline TpMuguga_01g00575 (anti575) & $\begin{array}{l}\text { hypothetical } \\
\text { protein }\end{array}$ & 366 & 14 & 197.4 & No \\
\hline TpMuguga_01g00972 (anti972) & $\begin{array}{l}\text { hypothetical } \\
\text { protein }\end{array}$ & 320 & 12 & 37.8 & Yes \\
\hline TpMuguga_03g00844 & $\begin{array}{l}\text { hypothetical } \\
\text { protein }\end{array}$ & 330 & $\mathrm{NE}$ & 13.3 & Yes \\
\hline TpMuguga_02g00792 & $\begin{array}{l}\text { hypothetical } \\
\text { protein }\end{array}$ & 331 & $\mathrm{NE}$ & 15 & Yes \\
\hline TpMuguga_03g00136 & $\begin{array}{l}\text { hypothetical } \\
\text { protein }\end{array}$ & 310 & $\mathrm{NE}$ & 20.6 & No \\
\hline TpMuguga_04g02375* & $\begin{array}{l}\text { hypothetical } \\
\text { protein }\end{array}$ & 296 & NE & 40 & No \\
\hline
\end{tabular}

Selected T. parva proteins predicted to contain a C-terminal GPI anchor signal and/or an Nterminal signal peptide. Data presented include ORF locus tag with the corresponding antisera in brackets, annotation, cloned gene fragment size and corresponding expressed protein size, the full protein size and whether the protein was identified by mass spectrometry in the sporozoite proteome (Nyagwange, Tijhaar et al. 2018). Hypothetical protein is of unknown function(s). GPI anchor predicted using the PredGPI (http://gpcr2.biocomp.unibo.it/predgpi/) and signal peptides predicted using the SignalP 4.1 server (http://www.cbs.dtu.dk/services/SignalP/)

(*) Reannotated from TP04_0030 and protein does not contain a predicted signal peptide; $(* *)$ Size excludes His-tag; (NE) Protein not expressed.

\section{Cloning, expression and purification of recombinant proteins}

Amplification of fragments of the selected genes by RT-PCR yielded amplicons of expected sizes ranging from 274 to 375 base pairs (Supplementary Fig. S1A). Fragments and not the whole proteins, were selected from the more conserved regions of the genes (Table 2). The conserved fragments would ensure broader protection but also avoid expression and solubility problems associated with the recombinant full-length proteins. All the fragments were inserted into pJET1.2 blunt vector and subsequently transferred to the expression plasmid 
pET28a (Supplementary Fig. S1B). All the expressed fragments were in pET28a except TpMuguga_01g00972, which was expressed in pGS-21a as GST fusion protein because expression with the pET28a vector was not successful (Supplementary Fig. S1C). All the recombinant proteins were expressed with a hexa-histidine tag that enables affinity purification by immobilized metal affinity chromatography (IMAC). Sequence analysis of the cloned gene fragments demonstrated $100 \%$ sequence identity with the published gene sequences (results not shown).

Analysis by SDS-PAGE demonstrated that $E$. coli cells transformed with pET28ainserts and pGS-21a - TpMuguga_01g00972 insert, expressed, considerable amounts of the six recombinant proteins after IPTG induction (Fig. 1a). Four constructs failed to express detectable recombinant protein (data not shown). All the expressed proteins were in the insoluble fractions (inclusion bodies) after cell lysis and were dissolved in $8 \mathrm{M}$ urea buffer and purified on $\mathrm{Ni}^{2+}$ chelating sepharose beads, employing the 6xHis-tags. Four of the expressed proteins bound to the column and were successfully eluted by addition of elution buffer. Once eluted, the recombinant proteins remained soluble after removal of urea arising from the wash buffers by step dialysis against PBS at $4{ }^{\circ} \mathrm{C}$ (Fig. 1b). Two proteins, $\mathrm{C}$ and $\mathrm{D}$ could not be eluted successfully and were extracted from SDS-PAGE gels following Nile red staining (see Materials and methods) and remained soluble in PBS.

(a)
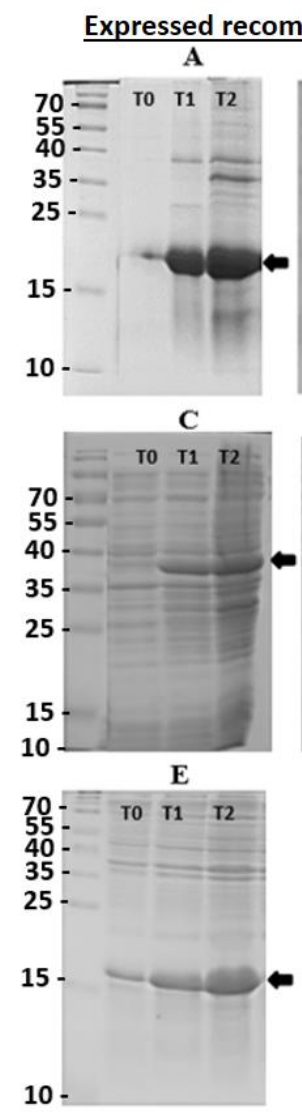

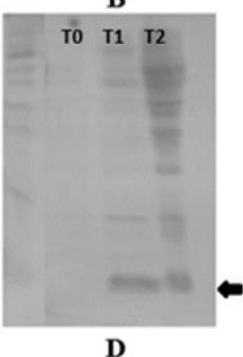

D

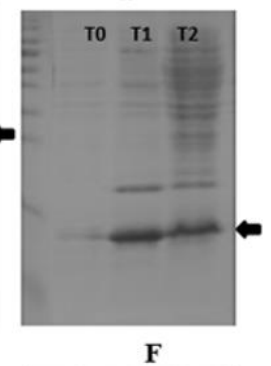

$\mathbf{F}$

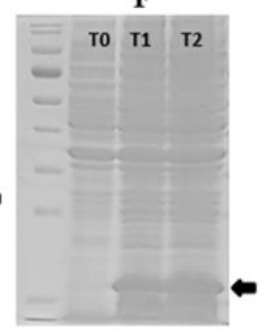

Purified recombinant proteins

(b)

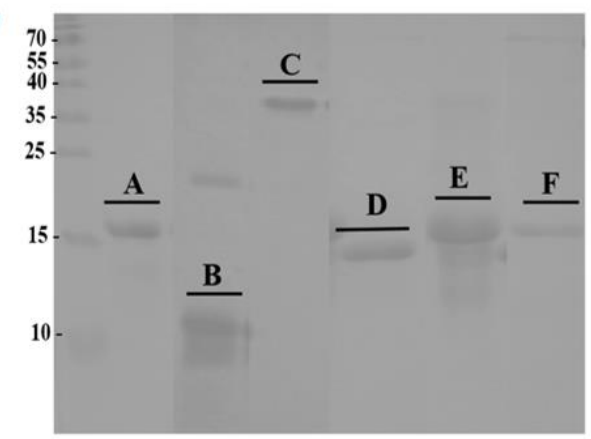

Recombinant proteins detected by antisera

(c)

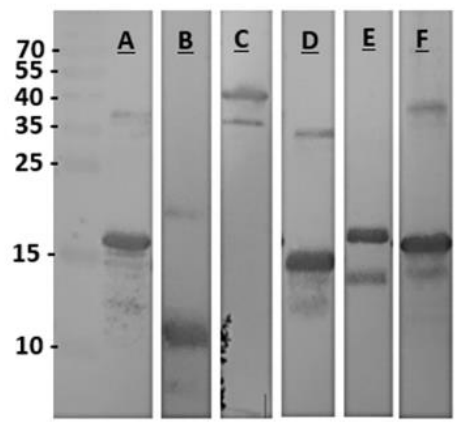

Figure 1. SDS-PAGE and western blot showing expressed (a), purified (b) and antisera detected (c) recombinant protein fragments. (a) Bacteria lysate before IPTG induction (T0), 4hrs (T1) and overnight (T2) post IPTG induction. (b) IMAC purified or gel extracted recombinant proteins are shown. Recombinant proteins include; TpMuguga_01g00939 (A), TpMuguga_01g00876 (B), TpMuguga_01g00972 $\quad$ (C), TpMuguga_01g00095 $\quad$ (D), TpMuguga_01g00575 (E) and TpMuguga_04g00437 (F). 


\section{Analysis of antibodies to recombinant proteins}

Each purified recombinant protein was used to immunize two mice. Sera from these mice showed indirect ELISA titres higher than 1000 (Fig. 2) and binding in immunoblots (Fig. 1c) to the corresponding recombinant proteins used for the immunizations. More importantly, when used in a 1:100 dilution all the antisera, apart from antisera 972 (Mann-Whitney U test $\mathrm{p}$ $=0.0022$; Fig. 3A), were able to neutralize sporozoite infectivity to a similar extent as the positive control, a monoclonal antibody (ARIV21.4) previously generated against the major sporozoite protein $\mathrm{p} 67$. At a higher antiserum dilution of 1:1000 two antisera (anti095, $\mathrm{p}=$ 0.0152 and anti437, $\mathrm{p}=0.0260$ ) still showed some neutralizing activity, although significantly lower than the antip67C. However, antisera 876 and 939 displayed similar or even higher sporozoite neutralizing activity than the anti-p67C positive control (Fig. 3B).
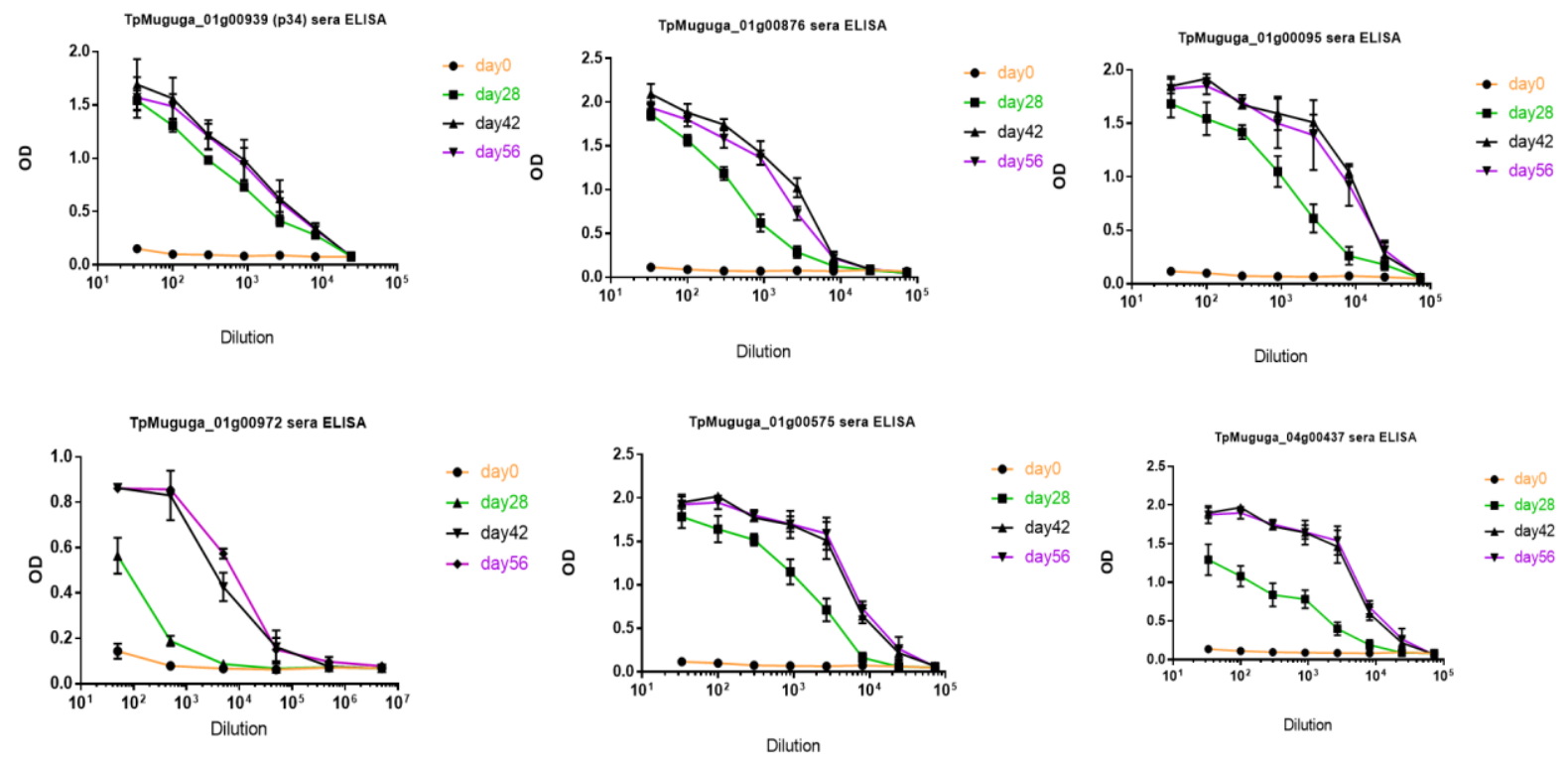

Figure 2. ELISA for antibody titres to the recombinant proteins. Immunization of mice was done at day 0 and three boosts performed biweekly thereafter. OD at $405 \mathrm{~nm}$ is shown relative to three-fold dilutions of the sera. 
A

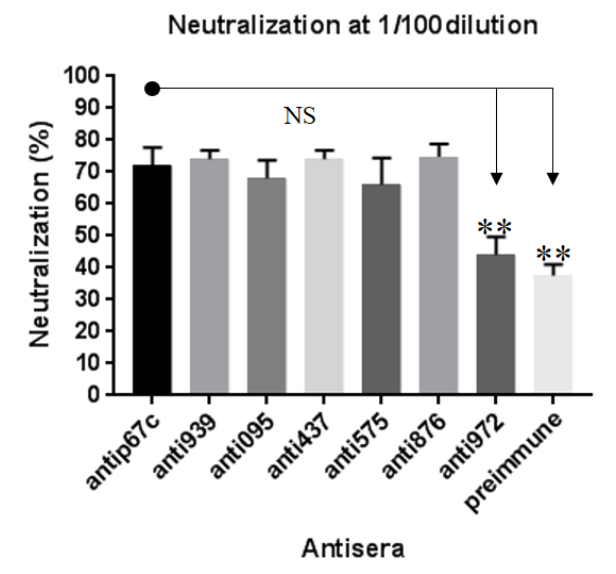

B

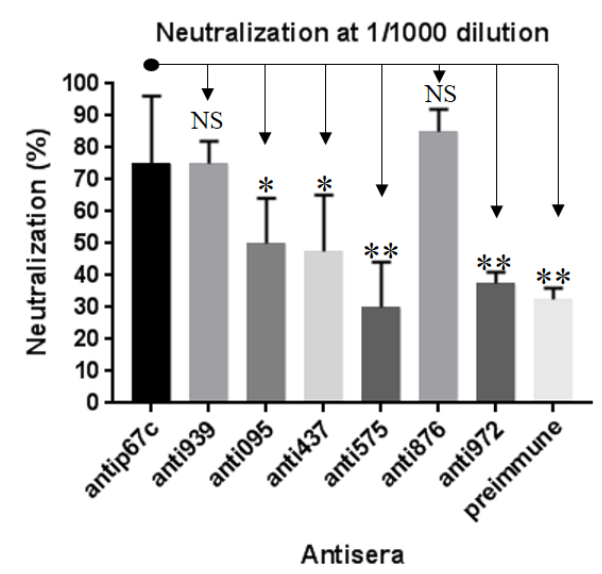

Figure 3. Summary of the in vitro neutralization of sporozoite infectivity. Monoclonal antibodies against p67c (positive control), normal mouse serum (pre-immune) and antisera against the six recombinant protein fragments were used for neutralization of sporozoites in vitro. Results are shown for sera - gene related to; TpMuguga_01g00939 (anti939), TpMuguga_01g00095 (anti095), TpMuguga_04g00437 (anti437), TpMuguga_01g00575 (anti575), TpMuguga_01g00876 (anti876) and TpMuguga_01g00972 (anti972). Antisera were diluted 1:100 (A) and 1:1000 (B).

\section{Conservation of selected gene fragments}

Ideal vaccine candidate antigens should be conserved amongst the various isolates of T. parva to ensure broad protection following vaccination. We used the re-annotated T. parva genome sequence information (cited in Tretina, Pelle et al. 2016) to developed a SNP map of the six expressed genes both the whole gene (WG) sequences and the expressed fragments (EF). We found that most of the genes are conserved amongst the cattle derived isolates than the two-wild buffalo derived isolates, Buffalo LAWR and Buffalo Z5E5, and that the EF are more conserved than the WG sequences (Table 2). For all the WG sequences except TpMuguga_01g00575 and TpMuguga_04g00437, non-synonymous SNPs made up <50\% of the SNPs observed (data not shown). TpMuguga_01g00095 WG sequence was the most conserved antigen being totally conserved amongst the cattle-derived isolates with just a single synonymous SNP representing a rate of $0.1 \%$ of SNPs per WG sequence length and fairly conserved with the two-wild buffalo derived isolates Buffalo LAWR (2\%) and Buffalo Z5E5 (2.1\%). TpMuguga_01g00575 WG sequence was the least conserved antigen with many SNPs relative to cattle derived isolates, Kiambu5 (23.5\%) and KiambuZ464/C12 (7.6\%) and also relative to the two buffalo derived isolates Buffalo LAWR and Buffalo Z5E5, 6.1\% and 7.7\% SNPs per WG sequence, respectively (Table 2). Although majority of the EF were conserved, polymorphism was observed amongst many of the WG sequences selected. 
Table 2. Nucleotide sequence polymorphism of open reading frames and recombinantly expressed fragments, in cattle and buffalo derived $T$. parva isolates. SNPs expressed as percentage of DNA sequence length for the whole gene (WG) sequence and recombinantly expressed fragment (EF).

\begin{tabular}{|c|c|c|c|c|c|c|c|c|c|c|c|c|}
\hline \multirow[t]{2}{*}{ Isolate } & \multicolumn{2}{|c|}{ TP01_0095 } & \multicolumn{2}{|c|}{ TP01_0575 } & \multicolumn{2}{|c|}{ TP01_0876 } & \multicolumn{2}{|c|}{ TP01_0939 } & \multicolumn{2}{|c|}{ TP01_0972 } & \multicolumn{2}{|c|}{ TP04_0437 } \\
\hline & WG & $\mathrm{EF}$ & WG & $\mathrm{EF}$ & WG & $\mathrm{EF}$ & WG & $\mathrm{EF}$ & WG & $\mathrm{EF}$ & WG & $\mathrm{EF}$ \\
\hline ChitongoZ2 & 0 & 0 & 5.7 & 0.3 & 0 & 0 & 2.3 & 0.3 & 0.5 & 0 & 1.5 & 0 \\
\hline Entebbe & 0 & 0 & 4.1 & 0.3 & 0 & 0 & 2.1 & 0.3 & 0.4 & 0 & 0.7 & 0 \\
\hline KateteB2 & 0 & 0 & 5.5 & 0.3 & 0.8 & 0 & 2.3 & 0.3 & 0.5 & 0 & 1.1 & 0 \\
\hline Katumba & 0 & 0 & 6.0 & 1.9 & 2.6 & 0.4 & 2.6 & 1.6 & 0.5 & 0 & 0.8 & 0 \\
\hline Kiambu5 & 0 & 0 & 23.5 & 2.5 & 7.1 & 1.1 & 3.0 & 1.6 & 0.5 & 0 & 1.8 & 0 \\
\hline KiambuZ464/C12 & 0 & 0 & 7.6 & 2.5 & 2.6 & 1.1 & 2.7 & 1.6 & 0.5 & 0 & 1.5 & 0 \\
\hline MandaliZ22 & 0 & 0 & 4.4 & 0.3 & 0 & 0 & 2.1 & 0.3 & 0.4 & 0 & 0.6 & 0 \\
\hline Marikebuni & 0 & 0 & 3.8 & 0.3 & 5.8 & 1.1 & 0.1 & 0.3 & 0.1 & 0 & 1.7 & 0 \\
\hline MugMar & 0 & 0 & 3.7 & 0.3 & 6.1 & 1.1 & 0.1 & 0.3 & 0.1 & 0 & 1.7 & 0 \\
\hline MugUg & 0 & 0 & 5.9 & 0.3 & 0.3 & 0 & 2.4 & 0.3 & 0.6 & 0 & 1.7 & 0 \\
\hline Muguga2* & 0 & 0 & 0 & 0 & 0 & 0 & 0 & 0 & 0 & 0 & 0 & 0 \\
\hline Nyakizu & 0.1 & 0 & 0.7 & 0.3 & 5.0 & 1.1 & 2.9 & 1.6 & 0.5 & 0 & 1.2 & 0 \\
\hline Serengeti & 0 & 0 & 0 & 0 & 0 & 0 & 0 & 0 & 0 & 0 & 0 & 0 \\
\hline Uganda & 0 & 0 & 5.9 & 0.3 & 0.3 & 0 & 2.4 & 0.3 & 0.6 & 0 & 1.7 & 0 \\
\hline Buffalo LAWR** & 2.0 & 1.2 & 6.1 & 0.3 & 3.2 & 0.4 & 2.0 & 1.1 & 1.4 & 1.9 & 2.8 & 0.6 \\
\hline Buffalo Z5E5** & 2.1 & 0.9 & 7.7 & 0.8 & 1.9 & 0.7 & 2.0 & 0.8 & 1.0 & 1.6 & 3.0 & 0.6 \\
\hline
\end{tabular}

The isolates shown include cattle derived and two buffalo derived isolates $(* *)$ and the reference genome isolate $(*)$. 


\section{Discussion}

GPI anchors are common attachment signals for surface proteins of parasites such as Plasmodium, Trypanosomes, Toxoplasma, etc. and many are promising vaccine candidate antigens (Ferguson 1999, Ferguson MAJ 2009). One such example is the circumsporozoite (CS) protein of Plasmodium which is the antigenic target of the malaria vaccine RTS, S (Lancet, 2015). Researchers have employed the strategy of targeting GPI anchored proteins for evaluation as candidate vaccine antigens. In this study, we also employed this strategy to select $T$. parva proteins predicted to contain GPI anchor signals for evaluation as vaccine candidates.

We selected a list of 10 genes with high probability of containing a GPI-anchored tail (Table 1). Using specific primers for the more conserved regions of the selected genes, we were able to synthesize cDNA of expected sizes in a one-step RTPCR reaction (Supplementary Fig. 1A). We have expressed six out of the 10 selected genes as recombinant proteins in E. coli. Five of the proteins were expressed with a His tag, which increases the molecular weight by approximately $1 \mathrm{kDa}$ (Fig. 1). TpMuguga_01g00972 was expressed as a GST fusion protein, adding $26 \mathrm{kDa}$ to the size resulting in a total size of $39 \mathrm{kDa}$ (Fig. 1C). Although sequencing data showed that the cloned sequences were in-frame, we were not successful in expressing four of the 10 selected gene fragments even after transfer to various expression vectors (pET28a, pQE30 and pGS-21a) and E. coli strains, BL21(DE3) star and JM109(DE3).

The six expressed recombinant proteins were used to raise antisera in mice. The antisera were found to bind to the respective protein product of the cloned gene fragments (Fig. 1c) and most importantly, antisera against two of the recombinant proteins, TpMuguga_01g00876 and TpMuguga_01g00939, highly $(>60 \%)$ neutralize sporozoite infectivity at 1000-fold dilution. Antisera against two additional proteins, TpMuguga_01g00095 and TpMuguga_04g00437, moderately (>30\%) neutralize sporozoite infection of bovine PBMCs in vitro (Fig. 3B).

In this study, we tested gene fragments. It is tempting to speculate that antisera to full length proteins of the four antigens would produce higher neutralizing activities because of the longer sequence with putative additional epitopes. Therefore, it is desirable to test the full length recombinant proteins for immunogenicity. However, expression of long proteins is usually accompanied by solubility and expression problems of the recombinant proteins. To overcome expression problems, other expression systems could be employed or several shorter fragments comprising the full protein can be combined and evaluated.

Among the protein fragments that produce high sporozoite neutralizing antibodies is TpMuguga_01g00939, a protein previously referred to as gp34, that undergoes GPI modification when expressed in mammalian cells (Xue, von Schubert et al. 2010). Although originally reported as a schizont stage specific antigen (Xue, von Schubert et al. 2010), we have recently identified gp34 protein in the sporozoite proteome (Nyagwange, Tijhaar et al. 2018). We therefore conclude that the protein is expressed in both parasite life-cycle stages. In the schizont stage, gp34 seems to play a role in parasite-host interaction during host cell division (Xue, von Schubert et al. 2010). Immunization with TpMuguga_04g00437, also known as p104 a sporozoite microneme/rhoptry protein (Ebel, Gerhards et al. 1999), resulted in mouse antisera that moderately neutralized sporozoite infection of bovine PBMCs in vitro. The p104 protein was originally identified by sporozoite neutralizing bovine antisera C16 (Iams, Young et al. 1990), but was never evaluated as a vaccine candidate antigen (Nene, Kiara et al. 2016). The p104 protein is also expressed at the surface of the schizont and recent evidence suggests a role for this protein in interacting with the host-cell mitotic machinery (Huber, Theiler et al. 2017). With the results presented here, it appears that gp34 and p104 also play a role in the lymphocyte 
invasion process, perhaps through additional interactions with host cell microtubules during invasion.

Neutralization of parasite infection of host cells is one of the most important features of an anti-sporozoite vaccine candidate antigen, and in this study, we have identified four vaccine candidates that are able to induce sporozoite neutralizing antibodies. Two of these proteins (p104 and gp34) were identified before and two are completely new, including TpMuguga_01g00876 which produced antibodies inducing the strongest sporozoite neutralizing activity. However, following previous observations in which rats immunized with recombinant polymorphic immuno-dominant molecule (PIM) make neutralizing antibodies while cattle immunized with the same do not (Toye, Metzelaar et al. 1995, Toye, Nyanjui et al. 1996), it is important to raise and test bovine antibodies against these antigens to formally confirm their role as candidate vaccine antigens.

\section{Acknowledgement}

We are grateful to Thomas Njoroge, Elias Awino and Robert Muriuki for analysis of the slides. We thank the CGIAR Research Program on Livestock and Fish, the Norman Borlaug Commemorative Research Initiative, an initiative between the Feed the Future program of USAID and USDA-ARS (58-5348-2-117F) and the Department for International Development of the United Kingdom and the Bill and Melinda Gates Foundation (OPP1078791) for financial support. 


\section{References}

Babo Martins, S., G. Di Giulio, G. Lynen, A. Peters and J. Rushton (2010). "Assessing the impact of East Coast Fever immunisation by the infection and treatment method in Tanzanian pastoralist systems." Preventive Veterinary Medicine 97(3-4): 175-182.

Bishop, R., V. Nene, J. Staeyert, J. Rowlands, J. Nyanjui, J. Osaso, S. Morzaria and A. Musoke (2003). "Immunity to East Coast fever in cattle induced by a polypeptide fragment of the major surface coat protein of Theileria parva sporozoites." Vaccine 21(11-12): 1205-1212.

Cingolani, P., A. Platts, L. L. Wang, M. Coon, T. Nguyen, L. Wang, S. J. Land, X. Lu and D. M. Ruden (2012). "A program for annotating and predicting the effects of single nucleotide polymorphisms, SnpEff: SNPs in the genome of Drosophila melanogaster strain w1118; iso-2; iso-3." Fly 6(2): 80-92.

Daban, J.-R., S. Bartolomé and A. Bermúdez (1996). Rapid Staining of Proteins in Polyacrylamide Gels with Nile Red. The Protein Protocols Handbook. J. M. Walker. Totowa, NJ, Humana Press: 179-185.

Delorenzi, M., A. Sexton, H. Shams-Eldin, R. T. Schwarz, T. Speed and L. Schofield (2002). "Genes for Glycosylphosphatidylinositol Toxin Biosynthesis in Plasmodium falciparum." Infection and Immunity 70(8): 4510-4522.

Dobbelaere, D., S. Z. Shapiro and P. Webster (1985). "Identification of a surface antigen on Theileria parva sporozoites by monoclonal antibody." Proceedings of the National Academy of Sciences 82(6): 1771-1775.

Dobbelaere, D. A. E., P. R. Spooner, W. C. Barry and A. D. Irvin (1984). "Monoclonal antibody neutralizes the sporozoite stage of different Theileria parva stocks." Parasite Immunology 6(4): 361-370.

Ebel, T., J. Gerhards, B. R. Binder and J. Lipp (1999). "Theileria parva 104 kDa micronemerhoptry protein is membrane-anchored by a non-cleaved amino-terminal signal sequence for entry into the endoplasmic reticulum." Molecular and Biochemical Parasitology 100(1): 19-26.

Emery, D. L. (1981). "Adoptive transfer of immunity to infection with Theileria parva (East Coast fever) between cattle twins." Research in Veterinary Science 30(3): 364-367.

Fawcett, D. W., S. Doxsey, D. A. Stagg and A. S. Young (1982b). "The entry of sporozoites of Theileria parva into bovine lymphocytes in vitro. Electron microscopic observations." European journal of cell biology 27(1): 10-21.

Ferguson, M. A. (1999). "The structure, biosynthesis and functions of glycosylphosphatidylinositol anchors, and the contributions of trypanosome research." Journal of Cell Science 112(17): 2799-2809.

Ferguson MAJ, K. T., Hart GW (2009). Essentials of Glycobiology. Cold Spring Harbor (NY), Cold Spring Harbor Laboratory Press.

Garrison, E. and G. Marth (2012). "Haplotype-based variant detection from short-read sequencing." arXiv preprint arXiv:1207.3907. 
Gilson, P. R., T. Nebl, D. Vukcevic, R. L. Moritz, T. Sargeant, T. P. Speed, L. Schofield and B. S. Crabb (2006). "Identification and Stoichiometry of Glycosylphosphatidylinositolanchored Membrane Proteins of the Human Malaria Parasite Plasmodium falciparum." Molecular \& Cellular Proteomics 5(7): 1286-1299.

Hall, R., N. R. Boulter, C. G. Brown, G. Wilkie, E. Kirvar, V. Nene, A. J. Musoke, E. J. Glass and S. P. Morzaria (2000). "Reciprocal cross-protection induced by sporozoite antigens SPAG1 from Theileria annulata and p67 from Theileria parva." Parasite Immunology 22(5): 223-230.

Huber, S., R. Theiler, D. de Quervain, O. Wiens, T. Karangenc, V. Heussler, D. Dobbelaere and K. Woods (2017). "The Microtubule-Stabilizing Protein CLASP1 Associates with the $<\mathrm{em}>$ Theileria annulata</em> Schizont Surface via Its Kinetochore-Binding Domain." mSphere 2(4).

Iams, K. P., J. R. Young, V. Nene, J. Desai, P. Webster, O. K. ole-MoiYoi and A. J. Musoke (1990). "Characterisation of the gene encoding a 104-kilodalton micronemerhoptry protein of Theileria parva." Molecular and Biochemical Parasitology 39(1): 47-60.

Ikezawa, H. (2002). "Glycosylphosphatidylinositol (GPI)-Anchored Proteins." Biological and Pharmaceutical Bulletin 25(4): 409-417.

Lancet (2015). "Efficacy and safety of RTS,S/AS01 malaria vaccine with or without a booster dose in infants and children in Africa: final results of a phase 3, individually randomised, controlled trial." Lancet 386(9988): 31-45.

McHardy, N., L. S. Wekesa, A. T. Hudson and A. W. Randall (1985). "Antitheilerial activity of BW720C (buparvaquone): a comparison with parvaquone." Research in Veterinary Science 39(1): 29-33.

McKeever, D. J., E. L. Taracha, E. L. Innes, N. D. MacHugh, E. Awino, B. M. Goddeeris and W. I. Morrison (1994). "Adoptive transfer of immunity to Theileria parva in the CD8+ fraction of responding efferent lymph." Proceedings of the National Academy of Sciences $\mathbf{9 1 .}$

Mhadhbi, M., A. Naouach, A. Boumiza, M. F. Chaabani, S. BenAbderazzak and M. A. Darghouth (2010). "In vivo evidence for the resistance of Theileria annulata to buparvaquone." Veterinary Parasitology 169(3-4): 241-247.

Morrison, W. I. (2009). "Progress towards understanding the immunobiology of Theileria parasites." Parasitology 136.

Morrison, W. I. and B. M. Goddeeris (1990). Cytotoxic T Cells in Immunity to Theileria parva in Cattle. T-Cell Paradigms in Parasitic and Bacterial Infections. S. H. E. Kaufmann. Berlin, Heidelberg, Springer Berlin Heidelberg: 79-93.

Musoke, A., S. Morzaria, C. Nkonge, E. Jones and V. Nene (1992). "A recombinant sporozoite surface antigen of Theileria parva induces protection in cattle." Proceedings of the National Academy of Sciences 89(2): 514-518.

Musoke, A. J., V. M. Nantulya, G. Buscher, R. A. Masake and B. Otim (1982). "Bovine immune response to Theileria parva: neutralizing antibodies to sporozoites." Immunology 45(4): 663-668. 
Musoke, A. J., V. M. Nantulya, F. R. Rurangirwa and G. Buscher (1984). "Evidence for a common protective antigenic determinant on sporozoites of several Theileria parva strains." Immunology 52(2): 231-238.

Nene, V., H. Kiara, A. Lacasta, R. Pelle, N. Svitek and L. Steinaa (2016). "The biology of Theileria parva and control of East Coast fever - Current status and future trends." Ticks and Tick-borne Diseases 7(4): 549-564.

Norval, R. A. I., B. D. Perry and A. Young (1992). The epidemiology of theileriosis in Africa, Academic press, London.

Patel, E., S. Mwaura, H. Kiara, S. Morzaria, A. Peters and P. Toye (2016). "Production and dose determination of the Infection and Treatment Method (ITM) Muguga cocktail vaccine used to control East Coast fever in cattle." Ticks and Tick-borne Diseases 7(2): 306-314.

Petersen, T. N., S. Brunak, G. von Heijne and H. Nielsen (2011). "SignalP 4.0: discriminating signal peptides from transmembrane regions." Nature Methods 8(10): 785-786.

Pierleoni, A., P. L. Martelli and R. Casadio (2008). "PredGPI: a GPI-anchor predictor." BMC Bioinformatics 9(1): 392.

Radley, D. E., C. G. D. Brown, M. J. Burridge, M. P. Cunningham, I. M. Kirimi, R. E. Purnell and A. S. Young (1975a). "East coast fever: 1. Chemoprophylactic immunization of cattle against Theileria parva (Muguga) and five theilerial strains." Veterinary Parasitology 1(1): 3541.

Radley, D. E., C. G. D. Brown, M. P. Cunningham, C. D. Kimber, F. L. Musisi, R. C. Payne, R. E. Purnell, S. M. Stagg and A. S. Young (1975b). "East coast fever: 3. Chemoprophylactic immunization of cattle using oxytetracycline and a combination of theilerial strains." Veterinary Parasitology 1(1): 51-60.

Shaw, M. K. (1996). "Theileria parvaSporozoite Entry into Bovine Lymphocytes Involves both Parasite and Host Cell Signal Transduction Processes." Experimental Parasitology 84(3): 344354.

Shaw, M. K. (2003). "Cell invasion by Theileria sporozoites." Trends in Parasitology 19(1): 26.

Tachado, S. D., P. Gerold, M. J. McConville, T. Baldwin, D. Quilici, R. T. Schwarz and L. Schofield (1996). "Glycosylphosphatidylinositol toxin of Plasmodium induces nitric oxide synthase expression in macrophages and vascular endothelial cells by a protein tyrosine kinasedependent and protein kinase C-dependent signaling pathway." The Journal of Immunology 156(5): 1897-1907.

Toye, P., J. Nyanjui, B. Goddeeris and A. J. Musoke (1996). "Identification of neutralization and diagnostic epitopes on PIM, the polymorphic immunodominant molecule of Theileria parva." Infection and Immunity 64(5): 1832-1838.

Toye, P. G., M. J. Metzelaar, P. L. Wijngaard, V. Nene, K. Iams, J. Roose, J. K. Nyanjui, E. Gobright, A. J. Musoke and H. C. Clevers (1995). "Characterization of the gene encoding the polymorphic immunodominant molecule, a neutralizing antigen of Theileria parva." The Journal of Immunology 155(3): 1370-1381. 
Tretina, K., R. Pelle and J. C. Silva (2016). "Cis regulatory motifs and antisense transcriptional control in the apicomplexan Theileria parva." BMC Genomics 17(1): 128.

Uilenberg, G. (1999). "Immunization against diseases caused by Theileria parva." Tropical Medicine and International Health 4: A12-A20.

von Heijne, G. (1990). "The signal peptide." The Journal of Membrane Biology 115(3): 195201.

Xue, G., C. von Schubert, P. Hermann, M. Peyer, R. Maushagen, J. Schmuckli-Maurer, P. Bütikofer, G. Langsley and D. A. E. Dobbelaere (2010). "Characterisation of gp34, a GPIanchored protein expressed by schizonts of Theileria parva and T. annulata." Molecular and Biochemical Parasitology 172(2): 113-120. 


\section{Supplementary figures}

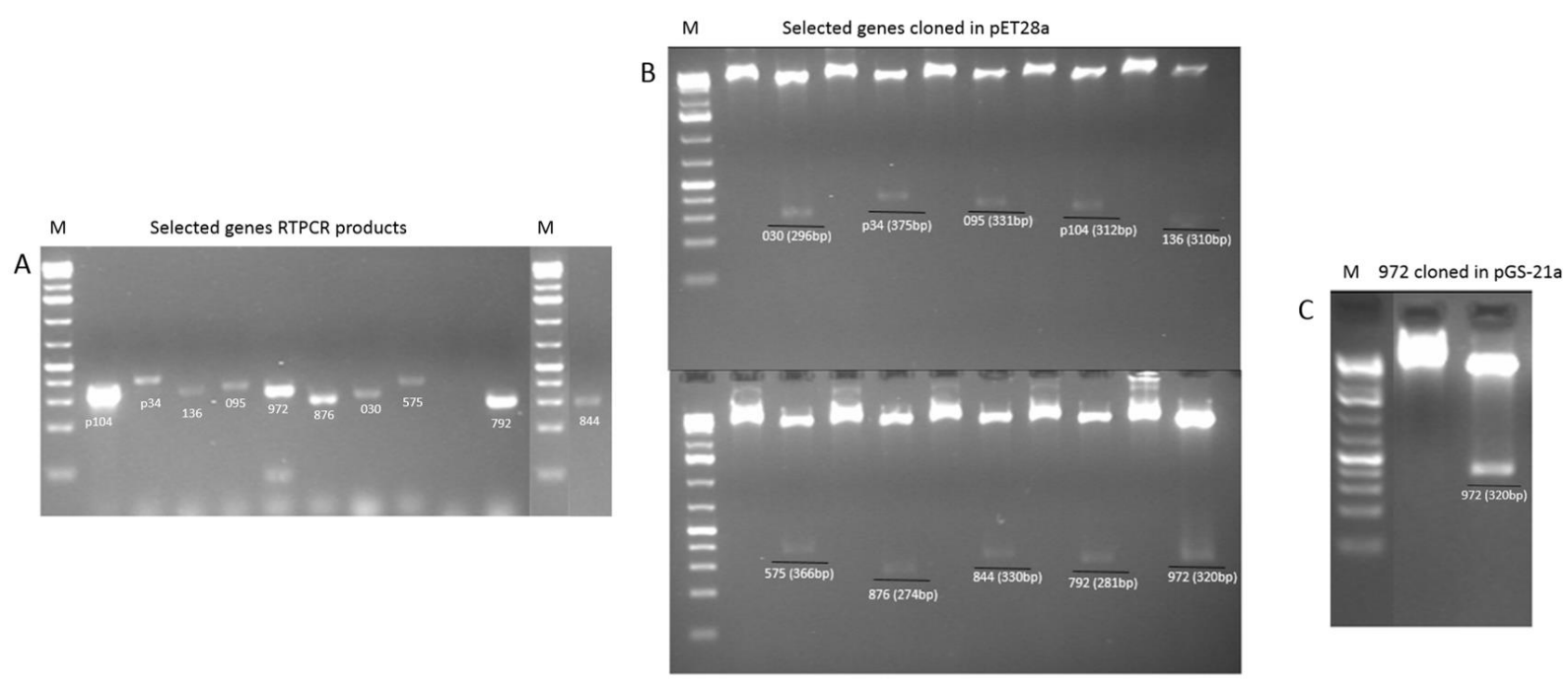

Supplementary figure S1. Selected gene fragments cDNA synthesis (A) and ligation in pET28a (B) and pGS-21a (C). Genes include; TpMuguga_04g00437 (p104), TpMuguga_01g00939 (p34), TpMuguga_03g00136 (136), TpMuguga_01g00095 (095), TpMuguga_01g00972 (972), TpMuguga_01g00876 (876), TpMuguga_04g00030 (030), TpMuguga_01g00575 (575), TpMuguga_02g00792 (792) and TpMuguga_03g00844 (844). Genes in pET28a (B) and pGS-21a (C) loaded as non-digested and BamHI/NotI digested. Size of fragments are shown in brackets. 
CHAPTER

\title{
Leveraging the Medicines for Malaria Venture malaria and pathogen boxes to discover lead chemical inhibitors of East Coast fever
}

\author{
James Nyagwange \\ Elias Awino \\ Edwin Tijhaar \\ Nicholas Svitek \\ Roger Pelle \\ Vishvanath Nene
}

Published in IJP: Drugs and Drug Resistance, 2019; 9:80-86 


\begin{abstract}
Chemotherapy of East Coast fever, a lymphoproliferative cancer-like disease of cattle causing significant economic losses in Africa, is largely dependent on the use of buparvaquone, a drug that was developed in the late 1980's. The disease is caused by the tick-borne pathogen Theileira parva. Buparvaquone can be used prophylactically to prevent disease and it is also active against tropical theileriosis, caused by the related parasite Theileria annulata. Recently, drug resistance was reported in T. annulata, and could also occur in T. parva. Therefore, there is need to identify new drugs that could be used for the control of Theileria infections. Using a ${ }^{3} \mathrm{H}$-thymidine incorporation assay we screened the Medicines for Malaria Venture (MMV) open source 400 malaria box and 396 pathogen box compounds to discover novel compounds with anti-parasitic activity. We identified nine malaria box compounds and eight pathogen box compounds that inhibit the proliferation of a $T$. parva infected cell line. However, only two compounds, MMV008212 (malaria box) and MMV688372 (pathogen box) represent promising leads with half maximal inhibitory concentration $\left(\mathrm{IC}_{50}\right)$ values of 0.78 and $0.61 \mu \mathrm{M}$, respectively, and half maximal cytotoxic concentration $\left(\mathrm{CC}_{50}\right)$ values $>5 \mu \mathrm{M}$. The remaining selected compounds exhibited a high degree of non-specific cytotoxicity $\left(\mathrm{CC}_{50}\right.$ values $<1.09$ $\mu \mathrm{M})$ on the proliferation of bovine peripheral blood mononuclear cells stimulated with concanavalin A. We also tested the anti-cancer drug, dasatinib, used in the therapy of some leukemias. Dasatinib was as active and safe as buparvaquone in vitro, with an $\mathrm{IC}_{50}$ of 5 and 4.2 $\mathrm{nM}$, respectively, and $\mathrm{CC}_{50}>10 \mu \mathrm{M}$. Our preliminary data suggest that it may be possible to repurpose compounds from the cancer field as well as MMV malaria and pathogen boxes.
\end{abstract}




\section{Introduction}

East Coast fever (ECF), a lymphoproliferative disease caused by Theileira parva is the most important tick-borne disease in sub-Saharan Africa. It kills a million cattle a year with an estimated economic loss of USD 300 million and impedes growth of the livestock industry. Theileria belongs to the phylum Apicomplexa, which contains other parasites responsible for major human and animal diseases, such as malaria, babesiosis, toxoplasmosis and cryptosporidiosis (Morrissette and Sibley 2002). Considerable progress has been made in developing vaccines for the control of some of these diseases. For example, a live infection and treatment method of immunization is commercially available for the control of ECF (Radley 1981) and tissue-culture vaccines are available for the control of tropical theileriosis caused by T. annulata (Brown 1990). Advanced clinical trials are in progress with a malaria vaccine (Lancet 2015). However, drug treatment often remains a frontline method of disease control.

Derivatives of naphthoquinones exhibit significant pharmacological properties and have given rise to development of anti-parasitic drugs, including commercial products to control malaria, e.g., atavaquone, a hydroxy-napthoquinone (Nixon, Moss et al. 2013). One of the byproducts of this effort gave rise to development of anti-theilerial drugs, e.g., parvaquone and the improved derivative, buparvaquone, that is the current drug of choice for treatment of theileriosis (McHardy, Wekesa et al. 1985). Members of this class of compounds display activity against other human and animals' parasites, e.g., trypanosomes (O. Salas, Faundez et al. 2011). Unfortunately, resistance to atavaquone, an analog of ubiquinone, emerged quite rapidly and drug resistance to atavaquone in Plasmodium is associated with mutations in the mitochondrial gene encoding apo-cytochrome b (Nixon, Moss et al. 2013). Resistance to other classes of anti-malarial drugs has also emerged, limiting the efficacy of several frontline drugs (Cui, Mharakurwa et al. 2015). The Medicines for Malaria Venture (MMV) was inaugurated in 1999, with a mandate of developing new anti-malarial drugs, as it was recognized that the pipeline for developing such drugs was small and not an attractive venture for the pharmaceutical industry.

Fortunately, T. parva resistance to buparvaquone has not been described. However, the recent identification of drug resistance in $T$. annulata is a cause for concern and suggests that this drug may be of limited veterinary use in the future. As for many tropical diseases, there is no program to develop new anti-theilerial drugs. Although focused on developing novel antimalarial drugs, MMV has catalyzed neglected disease drug discovery by making available drug-like and probe-like compounds available to the scientific community through the Malaria and Pathogen Box (Van Voorhis, Adams et al. 2016). A unique aspect of the biology of $T$. parva and T. annulata is that parasite infected leukocytes behave and proliferate like cancer cells in vitro, a property that is dependent on parasite viability. We have taken advantage of this phenomenon and the availability of MMV compounds to screen for molecules that inhibit the growth the $T$. parva cells.

We screened compounds in both the malaria and pathogen boxes against a bovine lymphocyte cell line infected with the schizont stage of T. parva and against bovine peripheral blood mononuclear cells (PBMC) stimulated by concanavalin A (ConA), the latter to determine cytotoxicity. We have identified two compounds with an in vitro therapeutic index $>5$, which could act as starting points for discovery of novel anti-theilerial drugs. In addition, we screened an anti-cancer drug, dasatinib that is used for treatment of chronic myelogenous leukemia and acute lymphoblastic leukemia, and found that it selectively kills the parasite with an in vitro therapeutic index $>2,000$ 


\section{Methods}

\section{Experimental compounds}

The MMV malaria box and pathogen box were obtained from the Medicines for Malaria Venture (MMV, Geneva, Switzerland). Plate mapping and full data on the malaria box were accessed at (http://www.mmv.org/research-development/malaria-box-supporting information) and (http://www.pathogenbox.org/) for the pathogen box. All plates were received at $10 \mathrm{mM}$ stock concentrations and diluted in $100 \%$ DMSO to form copies of the plates at $1 \mathrm{mM}$ concentration. From the $1 \mathrm{mM}$ stock plates serial dilutions were made in RPMI 1640 culture media to a $10 \mu \mathrm{M}$ working stock plates. Buparvaquone (Butalex) was used as a positive control drug and Dasatinib was purchased from Selleckchem, USA (cat no. S1021).

\section{In vitro parasite cytotoxicity assay}

All the compounds were initially tested for inhibitory activity on the growth of $T$. parva infected lymphocytes at $1 \mu \mathrm{M}$ final concentration. F100TpM, a bovine lymphocyte cell line infected by T. parva, was seeded in $100 \mu \mathrm{l}$ RPMI 1640 media at $1 \times 10^{4}$ cells per well in 96 well plates and incubated overnight in $5 \% \mathrm{CO}_{2}$ at $37^{\circ} \mathrm{C}$ before addition of drug compounds ( 0 to 2 $\mu \mathrm{M}$ final concentration). Compounds found to inhibit growth of $T$. parva infected lymphocytes were further screened for non-specific cytotoxicity on the proliferation of uninfected bovine cells. Briefly, 1 x $10^{4}$ peripheral blood mononuclear cells (PBMCs) isolated from uninfected bovine blood by Ficoll-Paque density gradient centrifugation were seeded in 100 $\mu$ R RPM 1640 media per well in 96 well plates and cultured overnight in $5 \% \mathrm{CO}_{2}$ at $37^{\circ} \mathrm{C}$ in the presence of concanavalin A (final concentration of $5 \mu \mathrm{g} / \mathrm{ml}$ ) before addition of drug compounds (0 to 10 $\mu \mathrm{M})$. Both cell lines were cultured in RPMI 1640 medium for 48 hours prior to pulsing with ${ }^{3} \mathrm{H}$-thymidine. Lower drug concentrations of buparvaquone were used to a maximum of 0.08 $\mu \mathrm{M}$. All compounds tested in triplicate wells.

\section{Thymidine incorporation as a marker for inhibitory activity}

Radiolabeled DNA precursor, ${ }^{3} \mathrm{H}$-thymidine is incorporated in DNA strands during cell replication and is often used as a measure of cell proliferation. All cells were pulsed with $20 \mu \mathrm{l}$ of RPMI 1640 media containing ${ }^{3} \mathrm{H}$-thymidine $(0.5 \mu \mathrm{Ci})$ per well and incubated in $5 \% \mathrm{CO} 2$ at $37^{\circ} \mathrm{C}$ for a minimum of $8 \mathrm{hrs}$ before harvesting. The cells were then harvested by a Filtermat Harvester (Perkin Elmer) onto Glass fiber matt filters (part No. 6005422) that captures the labelled DNA. The filters were then air- dried and placed in Omni Filter cassette and 30 $\mu 1$ of MicroScintTM (Perkin Elmer Cat No 6013611) liquid added, then sealed with TopSeal (Perkin Elmer, Part No 6050195) and loaded on TopCount NXT reader (Perkin Elmer) for determination of incorporation of ${ }^{3} \mathrm{H}$-thymidine.

\section{Calculation of $\mathrm{IC}_{50}$ and $\mathrm{CC}_{50}$ for bioactive compounds}

$\mathrm{IC}_{50}$ values were calculated using the Graph Pad Prism 7 software (GraphPad Software, Inc., La Jolla, CA), and average values of radio-isotope incorporation in wells with and without compound on the growth of F100TpM cells determined. The $\mathrm{CC}_{50}$ values were calculated using ${ }^{3} \mathrm{H}$-thymidine incorporation values of PBMC stimulated with conA incubated with different concentrations of the tested compound. 


\section{Results and Discussion}

In a search for new lead anti-theilerial compounds, we screened the open source MMV malaria box and pathogen box using a two-step process. Compound-induced inhibition (final concentration of $1 \mu \mathrm{M}$ ) of ${ }^{3} \mathrm{H}$-thymidine incorporation by a $T$. parva infected cell line (F100TpM) was used as a marker of anti-theilerial activity. Proliferation of infected cells is parasite-dependent, and appears to occur through manipulation of several complex host-cell signaling pathways (Shiels, Langsley et al. 2006). To get an indication of the in vitro potency of the different compounds on T.parva the concentration that inhibited $50 \%$ of the proliferation of F100TpM (the $\mathrm{IC}_{50}$ value) was determined. To determine the non-specific cytotoxicity of the compounds, the concentration that inhibited $50 \%$ ( $\mathrm{CC}_{50}$ values) of the proliferation of bovine PBMCs stimulated with conA was determined. Most infected cells lines are derived by "transformation" of T-lymphocytes by the parasite (Baldwin, Black et al. 1988). Since conA drives the proliferation of T-lymphocytes (Palacios 1982) we reasoned that these conA blasts represent a suitable control to assess non-specific cytotoxicity in vitro.

In the malaria and pathogen boxes, nine ( $\mathrm{IC}_{50}$ values ranging from 0.04 to $1.93 \mu \mathrm{M}$ ) and eight ( $\mathrm{IC}_{50}$ values ranging from 0.35 to $0.97 \mu \mathrm{M}$ ) compounds inhibiting TpM proliferation were identified, respectively, representing approximately a $2 \%$ hit rate (Table 1 and 2). However, the majority of these compounds were also highly active on inhibiting the uninfected conA stimulated PBMCs. Only two compounds, one from each box, MMV008212 and MMV688372, exhibited an in vitro therapeutic index $\left(\mathrm{CC}_{50} / \mathrm{IC}_{50}\right)$ of 8 and 10 , respectively. An index $>5$ has been used to determine parasite selectivity of MMV compounds (reviewed in Duffy, Sykes et al. 2017). In many cases the therapeutic index was close to or less than one in our assay. This might be due to the different cell lines and assays used. In our hands, the positive control drug, buparavquone had an $\mathrm{IC}_{50}$ of $4.2 \mathrm{nM}$ and a $\mathrm{CC}_{50}>10 \mu \mathrm{M}$, with a therapeutic index of more than 2,000. Interestingly, four pathogen box compounds were more inhibitory on the control conA stimulated PBMCs, than on F100TpM, indicating that there could be differences in the molecular and cellular biology of the two cell lines.

Of the malaria box compounds identified here, MMV008212, with a therapeutic index of 12 for T.parva infected lymphocytes, was previously shown to also have activities against Trypanosoma cruzi $(100 \%$ growth inhibition at $5 \mu \mathrm{M})$, Plasmodium berghei ookinete $(76 \%$ growth inhibition at $10 \mu \mathrm{M}), P$. falciparum gametocyte NF54-late stage (91\% growth inhibition at $5 \mu \mathrm{M})$ and $P$. falciparum 3D7 asexual blood stage (98\% growth inhibition at $5 \mu \mathrm{M})$ (reviewed in Van Voorhis, Adams et al. 2016). Cytotoxicity of this compound was observed only in one cell line (U87, 76\% cell death at $5 \mu \mathrm{M}$ ) of the nine cell lines tested previously (Van Voorhis, Adams et al. 2016). However, the mode of action of this compound is still unknown. The remaining eight malaria box compounds with activity against T.parva infected lymphocytes exhibited varied inhibitory activities on other organisms including Plasmodium, Toxoplasma, Leishmania, Cryptosporidium and Wolbachia (Table 1). Among them, compound MMV665800 has shown $P$. falciparum ATP4 inhibitor activity, while MMV006455 possibly acts through a respiratory target (reviewed in Van Voorhis, Adams et al. 2016). In general, these compounds exhibited less cytotoxicity on mammalian cell lines and zebrafish embryo that were tested previously (Van Voorhis, Adams et al. 2016). 
Table1. Malaria box compounds inhibiting growth of $T$. parva infected lymphocytes (F100TpM)

\begin{tabular}{|c|c|c|c|c|c|c|c|}
\hline Compound & Structure $^{\mathrm{a}}$ & $\begin{array}{l}\text { MW } \\
\mathrm{g} / \mathrm{mol}^{\mathrm{b}}\end{array}$ & $A \log P^{c}$ & $\begin{array}{l}\mathrm{IC}_{50}(\mu \mathrm{M}) \\
\text { F100TpM }\end{array}$ & $\begin{array}{c}\mathrm{CC}_{50}(\mu \mathrm{M}) \\
\text { Con A } \\
\text { blasts }\end{array}$ & $\begin{array}{c}\text { T.I }{ }^{\mathrm{d}} \\
\left(\mathrm{CC}_{50} / \mathrm{IC}_{50}\right)\end{array}$ & $\begin{array}{l}\text { Activity in other organisms and } \\
\text { cytotoxicity (reference) }\end{array}$ \\
\hline MMV008212 & & 280.32 & 3.59 & 0.78 & $>10$ & $>12$ & $\begin{array}{l}\text { Trypanosoma cruzi, P. berghei } \\
\text { ookinete, } P \text {. falciparum } \\
\text { gametocyte NF54-late stage } \\
\text { (Van Voorhis, Adams et al. } \\
2016 \text { ) }\end{array}$ \\
\hline MMV006455 & & 370.49 & 3.97 & 0.84 & 0.90 & 1.07 & $\begin{array}{l}P . \text { falciparum early ring stage } \\
\text { and gametocyte (Van Voorhis, } \\
\text { Adams et al. 2016) }\end{array}$ \\
\hline MMV665841 & & 273.33 & 3.13 & 0.36 & 0.66 & 1.83 & $\begin{array}{l}\text { T. cruzi and Wolbachia (Van } \\
\text { Voorhis, Adams et al. 2016) }\end{array}$ \\
\hline
\end{tabular}

104 | Chapter 5 


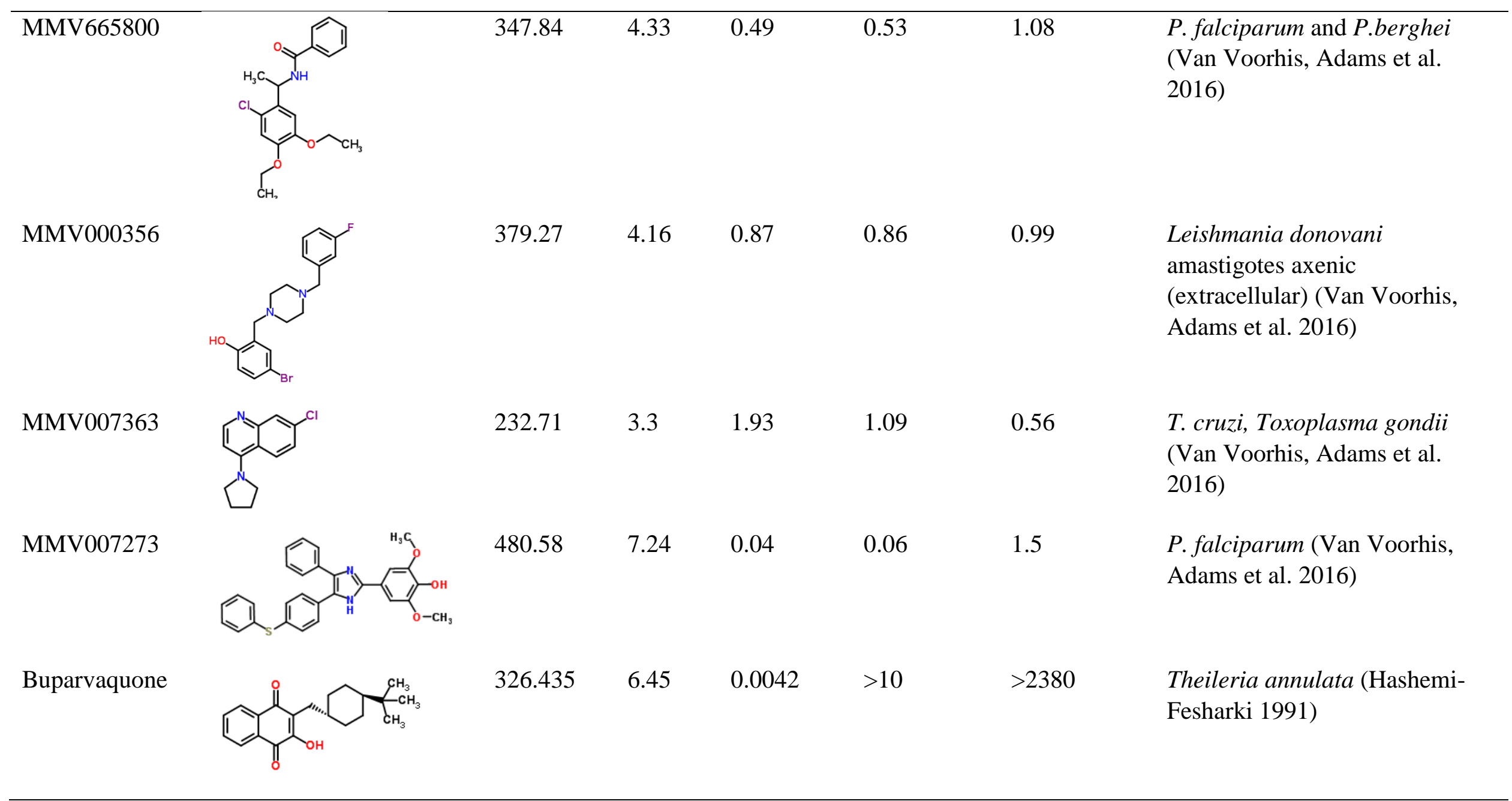

${ }^{a}$ Structure of drug compounds from ChemSpider (http://www.chemspider.com/) or DrugBank (https://www.drugbank.ca/). ${ }^{b}$ Molecular weight of the compound. ${ }^{\mathrm{c}}$ Lipophilicity index of the compound. ${ }^{\mathrm{d}}$ Therapeutic index (TI) of the compound 
Of the 8 pathogen box compounds that were shown in this study to display activity against T.parva infected lymphocytes, five were previously shown to also have antitrypanosomal activity, one has anti-malarial activity and two are reference compounds (Table 2). Mebendazole (MMV003152) is a known anti-helminthic drug that binds tubulin, inhibiting their assembly into microtubules and consequently perturbing the motility, division and the secretion processes of cells (Wampande, Richard McIntosh et al. 2007). In helminthes, binding of the drug leads to loss of cytoplasmic microtubules which perturbs glucose intake leading to exhaustion of glycogen reserves and consequent death (Oxberry, Gear et al. 2001). Auranofin (MMV688978) is a drug indicated for rheumatoid arthritis and thought to act through inhibition of nuclear factor kappa-B kinase subunit beta (Jeon, Byun et al. 2003) and thioredoxin reductase (Rigobello, Folda et al. 2005) leading to reduced inflammatory responses and reduced free radical production, respectively. The antimalarial compound, MMV023985 has CDPK1 or PK7 proposed as the target (reviewed in Duffy, Sykes et al. 2017). Although these compounds demonstrated activities on F100TpM with IC50s $<1 \mu \mathrm{M}$, their low therapeutic index questions a role for them as anti-theilerial lead compounds. MV688372, which had a high therapeutic index against F100TpM cells has anti-trypanosomal activity. This compound is a substituted 2-phenylimidazopyridine with activities against Trypanosoma brucei brucei and $T$. cruzi with therapeutic indexes of 230 and 24, respectively, in relation to HEK293 cells (Duffy, Sykes et al. 2017). The mode of action of MMV688372 is still unclear, but a structurally related azabenzoxazole has been identified as a proteasome inhibitor in kinetoplastid parasites (Duffy, Sykes et al. 2017). 
Table2. Pathogen box compounds inhibiting growth of $T$. parva infected lymphocytes (F100TpM)

\begin{tabular}{|c|c|c|c|c|c|c|c|}
\hline Compound & Structure $^{\mathrm{a}}$ & $\begin{array}{l}\mathrm{MW}^{\mathrm{b}} \\
(\mathrm{g} / \mathrm{mol})\end{array}$ & $\mathrm{A} \log \mathrm{P}^{\mathrm{c}}$ & $\begin{array}{l}\mathrm{IC}_{50}(\mu \mathrm{M}) \\
\mathrm{F} 100 \mathrm{TpM}\end{array}$ & $\begin{array}{l}\mathrm{CC}_{50} \\
(\mu \mathrm{M}) \\
\text { Con A } \\
\text { blasts }\end{array}$ & $\begin{array}{c}\mathrm{T} . \mathrm{I}^{\mathrm{d}} \\
\left(\mathrm{CC}_{50} / \mathrm{IC}_{50}\right)\end{array}$ & $\begin{array}{l}\text { Activity in other } \\
\text { organisms and } \\
\text { cytotoxicity (reference) }\end{array}$ \\
\hline MMV688372 & & 401.44 & 3.83 & 0.61 & 5.3 & 8.69 & $\begin{array}{l}\text { Anti-Trypanosoma } \\
\text { (Duffy, Sykes et al. 2017) }\end{array}$ \\
\hline MMV676600 & & 474.55 & 2.06 & 0.55 & $<0.001$ & $<0.001$ & $\begin{array}{l}\text { Anti-Trypanosoma } \\
\text { (Duffy, Sykes et al. 2017) }\end{array}$ \\
\hline
\end{tabular}




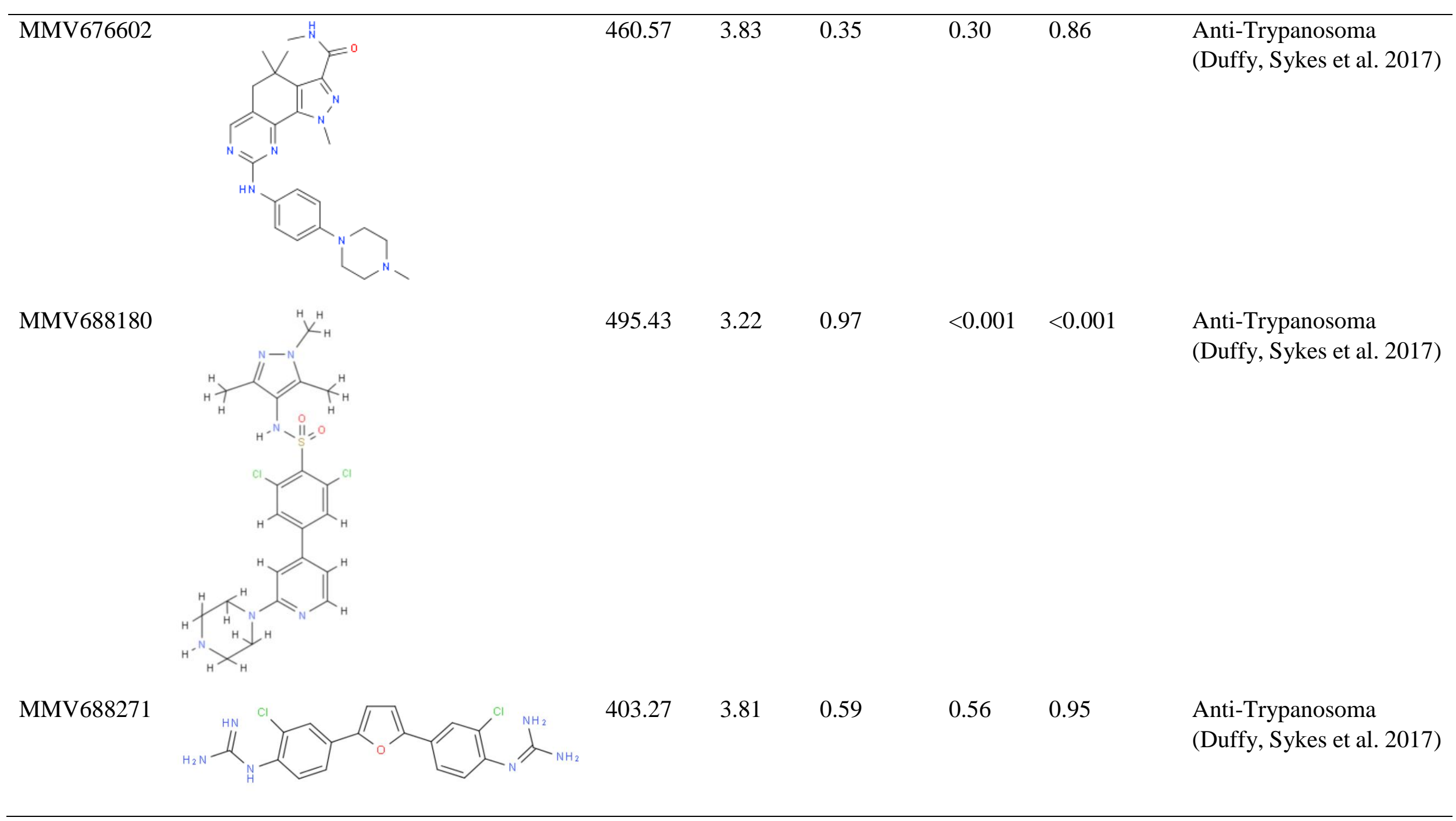

108 | Chapter 5 


\begin{tabular}{|c|c|c|c|c|c|c|}
\hline MMV023985 & 324.38 & 3.18 & 0.52 & $<0.001$ & $<0.001$ & $\begin{array}{l}\text { Anti-malarial (Duffy, } \\
\text { Sykes et al. 2017) }\end{array}$ \\
\hline $\begin{array}{l}\text { MMV003152 } \\
\text { (Mebendazol } \\
\text { e) }\end{array}$ & 295.29 & 3.06 & 0.36 & $<0.001$ & $<0.001$ & $\begin{array}{l}\text { Anti-helminthic } \\
\text { (Oxberry, Gear et al. } \\
\text { 2001) }\end{array}$ \\
\hline $\begin{array}{l}\text { MMV688978 } \\
\text { (Auranofin) }\end{array}$ & 678.484 & - & 0.54 & 0.40 & 0.74 & $\begin{array}{l}\text { Rheumatoid arthritis drug } \\
\text { (Jeon, Byun et al. 2003) }\end{array}$ \\
\hline
\end{tabular}

${ }^{a}$ Structure of drug compounds from ChemSpider (http://www.chemspider.com/) or DrugBank (https://www.drugbank.ca/). ${ }^{b}$ Molecular weight of the compound. ${ }^{\mathrm{c}}$ Lipophilicity index of the compound. ${ }^{\mathrm{d}}$ Therapeutic index (TI) of the compound 
The MMV malaria box was previously screened for activity against Theileria annulata by Hostettler et al (2016) and MMV665820 was the only compound that was identified in our anti-T.parva assay that also had activity against T. annulata (Hostettler, Müller et al. 2016). Although this compound did not impair viability of the human foreskin fibroblast control cells in the T. annulata assay, it was eliminated as a lead compound for not specifically targeting the parasite since it failed to lower the relative expression of $T$. annulata gene TaSP by $50 \%$ (Hostettler, Müller et al. 2016). In our assay, the therapeutic index for this compound was 1.67 leading to its elimination as a lead compound. The differences in drug activities between these two related parasites illustrates the differences in biology between these parasites and the tightrope walk towards development of anti-theilerial drug. The pathogen box compounds we have identified should therefore, be tested against $T$. annulata, just as was done for the MMV malaria box compounds.

Dasatinib exhibited very potent inhibitory activity on F100TpM cells with $\mathrm{IC}_{50}(5 \mathrm{nM})$ and $\mathrm{CC}_{50}(>10 \mu \mathrm{M})$ values similar to buparvaquone, the current anti-ECF drug of choice. It will be interesting to test dasatinib activity on T. annulata and other transforming Theileria pathogen cell lines. Dasatinib is a commercial drug approved and indicated for chronic myelogenous leukemia and acute lymphoblastic leukemia (Talpaz, Shah et al. 2006, Steinberg 2007). It is being considered for treatment of other cancers (Finn, Dering et al. 2007, Hochhaus, Baccarani et al. 2008, Johnson, Bekele et al. 2010). In humans, the drug has multiple targets including tyrosine-protein kinases (Bcr-Abl, Lck and Src family) (Quintas-Cardama, Kantarjian et al. 2006), platelet-derived growth factor receptor beta (Chen, Lee et al. 2006) and signal transducer and activator of transcription 5B (Nam, Williams et al. 2007). Recent target similarity search using another apicomplexan parasite ( $P$. falciparum) proteome identified ABC transporters as possible target for dasatinib (Mogire, Akala et al. 2017). Therefore, dasatinib's mode of action on T. parva infected lymphocytes could be through one or a combination of the targets, as these cells exhibit cancer-like properties with an up-regulation of growth factor receptors, NF-kB and tyrosine protein kinase cell-signaling pathways, among other cellular changes (Shiels, Langsley et al. 2006). This raises the possibility that the inhibitory activity of dasatinib on parasite infected cells is via inhibiting a host cellular pathway, rather than directly targeting the pathogen, and opens an additional avenue for drug discovery for Theileria. Although dasatinib might have a direct effect on the parasite, this was not tested in our current assay and we recommend testing this in future as this may reveal the mode of action of this drug on the parasites.

In conclusion, we have identified two lead MMV compounds one from the malaria box and the other from the pathogen box with a therapeutic index $>5$ that present starting points for development of alternative drugs to control ECF, and, possibly other forms of theileriosis. In addition, we have demonstrated a very high therapeutic index of dasatinib on a T. parva infected lymphocyte cell line. A large number of related tyrosine kinase inhibitors are available and our results suggests that these molecules as well as other anti-cancer drugs could be explored for their use as repurposed anti-theilerial drugs, provided cost is not an inhibitory factor.

\section{Acknowledgement}

We are grateful to Robert Mugambi and Elizabeth Kibwana (International Livestock Research Institute, Kenya) for providing cells. We thank the CGIAR Research Program on Livestock and Fish, Kenya, the Norman Borlaug Commemorative Research Initiative, an initiative between the Feed the Future program of United States Agency for International Development, USA and United States Department of Agriculture-Agricultural Research 
Service, USA (58-5348-2-117F) and the Department for International Development of the United Kingdom and the Bill and Melinda Gates Foundation, USA (OPP1078791) for financial support. We would also like to thank MMV for provision of the Malaria and Pathogen box compounds. 


\section{References}

Baldwin, C. L., et al. (1988). "Bovine T cells, B cells, and null cells are transformed by the protozoan parasite Theileria parva." Infection and Immunity 56(2): 462-467.

Brown, C. G. (1990). "Control of tropical theileriosis (Theileria annulata infection) of cattle." Parassitologia 32(1): 23-31.

Chen, Z., et al. (2006). "Potent inhibition of platelet-derived growth factor-induced responses in vascular smooth muscle cells by BMS-354825 (dasatinib)." Molecular Pharmacology 69(5): $1527-1533$.

Cui, L., et al. (2015). "Antimalarial Drug Resistance: Literature Review and Activities and Findings of the ICEMR Network." The American Journal of Tropical Medicine and Hygiene 93(3_Suppl): 57-68.

Duffy, S., et al. (2017). "Screening the Medicines for Malaria Venture Pathogen Box across Multiple Pathogens Reclassifies Starting Points for Open-Source Drug Discovery." Antimicrobial Agents and Chemotherapy 61(9).

Finn, R. S., et al. (2007). "Dasatinib, an orally active small molecule inhibitor of both the src and abl kinases, selectively inhibits growth of basal-type/"triple-negative" breast cancer cell lines growing in vitro." Breast Cancer Research and Treatment 105(3): 319-326.

Hashemi-Fesharki, R. (1991). "Chemotherapeutic value of parvaquone and buparvaquone against Theileria annulata infection of cattle." Research in Veterinary Science 50(2): 204-207.

Hochhaus, A., et al. (2008). "Dasatinib induces durable cytogenetic responses in patients with chronic myelogenous leukemia in chronic phase with resistance or intolerance to imatinib." Leukemia 22: 1200.

Hostettler, I., et al. (2016). "In vitro screening of the open source MMV malaria box reveals novel compounds with profound activities against Theileria annulata schizonts." Antimicrobial Agents and Chemotherapy.

Jeon, K. I., et al. (2003). "Gold compound auranofin inhibits IkappaB kinase (IKK) by modifying Cys-179 of IKKbeta subunit." Exp Mol Med 35(2): 61-66.

Johnson, F. M., et al. (2010). "Phase II Study of Dasatinib in Patients With Advanced NonSmall-Cell Lung Cancer." Journal of Clinical Oncology 28(30): 4609-4615.

Lancet (2015). "Efficacy and safety of RTS,S/AS01 malaria vaccine with or without a booster dose in infants and children in Africa: final results of a phase 3, individually randomised, controlled trial." Lancet 386(9988): 31-45. 
McHardy, N., et al. (1985). "Antitheilerial activity of BW720C (buparvaquone): a comparison with parvaquone." Research in Veterinary Science 39(1): 29-33.

Mogire, R. M., et al. (2017). "Target-similarity search using Plasmodium falciparum proteome identifies approved drugs with anti-malarial activity and their possible targets." PLoS One 12(10): e0186364.

Morrissette, N. S. and L. D. Sibley (2002). "Cytoskeleton of Apicomplexan Parasites." Microbiology and Molecular Biology Reviews 66(1): 21-38.

Nam, S., et al. (2007). "Dasatinib (BMS-354825) inhibits Stat5 signaling associated with apoptosis in chronic myelogenous leukemia cells." Molecular Cancer Therapeutics 6(4): 14001405 .

Nixon, G. L., et al. (2013). "Antimalarial pharmacology and therapeutics of atovaquone." Journal of Antimicrobial Chemotherapy 68(5): 977-985.

O. Salas, C., et al. (2011). "Natural and Synthetic Naphthoquinones Active Against Trypanosoma Cruzi: An Initial Step Towards New Drugs for Chagas Disease." Current Medicinal Chemistry 18(1): 144-161.

Oxberry, M. E., et al. (2001). "Assessment of benzimidazole binding to individual recombinant tubulin isotypes from Haemonchus contortus." Parasitology 122(Pt 6): 683-687.

Palacios, R. (1982). "Concanavalin A triggers T lymphocytes by directly interacting with their receptors for activation." The Journal of Immunology 128(1): 337-342.

Quintas-Cardama, A., et al. (2006). "Targeting ABL and SRC kinases in chronic myeloid leukemia: experience with dasatinib." Future Oncol 2(6): 655-665.

Radley, D. E. (1981). Infection and Treatment Method of Immunization Against Theileriosis. Advances in the Control of Theileriosis: Proceedings of an International Conference held at the International Laboratory for Research on Animal Diseases in Nairobi, 9-13th February, 1981. A. D. Irvin, M. P. Cunningham and A. S. Young. Dordrecht, Springer Netherlands: 227-237.

Rigobello, M. P., et al. (2005). "Effect of auranofin on the mitochondrial generation of hydrogen peroxide. Role of thioredoxin reductase." Free Radic Res 39(7): 687-695.

Shiels, B., et al. (2006). "Alteration of host cell phenotype by Theileria annulata and Theileria parva: mining for manipulators in the parasite genomes." International Journal for Parasitology 36(1): 9-21. 
Steinberg, M. (2007). "Dasatinib: a tyrosine kinase inhibitor for the treatment of chronic myelogenous leukemia and philadelphia chromosome-positive acute lymphoblastic leukemia." Clin Ther 29(11): 2289-2308.

Talpaz, M., et al. (2006). "Dasatinib in imatinib-resistant Philadelphia chromosome-positive leukemias." N Engl J Med 354(24): 2531-2541.

Van Voorhis, W. C., et al. (2016). "Open Source Drug Discovery with the Malaria Box Compound Collection for Neglected Diseases and Beyond." PLoS Pathogens 12(7): e1005763.

Wampande, E. M., et al. (2007). "Classical ligands interact with native and recombinant tubulin from Onchocerca volvulus with similar rank order of magnitude." Protein Expr Purif 55(2): 236-245. 


\section{Chapter}

\section{Summarizing Discussion}

James Nyagwange 


\section{Introduction and aims of thesis}

ECF caused by the hemoprotozoan pathogen Theileria parva is the leading tick-borne disease of cattle in sub-Saharan Africa, causing death of cattle and significant economic losses (Norval, Perry et al. 1992, De Deken, Martin et al. 2007). Currently control of the disease is dependent on vaccination and drug treatment. The infection and treatment method of vaccination involves deliberate infection with live sporozoites from three strains namely $T$. parva Muguga, Kiambu5 and Serengeti (known as Muguga cocktail) and simultaneous treatment with a long-acting oxytetracycline. Although effective, this method has serious limitations which have been discussed in detail in Chapter 1. Briefly, the immunity generated by the vaccine is strain specific and immunized cattle can become life-long asymptomatic carriers of the parasite, posing risk for the spread of the disease through introduction of 'foreign' T. parva strains in areas where the strains in the vaccine are not present. The production and distribution of the vaccine involves complex procedures requiring infrastructure and specialized expertise which are not always available. These concerns undermine the widespread uptake of this vaccine (Chapter 1). There have been efforts to identify sporozoite antigens that are targets of neutralizing antibodies and one protein, p67 is considered the lead candidate for development of a subunit vaccine. However, this protein only protects only a proportion of immunized cattle (Chapter 1). Although research is ongoing on different formulations and immunization regimen to improve the efficacy of this antigen, protection against ECF might be improved by additional sporozoite antigens that induce sporozoite neutralizing antibodies. Chemotherapy is another method of ECF control and is currently dependent on the use of buparvaquone, a drug that was developed in the late 1980's and to which resistance has been reported in the related parasite Theileria annulata. Fortunately, resistance has not been reported in T. parva, but this could occur, underscoring the urgency for discovery of new cost effective drugs.

Traditionally, acaricides were used to prevent tick infestation and by extension ECF control. However, as discussed in Chapter 1, this method is not sustainable as parasite challenge occurs over many months of the year, thereby requiring application of acaricides over prolonged periods making it expensive and detrimental to the environment. Additionally, this method leaves the cattle population susceptible to infection by tick borne pathogens and vulnerable to disease outbreaks, should the acaricides be unavailable due to local political or economic changes.

These shortcomings of ECF control measures highlight the need for development of an effective subunit vaccine and discovery of alternative drug compounds to provide a sustainable means of controlling this disease.

The research described in this thesis (summarized in Figure 1) therefore aimed to characterize the sporozoite proteome and identify novel proteins from the sporozoite stage that can be evaluated as vaccine antigens. Furthermore, this thesis aimed to recombinantly express and evaluate some of the identified proteins for neutralization of sporozoite infection of lymphocytes. In addition, this study aimed at identifying new drug compounds that could be used for the control of Theileria infections. Towards this end we took advantage of the open source MMV malaria box, pathogen box and anti-cancer drug dasatanib to screen for molecules that inhibit the growth of T. parva infected lymphoblastoid cells. 


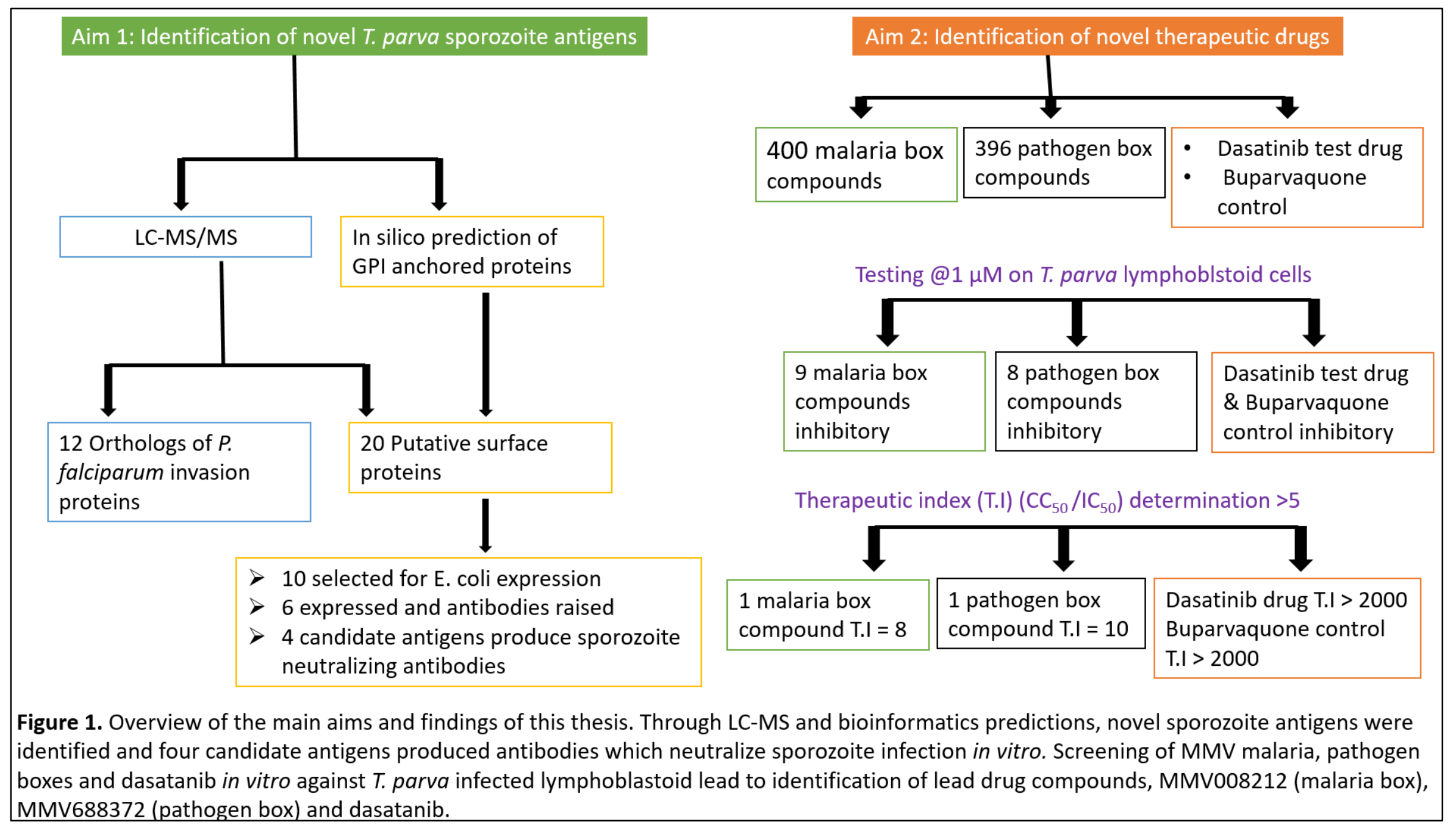

117 | Ch a p t e r 6 


\section{ECF vaccine development challenges}

Vaccine development had its roots in the work of Edward Jenner (1749-1823), who discovered how to protect people from smallpox through inoculation with a harmless but related virus, cowpox and Louis Pasteur (1822-1895) who developed the first rabies vaccine (Fenner 2000). Since then, vaccines have become the most cost-effective means of controlling diseases with successful eradication of diseases such as smallpox and rinderpest, with great progress towards poliomyelitis eradication.

Vaccine development follows approaches that either make use of whole organisms, weakened or alive or components of the pathogens. Live vaccines can elicit both humoral and cellular immunity and single or few doses usually give lifelong protection (Hansson, Nygren et al. 2000). The Infection and Treatment Method (ITM) vaccination against ECF is a good example of this type of vaccine in veterinary use. However, live vaccines have the potential to cause disease through replication of the pathogens in the host. To circumvent this, the live organisms are usually attenuated, for example by multiple passages in media, to prevent them from causing disease (Hansson, Nygren et al. 2000). In Theileria, vaccination with passaged infected leukocyte cell lines was evaluated and this approach induced immunity against $T$. annulata but a similar approach for T. parva was not successful (Morrison and McKeever 2006). Transfer of infection by T. parva infected leukocyte cells occurred at a much lower frequency, and immunity was only achieved definitively by administering large doses $\left(\geq 10^{8}\right.$ cells) of parasitized cells (Morrison and McKeever 2006). Therefore, this method of vaccination continued to be used in $T$. annulata while $T$. parva vaccination adopted the ITM method (discussed in Chapter 1). The ITM method is possible because of oxtetracycline, which is administered as a slow release formulation with activity lasting 5 to 6 days. This delays development of the parasite leading to mild infection with recovery and induction of immunological memory. Nevertheless, the risk of these organisms reverting to the original virulent strain or forming new recombinant virulent strains presents a disadvantage of live vaccines such as ITM.

Subunit vaccines on the other hand are designed to include only portions of the pathogen required for protective immunization and are therefore safer than whole-inactivated or live-attenuated vaccines (Hansson, Nygren et al. 2000). By combining technological possibilities with knowledge in areas of immunology and molecular biology, candidate antigens can be identified and delivered to the susceptible hosts inducing broad immunological response and long-lived memory. Recombinant DNA techniques are now dominating the strive for subunit vaccines with DNA vaccines such as West Nile-Innovator® DNA, by Fort Dodge and APEX-IHN@, by Novartis already licenced for veterinary use in horses and farm raised salmons respectively (Dalmo 2018). However, unlike live attenuated or killed vaccines, most subunit antigens lack self-adjuvanting and immunomodulatory components (Hansson, Nygren et al. 2000). This poses challenge in the development of subunit vaccines since they are often poorly immunogenic and have short in vivo half-life (Hansson, Nygren et al. 2000). However, these can be circumvented for example, by choice of a good delivery system and/or adjuvants (Liljeqvist and Ståhl 1999, Hansson, Nygren et al. 2000). In T. parva, studies are in progress with different formulations of p67 including; hepatitis B core expressed surface p67, p67 antigen in slow release vesicles and p67 expressing nanoparticles (Lacasta et al, unpublished data). Previous formulations of p67 based vaccines have induced varied protection capacities ranging from 13 to $70 \%$ (reveiwed in Nene, Kiara et al. 2016) as discussed in Chapter 1. 
Challenges with p67 vaccines stem from observations that cattle immunized produce high antibody titres against p67, but in most experiments there has been no consistent correlate of various antibody assays with immunity (Nene, Kiara et al. 2016). Furthermore levels of immunity elicited by the vaccines in the field trials were overall lower compared to the results obtained under well controlled experimental challenge (Nene, Kiara et al. 2016).

\section{Identification of T. parva candidate vaccine antigens}

To identify novel antigens and to improve understanding of the biology of T. parva, a Multidimensional Protein Identification Technology (MudPIT) mass spectrometry-based approach (reviewed in Schirmer, Yates et al. 2003) was followed in Chapter 2, to characterize the proteome of $T$. parva sporozoites purified by ion-exchange chromatography (Musoke, Morzaria et al. 1992). The MudPIT method chosen allows for analysis of fractions containing several proteins using the bottom-up approach. The method basically involves direct proteolysis of the proteins in the mixture and generation of a large number of peptides which are subsequently separated by liquid chromatography before tandem mass spectrometry (Han, Aslanian et al. 2008). Mass spectra are then generated and collected for as many peptides as possible, and the results are searched by an algorithmic comparison (via SEQUEST or MASCOT) against a database of proteins derived from genomic sequencing to identify the peptides (Han, Aslanian et al. 2008). This approach was more appropriate for our sample, which contained a mixture of proteins than the top down methods which allows for identification of single or less complex protein mixtures and involves ionization of intact proteins without enzymatic digestions (Han, Aslanian et al. 2008). As reported in Chapter 2, a total of 4,780 proteins were identified; 2,773 R. appendiculatus proteins and 2,007 T. parva proteins, representing approximately $50 \%$ of the total predicted re-annotated $T$. parva proteome of 4084 proteins. About $40 \%$ of the identified proteins are annotated as hypothetical proteins providing evidence that real genes encode for these proteins, although their function remains unknown. This pool of hypothetical proteins presents an opportunity for discovery of novel antigens.

The DE-52 column purification method we employed provided better coverage for T. parva proteins than reported for $P$. falciparum sporozoites that also resides in the salivary glands of the vector. $P$. falciparum proteomic studies based on DE-52 column purification reported $\sim 13 \%$ (Lasonder, Janse et al. 2008), 19\% (Florens, Washburn et al. 2002) and 36\% (Lindner, Swearingen et al. 2013) of the 5524 annotated P. falciparum genes. Although tick vector proteins constituted $58 \%$ of the total proteins identified, this was still better compared with the $P$. falciparum studies in which mosquito proteins made up $60.1 \%$ to $89 \%$ of the proteins (Lasonder, Janse et al. 2008, Lindner, Swearingen et al. 2013). There are a number of factors that could have resulted in better coverage for $T$. parva proteome compared to $P$. falciparum proteome and also less contamination with vector derived proteins. Since the same DE-52 column purification method was used, differences in sample quality and processing prior to the column purification could have contributed to the difference. For instance, after homogenization of the sporozoite infected tick salivary glands we included a centrifugation step to pellet the insoluble tick material and enrich the sporozoites in the supernatant. In the three studies mentioned above, only Florens et al (2002) reported inclusion of a centrifugation step to remove the large mosquito debris (Florens, Washburn et al. 2002). The quality of the starting sample such as the number of the starting sporozoites, which is dependent on infection rates can also influence the coverage for the parasite proteins, as more parasite starting material should lead to more parasite protein identifications. For our study salivary glands were dissected from 300 adult ticks infected with $T$. parva Muguga isolate with approximately 4$5 \times 10^{8}$ sporozoites (mean infection rate of $\sim 28,570$ sporozoites/acinus, $\sim 15-20,000$ infected 
acini) as starting material. Whereas Lindner et al and Florens et al did not state the number of starting of sporozoites in the starting sample, Lasonder et al reported approximately $1-4 \times 10^{7}$ sporozoites as starting material, approximately 10 -fold less than our study with $T$. parva. The main challenge with proteomic studies on salivary glands sporozoites is the contamination with vector proteins since there are no in vitro methods to culture sporozoite stages and harvest vector free parasites. To reduce vector contamination, double purification in which $17 \% \mathrm{w} / \mathrm{v}$ Accudenz cushion purification followed by DEAE-cellulose chromatography was employed Lindner et al (2013) and found to reduce vector contamination from $60.1 \%$ to $21 \%$ (Lindner, Swearingen et al. 2013). Such a method can be adapted for purification of $T$. parva sporozoites from tick salivary glands in future studies. Another method to improve sporozoite purity is by using antibodies which bind sporozoite surface proteins such as anti-p67 monoclonal antibodies to label and sort sporozoites from vector mixtures by Fluorescence-activated cell sorting (FACS) provided there are enough sporozoites and its cost effective. In our hands staining with monoclonal antibody, ARIV21.4 against p67C fragment resulted in very little recovery of sporozites, requiring several samples to get enough sporozoites for mass spectrometry. Optimization of antibody staining protocol and/or use of multiple antibodies targeting different surface proteins might improve sporozoite yield after sorting.

We employed bioinformatics following mass spectrometry on sporozoite whole cell lysates to identify surface proteins that are likey to be vaccine candidate antigens ( Chapter 2). Although it was possible to identify many proteins including known surface antigens such as p67, providing confidence in the data, other studies such as Lindner et al (2013) have employed surface biotinylation followed by streptavidin capture to identify such proteins in $P$. falciparum (Lindner, Swearingen et al. 2013). The latter method focuses on the surface proteome of sporozoites and provides more confidence that the proteins are located on the surface or secreted and could therefore be vaccine antigens. However, by targeting the whole cell proteome, we were able to identify more proteins providing better understanding of the parasite biology. For instance, we identified proteins involved in metabolic processes such as glycolysis and citric acid cycle (Chapter 2, Figure 1) and proteins involved host cell transformation (Chapter 2, section 3.5). To identify novel $T$. parva sporozoites proteins that play a role in host entry, we clustered the identified proteins into orthologous groups with $P$. falciparum genes, since this malaria causing parasite is well studied and its genomics, transcriptomics and proteomics data is available. Clustering revealed orthologs of several proteins associated with host cell invasion by $P$. falciparum, among them AMA-1 and CelTOS, which are microneme proteins and leading malaria vaccine candidates (Kariu, Ishino et al. 2006, Remarque, Faber et al. 2008). Orthologs of these proteins in T. parva can be recombinantly expressed and tested for immunogenicity in cattle, and protection against parasite challenge.

Failure to identify some of the expected T. parva proteins e.g. the polymorphic immunodominant molecule (PIM), a well-known antigen (Toye, Goddeeris et al. 1991) does not directly imply absence of these proteins in the sample. There are several reasons why a protein may not be identified by proteomics. Trypsin digestion of proteins with low or irregular arginine/lysine content can lead to very short and very long tryptic peptides that fall out of the acquired mass range and may therefore not be detected. This was possibly the case with PIM protein whose sequence contains large repetitive domain rich in glutamine and proline amino acid residues but devoid of lysine and arginine residues (Toye, Goddeeris et al. 1991). An in silico digestion of PIM with trypsin led to prediction of few detectable tryptic peptides. Other possible reasons for failure to detect proteins include; peptides from low abundance proteins 
may fall below the detection limit or are simply not sequenced by the mass spectrometer due to limited dynamic range and/or speed of instrument acquisition. Furthermore, unknown, complex, or amino acid modifications leading to alteration of the peptide mass can only be detected in some cases by the Peaks software.

In Chapter 3, the 2,773 tick proteins co-purified with sporozoites were also analyzed. We hypothesized that some of these proteins persisting after DE-52 column purification may be bound or associated with sporozoites and therefore may be important vaccine candidates themselves. Our analysis revealed a list of known tick antigens, some of which are being explored for development of anti-tick vaccines such as RIM36 (Bishop, Lambson et al. 2002). Tick proteins involved in host immunomodulation such as ixodegrins and lipocalins were also found through this analysis. Whereas host immunomodulation proteins are reported to be useful for successful tick feeding, association with sporozoites would make them important antigens as they could aid sporozoite infection of host cells. These tick proteins therefore present an opportunity for a combined vaccine approach targeting both the vector and the parasite. However, it was not possible to identify the specific sporozoite bound tick proteins due to the large number of tick proteins still present after elimination of housekeeping proteins and proteins of known functions highlighting the limitation of the purification method used. As discussed above, methods that lead to a purer sporozoite sample such as antibody staining and FACS sorting, following DE-52 column and 17\% w/v Accudenz cushion purification would improve chances of identifying these proteins.

\section{Neutralization of infection by antibodies from candidate antigens}

Whereas different formulations and delivery systems for p67 antigen, e.g. viral vectors, could improve immune response to the antigen, addition of novel sporozoite (associated) antigens to a p67 vaccine might increase the level of induced protection, due to the additional immunogenic epitopes. GPI anchors are common attachment signals for surface proteins of parasites such as Plasmodium, Trypanosomes, Toxoplasma, etc. and many are promising vaccine candidate antigens (Ferguson 1999, Ferguson MAJ 2009). One such example is the circumsporozoite (CS) protein of Plasmodium which is the antigenic target of the malaria vaccine RTS, S (Lancet, 2015). In an attempt to identify surface antigens, we searched the reannotated T. parva genome (cited in Tretina, Pelle et al. 2016) for genes predicted to contain C-terminal GPI anchor signals, since they are likely to be located on the cell surface. Out of the 21 highly probable GPI anchored proteins predicted by PredGPI (Pierleoni, Martelli et al. 2008), we selected the top 10 highly probable proteins for our study. We were able to express conserved fragments of six of the proteins, raised murine antisera with these recombinant proteins and performed sporozoite neutralization assays (SNA) (Chapter 4). SNA is a common assay for screening of antigens to establish whether they are candidates for antisporozoite vaccine development. This method is used in several studies involving parasites with sporozoite stages such as Plasmodium, Cryptosporidium, Eimeria, etc. (Crane, Murray et al. 1988, Perryman, Riggs et al. 1990, Kumar, Oliveira et al. 2004). In Chapter 3, we show that antisera to two proteins, TpMuguga_01g00876 and TpMuguga_01g00939 (gp34), showed similar or better sporozoites neutralization compared to the positive control p67 monoclonal antibody. Whereas TpMuguga_01g00876 is a novel antigen with sporozoite neutralization activity, gp34 was described before as a schizont specific antigen by Xue et al (2010), but was never tested for sporozoite neutralization, perhaps since it was believed to be a schizont specific antigen. However, we identified this protein by mass spectrometry (Chapter 2) with 12 unique 
peptides (peptides that match the particular protein sequence only, and do not match any other protein in the database), providing confidence of its existence in the sporozoite stage. The other two recombinant proteins, TpMuguga_01g00095 and TpMuguga_04g00437 (p104), produced antisera which showed some neutralization, but to a lesser extent when compared to the p67 monoclonal antibody (Chapter 4). TpMuguga_01g00095 is another novel antigen but p104, is a sporozoite microneme/rhoptry protein (Ebel, Gerhards et al. 1999) which was identified before, but was never evaluated as vaccine antigen. These four are therefore promising vaccine candidate antigens that should be formally validated in cattle for production of sporozoite neutralizing antibodies and for protection against parasite challenge. However, priority should be given to the two proteins, TpMuguga_01g00876 and gp34 which, produced the strongest neutralizing antisera. The latter protein has been shown to undergo GPI modification when expressed in mammalian cells (Xue, von Schubert et al. 2010) pointing to a possibility of this protein existing as a GPI anchored protein in T. parva. Since there is no direct evidence for addition of GPI anchors to T. parva expressed proteins, we searched for enzymes of the GPI biosynthesis pathway and found eight Plasmodium homologs (Delorenzi, Sexton et al. 2002) in T. parva genome pointing to the existence of a process for GPI anchor addition to T. parva proteins. Four of the eight enzymes identified from the genome were confirmed to be expressed in the sporozoite proteome (Chapter 2).

\section{Mechanism of protective immunity by prospective subunit vaccine}

Surface and secreted proteins such as p67 and the vaccine candidates identified in this thesis can elicit antibody production leading to protective immunity by limiting the establishment of the sporozoites and preventing infection. Antibodies to these proteins can also enhance phagocytosis of sporozoites by opsonization and provide $\mathrm{Fc}$ receptors for $\mathrm{C} 1 \mathrm{q}$ binding triggering complement cascade and formation of membrane attack complex on the surface of sporozoites (Musoke, Morzaria et al. 1992). Generally, identified exogenous antigens such as p67, which is shed before parasite entry into host cells provides a CD4 dependent immunity. The mechanism of which involves the protein being endocytosed by lymphocytes and dendritic cells, processed into peptides and displayed on MHC class II molecules. Such a mechanism would lead to stimulation of CD4 T cells which helps in production of antibodies, useful for neutralization, opsonization and complement dependent lysis (Musoke, Morzaria et al. 1992). In addition to known sporozoite surface and secreted proteins, we identified all the characterized schizont CD8 T cell antigens in the sporozoite proteome (Graham, Pelle et al. 2006, Graham, Pellé et al. 2008). Among the schizont CD8 T cell antigens are housekeeping genes such as, hsp90, translation elongation initiation factor $1 \mathrm{~A}$, etc. and therefore not surprising to find at the sporozoites stage. However, identification of all schizont CD8 T cell antigens in the sporozoite stage, suggests that for $T$. parva infection, both direct and cross presentation mechanisms are involved in priming CTL responses in vivo by dendritic cells. Cross presentation is the processes by which antigen presenting cells such as dendritic cells uptake exogenous antigens, process them into peptides and display them on MHC class I molecules for priming CTL response (Cruz, Colbert et al. 2017). The process of peptide display on MHC class I molecules is present in all cells, but presentation of peptides is usually restricted for self- antigens or antigens of pathogens infecting the cells. This mechanism known as direct presentation, has been adapted by the immune system to help in identifying cells infected by pathogens such that, cells displaying foreign peptides are destroyed while cells displaying self-peptides are tolerated by CTL (Cruz, Colbert et al. 2017). However, since naïve CD8 T cells do not directly patrol peripheral tissues looking for antigen presenting cells, dendritic cells must survey the peripheral tissues where they collect exogenous antigens 
through phagocytosis or other endocytic mechanisms and then migrate to the $\mathrm{T}$ cell zone in lymph nodes and display the antigens acquired as MHC class I bound peptides (Cruz, Colbert et al. 2017). This ability of dendritic cells to present exogenous antigens as peptides on MHC class I peptides implies that dendritic cells can present $T$. parva peptides to CD8 T cells via both direct and cross presentation. The latter by uninfected dendritic cells while the former by T. parva infected dendritic cells. The finding of CD8 antigens in the sporozoite suggests that sporozoites phagocytosed by uninfected dendritic cells are processed and peptides cross presented to CD8 T cells. Therefore, an ideal subunit vaccine for ECF control should be able to induce B cells, CD4 and CD8 T-cells. A future vaccine can therefore combine humoral inducing antigens such as p67 or the candidates identified herein with CD8 T cell antigens especially Tp1 and Tp2 since they have been found to be dominant targets of the CD8+ T-cell response in cattle expressing the A18 and A10 class I MHC haplotypes, respectively (Pelle, Graham et al. 2011).

\section{Identification of lead chemical inhibitors of T. parva infected lymphoblastoid cells}

Chemotherapy of ECF and tropical theileriosis, caused by T. parva and T. annulata respectively, is largely dependent on the use of buparvaquone, a derivative of naphthoquinones developed in the 1980's. Other than buparvaquone, derivatives of naphthoquinones have given rise to development of anti-parasitic drugs, including commercial products to control malaria, such as, atavaquone, a hydroxy-napthoquinone (Nixon, Moss et al. 2013). Unfortunately, resistance to atavaquone emerged quite rapidly, and drug resistance to atavaquone in Plasmodium is associated with mutations in the mitochondrial gene encoding apo-cytochrome b (Nixon, Moss et al. 2013). Fortunately, T. parva resistance to buparvaquone has not been described. However, the recent identification of drug resistance in T. annulata is a cause for concern as resistance might occur in T. parva, which would make this drug of limited veterinary use in the future.

The Medicines for Malaria Venture (MMV) was inaugurated in 1999, with a mandate to develope new anti-malarial drugs, as it was recognized that the pipeline for developing such drugs was small and not an attractive venture for the pharmaceutical industry. MMV has catalyzed neglected disease drug discovery by making drug-like and probe-like compounds available to the scientific community through the Malaria and Pathogen Box (Van Voorhis, Adams et al. 2016). We took advantage of the availability of these compounds and screened them against a bovine lymphocyte cell line infected with the schizont stage of T. parva (TpM). A unique aspect of the biology of T. parva and T. annulata is that parasite infected leukocytes behave and proliferate like cancer cells in vitro, a property that is dependent on parasite viability. This phenomenon made it possible to screen for molecules that inhibit the growth of the T. parva infected cells. In addition to MMV compounds, we also screened the cancer drug dasatinib and used buparvaquone as control drug in these in vitro assays.

In the malaria and pathogen boxes, nine ( $\mathrm{IC}_{50}$ values ranging from 0.04 to $1.93 \mu \mathrm{M}$ ) and eight ( $\mathrm{IC}_{50}$ values ranging from 0.35 to $0.97 \mu \mathrm{M}$ ) compounds inhibiting TpM proliferation were identified, respectively, representing approximately $2 \%$ hit rate. Two compounds, MMV008212 and MMV688372, from malaria box and pathogen box respectively, exhibited an in vitro therapeutic index $\left(\mathrm{CC}_{50} / \mathrm{IC}_{50}\right)$ of 8 and 10 , respectively. Dasatanib and control drug buparvaquone exhibited therapeutic indexes $>2000$. An index $>5$ has been used to determine parasite selectivity of MMV compounds (reviewed in Duffy, Sykes et al. 2017). These compounds with therapeutic indexes > 5 present lead starting point compounds for the development of new anti-theilerial drugs. Although the majority of the malaria and pathogen box compounds inhibiting TpM were also highly active on inhibiting the control cell line, they 
have been found to be less toxic in other cells such as zebrafish, HEK293 etc (Duffy, Sykes et al. 2017). However, the low therapeutic indexes <5, raises questions on the role of these compounds as anti-theilerial drugs. Interestingly, four pathogen box compounds were inhibitory on the control cell line, than on F100TpM, indicating that there could be differences in the molecular and cellular biology of the two cell lines.

The lead malaria box compound, MMV008212, has been tested against other parasites and has activities against Trypanosoma cruzi $(100 \%$ growth inhibition at $5 \mu \mathrm{M})$, Plasmodium berghei ookinete $(76 \%$ growth inhibition at $10 \mu \mathrm{M}), P$. falciparum gametocyte NF54-late stage (91\% growth inhibition at $5 \mu \mathrm{M}$ ) and $P$. falciparum 3D7 asexual blood stage (98\% growth inhibition at $5 \mu \mathrm{M}$ ) (reviewed in Van Voorhis, Adams et al. 2016). Cytotoxicity of this compound was observed only in one cell line (U87, 76\% cell death at $5 \mu \mathrm{M}$ ) of the nine cell lines tested (Van Voorhis, Adams et al. 2016). However, its mode of action is still unknown. MV688372, pathogen box compound with the high therapeutic index against F100TpM cells has anti-trypanosomal activity. This compound is a substituted 2-phenylimidazopyridine with activities against Trypanosoma brucei brucei and T. cruzi with therapeutic indexes of 230 and 24, respectively, in relation to HEK293 cells (Duffy, Sykes et al. 2017). The mode of action of MMV688372 is still unclear, but a structurally related azabenzoxazole has been identified as a proteasome inhibitor in kinetoplastid parasites (Duffy, Sykes et al. 2017). Dasatinib, which exhibited very potent inhibitory activity on F100TpM cells is a commercial drug approved and indicated for chronic myelogenous leukemia and acute lymphoblastic leukemia (Talpaz, Shah et al. 2006, Steinberg 2007). It is being considered for treatment of other cancers (Finn, Dering et al. 2007, Hochhaus, Baccarani et al. 2008, Johnson, Bekele et al. 2010)

Comparing the screening results of the malaria box in T. annulata (Hostettler, Müller et al. 2016) to T. parva revealed only one common inhibitory compound, MMV665820 in both parasites. However, in both cases the compound was eliminated as a lead, in T. parva we eliminated it for low therapeutic index while in $T$. annulata it was eliminated for not specifically targeting the parasite (Hostettler, Müller et al. 2016). The rest of T. parva inhibitory compounds were not leads in $T$. annulata screens and vice versa, illustrating the difficulty of developing a universal anti-theilerial drug. The pathogen box compound, MMV688372 and dasatanib, which are inhibitory to T. parva infected cells and have high therapeutic indexes, should be tested in T. annulata.

\section{Recommendations for future research}

The major sporozoite antigen, p67 has been the focus and lead antigen for the development of a subunit vaccine against ECF since the 1980s. Although considerable progress has been made with this antigen, it is becoming clear that this single antigen may not be able to provide sufficient protection. To provide a denser map of sporozoite antigens, we defined the sporozoite proteome by mass spectrometry and identified novel parasite antigens. We recommend screening some of these antigens for production of anti-sporozoite neutralizing antibodies. Priority should be given to antigens that have been tested in related organisms as vaccine antigens and found to induce protective antibodies such as CelTOs and AMA-1 (Table 2, Chapter 2) and novel putative surface proteins (Table 4, Chapter 2) which we have not tested. Although desirable to test these antigens directly in cattle, it might be cost -effective to eliminate antigens producing non-neutralizing antibodies by a preliminary murine study as described in this thesis.

We have provided preliminary evidence that some of the antigens we selected and expressed recombinantly generates sporozoite neutralizing antibodies. However, following findings in which rats produced sporozoite neutralizing antibodies but cattle did not against certain recombinant antigens, we recommend evaluation of these antigens in cattle, in combination with p67 antigen to assess the nature of protection conferred by such a multivalent 
vaccine. Since we tested gene fragments but not the whole protein, it is tempting to speculate that antisera to full length proteins of the four promising antigens would produce higher neutralizing activities because of the longer sequence with putative additional epitopes. Therefore, it is desirable to test the full length recombinant proteins for immunogenicity. However, since E. coli expression of long proteins is usually accompanied by solubility and expression problems of the recombinant proteins, we recommend other expression systems such as the baculovirus expression system in insect cells or the yeast Pichia pastoris or mammalian cells for full length expressions (Tebaldi, Williams et al. 2017). Alternatively, several shorter fragments comprising the full protein can be expressed, combined and evaluated.

In Chapter 3, we have reported on known tick vaccine antigens identification and several tick proteins associated with host immune modulation. However, for anti-sporozoite vaccines, it is necessary to identify the specific tick proteins bound on the sporozoite surface, which was not possible from the purification method described in this thesis. We recommend additional purification step, involving staining the sporozoites by monoclonal antibodies against surface protein, such as p67, followed by FACS analysis and sorting. Such a purer sample would reveal the specific tick proteins associated with the sporozoites.

Finally, on vaccine development, the finding of CD8 T-cell antigens in the sporozoite proteome suggests a possibility of cross-presentation of exogenous antigens by dendritic cells to prime CTL responses in vivo. By taking advantage of this process, future vaccines could be a combination of sporozoite antigens such as p67 and/or the ones identified in this study and schizont antigens, especially $\mathrm{Tp} 1$ and $\mathrm{Tp} 2$ since they have been found to be dominant targets of the CD8+ T-cell response in cattle expressing the A18 and A10 class I MHC haplotypes, respectively (Pelle, Graham et al. 2011). Such a combination vaccine might provide an improved protection by inducing both humoral and cellular responses.

The drug compounds identified in this thesis (Chapter 5), via in vitro assays represent lead compounds that could act as starting points for the development of drugs against T. parva and possibly $T$. annulata. Although we have observed inhibition of growth of $T$. parva infected lymphoblasts, we did not test the effect of these compounds on the parasite directly. We recommend such tests as they could reveal the modes of action of these compounds and rule out the possibility that the observed inhibition is based on other differences between the test and control cells other than infection by the parasite. Such a test can be achieved for example, by measuring the transcription levels of parasite genes in the course of drug administration in relation to host genes by quantitative reverse transcriptase PCR.

Whereas the malaria box compounds have been screened in $T$. annulata, the pathogen box compounds have not been screened for activity against this parasite. We recommend screening of the pathogen box compounds in T. annulata especially the compounds found to be active in T. parva as that could lead to discovery of a lead anti-theilerial compound. The cancer drug, dasatinib was as effective as the standard anti-Theileria drug buparvaquone in in vitro assays described in Chapter 5. This drug should be screened in $T$. annulata as well and should be evaluated in cattle for control of ECF. 


\section{References}

Abdelhaleem, M. (2004). "Do human RNA helicases have a role in cancer?" Biochimica et Biophysica Acta (BBA) - Reviews on Cancer 1704(1): 37-46.

Aurrecoechea, C., J. Brestelli, B. P. Brunk, S. Fischer, B. Gajria, X. Gao, A. Gingle, G. Grant, O. S. Harb, M. Heiges, F. Innamorato, J. Iodice, J. C. Kissinger, E. T. Kraemer, W. Li, J. A. Miller, V. Nayak, C. Pennington, D. F. Pinney, D. S. Roos, C. Ross, G. Srinivasamoorthy, J. C. J. Stoeckert, R. Thibodeau, C. Treatman and H. Wang (2010). "EuPathDB: a portal to eukaryotic pathogen databases." Nucleic Acids Research 38(suppl_1): D415-D419.

Babo Martins, S., G. Di Giulio, G. Lynen, A. Peters and J. Rushton (2010). "Assessing the impact of East Coast Fever immunisation by the infection and treatment method in Tanzanian pastoralist systems." Preventive Veterinary Medicine 97(3-4): 175-182.

Baldwin, C. L., S. J. Black, W. C. Brown, P. A. Conrad, B. M. Goddeeris, S. W. Kinuthia, P. A. Lalor, N. D. MacHugh, W. I. Morrison and S. P. Morzaria (1988). "Bovine T cells, B cells, and null cells are transformed by the protozoan parasite Theileria parva." Infection and Immunity 56(2): 462-467.

Ballingall, K. T., D. M. Mwangi, N. D. MacHugh, E. L. N. Taracha, P. Totte and D. J. McKeever (2000). "A highly sensitive, non-radioactive assay for T cell activation in cattle: applications in screening for antigens recognised by CD4+ and CD8+ T cells." Journal of Immunological Methods 239(1-2): 85-93.

Beaufays, J., B. Adam, C. Menten-Dedoyart, L. Fievez, A. Grosjean, Y. Decrem, P. P. Prevot, S. Santini, R. Brasseur, M. Brossard, M. Vanhaeverbeek, F. Bureau, E. Heinen, L. Lins, L. Vanhamme and E. Godfroid (2008). "Ir-LBP, an ixodes ricinus tick salivary LTB4-binding lipocalin, interferes with host neutrophil function." PLoS One 3(12): e3987.

Birth, D., W. C. Kao and C. Hunte (2014). "Structural analysis of atovaquone-inhibited cytochrome bc1 complex reveals the molecular basis of antimalarial drug action." Nat Commun 5: 4029.

Bishop, R., B. Lambson, C. Wells, P. Pandit, J. Osaso, C. Nkonge, S. Morzaria, A. Musoke and V. Nene (2002). "A cement protein of the tick Rhipicephalusappendiculatus, located in the secretory e cell granules of the type III salivary gland acini, induces strong antibody responses in cattle." International Journal for Parasitology 32(7): 833-842.

Bishop, R., V. Nene, J. Staeyert, J. Rowlands, J. Nyanjui, J. Osaso, S. Morzaria and A. Musoke (2003). "Immunity to East Coast fever in cattle induced by a polypeptide fragment of the major surface coat protein of Theileria parva sporozoites." Vaccine 21(11-12): 1205-1212. 
Brown, C. G. (1990). "Control of tropical theileriosis (Theileria annulata infection) of cattle." Parassitologia 32(1): 23-31.

Brown, W. C., T. F. McElwain, G. H. Palmer, S. E. Chantler and D. M. Estes (1999). "Bovine CD4+ T-Lymphocyte Clones Specific for Rhoptry-Associated Protein 1 of Babesia bigemina Stimulate Enhanced Immunoglobulin G1 (IgG1) and IgG2 Synthesis." Infection and Immunity 67(1): 155-164.

Brown, W. C., M. K. Shaw, P. A. Conrad and T. T. Dolan (1989). "Theileria parva: reappearance of schizonts in infected lymphoblastoid cells treated with parvaquone is dependent on interleukin 2-like growth factors." Exp Parasitol 68(3): 308-325.

Brown, W. C., C. Sugimoto and D. J. Grab (1989). "Theileria parva: Bovine helper T cell clones specific for both infected lymphocytes and schizont membrane antigens." Experimental Parasitology 69(2): 234-248.

Brown, W. C., S. Zhao, K. S. Logan, D. J. Grab and A. C. Rice-Ficht (1995). "Identification of candidate vaccine antigens of bovine hemoparasites Theileria parva and Babesia bovis by use of helper T cell clones." Vet Parasitol 57(1-3): 189-203.

Budu, A. and C. R. S. Garcia (2012). "Generation of second messengers in Plasmodium." Microbes and Infection 14(10): 787-795.

Büscher, G. and J. Tangus (1986). "Quantitative studies on Theileria parva in the salivary glands of Rhipicephalus appendiculatus adults: Search for conditions for high infections." International Journal for Parasitology 16(2): 121-129.

Cao, J., O. Kaneko, A. Thongkukiatkul, M. Tachibana, H. Otsuki, Q. Gao, T. Tsuboi and M. Torii (2009). "Rhoptry neck protein RON2 forms a complex with microneme protein AMA1 in Plasmodium falciparum merozoites." Parasitology International 58(1): 29-35.

Chen, Z., F. Y. Lee, K. N. Bhalla and J. Wu (2006). "Potent inhibition of platelet-derived growth factor-induced responses in vascular smooth muscle cells by BMS-354825 (dasatinib)." Mol Pharmacol 69(5): 1527-1533.

Cingolani, P., A. Platts, L. L. Wang, M. Coon, T. Nguyen, L. Wang, S. J. Land, X. Lu and D. M. Ruden (2012). "A program for annotating and predicting the effects of single nucleotide polymorphisms, SnpEff: SNPs in the genome of Drosophila melanogaster strain w1118; iso-2; iso-3." Fly 6(2): 80-92.

Cowman, A. F. and B. S. Crabb (2006). "Invasion of Red Blood Cells by Malaria Parasites." Cell 124(4): 755-766. 
Crane, M. S., P. K. Murray, M. J. Gnozzio and T. T. MacDonald (1988). "Passive protection of chickens against Eimeria tenella infection by monoclonal antibody." Infection and Immunity 56(4): 972-976.

Cruz, F. M., J. D. Colbert, E. Merino, B. A. Kriegsman and K. L. Rock (2017). "The Biology and Underlying Mechanisms of Cross-Presentation of Exogenous Antigens on MHC-I Molecules." Annual Review of Immunology 35(1): 149-176.

Cui, L., S. Mharakurwa, D. Ndiaye, P. K. Rathod and P. J. Rosenthal (2015). "Antimalarial Drug Resistance: Literature Review and Activities and Findings of the ICEMR Network." The American Journal of Tropical Medicine and Hygiene 93(3_Suppl): 57-68.

Cupp, E. W. (1991). "Biology of Ticks." Veterinary Clinics of North America: Small Animal Practice 21(1): 1-26.

Curtidor, H., L. C. Patiño, G. Arévalo-Pinzón, M. E. Patarroyo and M. A. Patarroyo (2011). "Identification of the Plasmodium falciparum rhoptry neck protein 5 (PfRON5)." Gene 474(12): 22-28.

Daban, J.-R., S. Bartolomé and A. Bermúdez (1996). Rapid Staining of Proteins in Polyacrylamide Gels with Nile Red. The Protein Protocols Handbook. J. M. Walker. Totowa, NJ, Humana Press: 179-185.

Dalmo, R. A. (2018). "DNA vaccines for fish: Review and perspectives on correlates of protection." Journal of Fish Diseases 41(1): 1-9.

De Deken, R., V. Martin, A. Saido, M. Madder, J. Brandt and D. Geysen (2007). "An outbreak of East Coast Fever on the Comoros: A consequence of the import of immunised cattle from Tanzania?" Veterinary Parasitology 143(3): 245-253.

Decrem, Y., J. Beaufays, V. Blasioli, K. Lahaye, M. Brossard, L. Vanhamme and E. Godfroid (2008). "A family of putative metalloproteases in the salivary glands of the tick Ixodes ricinus." Febs j 275(7): 1485-1499.

Delorenzi, M., A. Sexton, H. Shams-Eldin, R. T. Schwarz, T. Speed and L. Schofield (2002). "Genes for Glycosylphosphatidylinositol Toxin Biosynthesis in Plasmodium falciparum." Infection and Immunity 70(8): 4510-4522.

Dessauge, F., R. Lizundia, M. Baumgartner, M. Chaussepied and G. Langsley (2005). "Taking the Myc is bad for Theileria." Trends in Parasitology 21(8): 377-385. 
Di Giulio, G., G. Lynen, S. Morzaria, C. Oura and R. Bishop (2009). "Live immunization against East Coast fever - current status." Trends in Parasitology 25(2): 85-92.

Dobbelaere, D. and V. Heussler (1999). "Transformation of Leukocytes by Theileria parva and T. annulata." Annual Review of Microbiology 53(1): 1-42.

Dobbelaere, D., S. Z. Shapiro and P. Webster (1985). "Identification of a surface antigen on Theileria parva sporozoites by monoclonal antibody." Proceedings of the National Academy of Sciences 82(6): 1771-1775.

Dobbelaere, D. A. E. and P. Küenzi (2004). "The strategies of the Theileria parasite: a new twist in host-pathogen interactions." Current Opinion in Immunology 16(4): 524-530.

Dobbelaere, D. A. E., I. J. Roditi, T. s. M. Coquerelle, C. Kelke, M. Eichhorn and R. O. Williams (1991). "Lymphocytes infected with Theileria parva require both cell-cell contact and growth factor to proliferate." European Journal of Immunology 21(1): 89-95.

Dobbelaere, D. A. E., P. R. Spooner, W. C. Barry and A. D. Irvin (1984). "Monoclonal antibody neutralizes the sporozoite stage of different Theileria parva stocks." Parasite Immunology 6(4): 361-370.

Duffy, S., M. L. Sykes, A. J. Jones, T. B. Shelper, M. Simpson, R. Lang, S.-A. Poulsen, B. E. Sleebs and V. M. Avery (2017). "Screening the Medicines for Malaria Venture Pathogen Box across Multiple Pathogens Reclassifies Starting Points for Open-Source Drug Discovery." Antimicrobial Agents and Chemotherapy 61(9).

Dvorin, J. D., D. C. Martyn, S. D. Patel, J. S. Grimley, C. R. Collins, C. S. Hopp, A. T. Bright, S. Westenberger, E. Winzeler, M. J. Blackman, D. A. Baker, T. J. Wandless and M. T. Duraisingh (2010). "A Plant-Like Kinase in Plasmodium falciparum Regulates Parasite Egress from Erythrocytes." Science 328(5980): 910-912.

Ebel, T., J. Gerhards, B. R. Binder and J. Lipp (1999). "Theileria parva 104 kDa micronemerhoptry protein is membrane-anchored by a non-cleaved amino-terminal signal sequence for entry into the endoplasmic reticulum." Molecular and Biochemical Parasitology 100(1): 19-26.

Emanuelsson, O., H. Nielsen, S. Brunak and G. von Heijne (2000). "Predicting Subcellular Localization of Proteins Based on their N-terminal Amino Acid Sequence." Journal of Molecular Biology 300(4): 1005-1016.

Emery, D. L. (1981). "Adoptive transfer of immunity to infection with Theileria parva (East Coast fever) between cattle twins." Research in Veterinary Science 30(3): 364-367. 
Fankhauser, N. and P. Mäser (2005). "Identification of GPI anchor attachment signals by a Kohonen self-organizing map." Bioinformatics 21(9): 1846-1852.

Fawcett, D. W., G. Büscher and S. Doxsey (1982). "Salivary gland of the tick vector of east coast fever. IV. Cell type selectivity and host cell responses to Theileria parva." Tissue and Cell 14(2): 397-414.

Fawcett, D. W., S. Doxsey, D. A. Stagg and A. S. Young (1982b). "The entry of sporozoites of Theileria parva into bovine lymphocytes in vitro. Electron microscopic observations." European journal of cell biology 27(1): 10-21.

Fenner, F. (2000). "Adventures with poxviruses of vertebrates." FEMS Microbiology Reviews 24(2): 123-133.

Ferguson, M. A. (1999). "The structure, biosynthesis and functions of glycosylphosphatidylinositol anchors, and the contributions of trypanosome research." Journal of Cell Science 112(17): 2799-2809.

Ferguson MAJ, K. T., Hart GW (2009). Essentials of Glycobiology. Cold Spring Harbor (NY), Cold Spring Harbor Laboratory Press.

Finn, R. S., J. Dering, C. Ginther, C. A. Wilson, P. Glaspy, N. Tchekmedyian and D. J. Slamon (2007). "Dasatinib, an orally active small molecule inhibitor of both the src and abl kinases, selectively inhibits growth of basal-type/"triple-negative" breast cancer cell lines growing in vitro." Breast Cancer Research and Treatment 105(3): 319-326.

Florens, L., M. P. Washburn, J. D. Raine, R. M. Anthony, M. Grainger, J. D. Haynes, J. K. Moch, N. Muster, J. B. Sacci, D. L. Tabb, A. A. Witney, D. Wolters, Y. Wu, M. J. Gardner, A. A. Holder, R. E. Sinden, J. R. Yates and D. J. Carucci (2002). "A proteomic view of the Plasmodium falciparum life cycle." Nature 419(6906): 520-526.

Francischetti, I. M. B., V. My Pham, B. J. Mans, J. F. Andersen, T. N. Mather, R. S. Lane and J. M. C. Ribeiro (2005). "The transcriptome of the salivary glands of the female western blacklegged tick Ixodes pacificus (Acari: Ixodidae)." Insect Biochemistry and Molecular Biology 35(10): 1142-1161.

Gachet, C. (2008). "P2 receptors, platelet function and pharmacological implications." Thromb Haemost 99(3): 466-472.

Gardner, M. J., R. Bishop, T. Shah, E. P. de Villiers, J. M. Carlton, N. Hall, Q. Ren, I. T. Paulsen, A. Pain, M. Berriman, R. J. M. Wilson, S. Sato, S. A. Ralph, D. J. Mann, Z. Xiong, S. J. Shallom, J. Weidman, L. Jiang, J. Lynn, B. Weaver, A. Shoaibi, A. R. Domingo, D. Wasawo, J. Crabtree, J. R. Wortman, B. Haas, S. V. Angiuoli, T. H. Creasy, C. Lu, B. Suh, J. C. Silva, 
T. R. Utterback, T. V. Feldblyum, M. Pertea, J. Allen, W. C. Nierman, E. L. N. Taracha, S. L. Salzberg, O. R. White, H. A. Fitzhugh, S. Morzaria, J. C. Venter, C. M. Fraser and V. Nene (2005). "Genome Sequence of Theileria parva, a Bovine Pathogen That Transforms Lymphocytes." Science 309(5731): 134-137.

Garrison, E. and G. Marth (2012). "Haplotype-based variant detection from short-read sequencing." arXiv preprint arXiv:1207.3907.

Geysen, D., T. Bazarusanga, J. Brandt and T. T. Dolan (2004). "An unusual mosaic structure of the PIM gene of Theileria parva and its relationship to allelic diversity." Molecular and Biochemical Parasitology 133(2): 163-173.

Gilson, P. R., T. Nebl, D. Vukcevic, R. L. Moritz, T. Sargeant, T. P. Speed, L. Schofield and B. S. Crabb (2006). "Identification and Stoichiometry of Glycosylphosphatidylinositolanchored Membrane Proteins of the Human Malaria Parasite Plasmodium falciparum." Molecular \& Cellular Proteomics 5(7): 1286-1299.

Graham, S. P., Y. Honda, R. Pellé, D. M. Mwangi, E. J. Glew, E. P. de Villiers, T. Shah, R. Bishop, P. van der Bruggen, V. Nene and E. L. N. Taracha (2007). "A novel strategy for the identification of antigens that are recognised by bovine MHC class I restricted cytotoxic T cells in a protozoan infection using reverse vaccinology." Immunome Research 3: 2-2.

Graham, S. P., R. Pelle, Y. Honda, D. M. Mwangi, N. J. Tonukari, M. Yamage, E. J. Glew, E. P. de Villiers, T. Shah, R. Bishop, E. Abuya, E. Awino, J. Gachanja, A. E. Luyai, F. Mbwika, A. M. Muthiani, D. M. Ndegwa, M. Njahira, J. K. Nyanjui, F. O. Onono, J. Osaso, R. M. Saya, C. Wildmann, C. M. Fraser, I. Maudlin, M. J. Gardner, S. P. Morzaria, S. Loosmore, S. C. Gilbert, J. C. Audonnet, P. van der Bruggen, V. Nene and E. L. Taracha (2006). "Theileria parva candidate vaccine antigens recognized by immune bovine cytotoxic T lymphocytes." Proc Natl Acad Sci U S A 103(9): 3286-3291.

Graham, S. P., R. Pellé, M. Yamage, D. M. Mwangi, Y. Honda, R. S. Mwakubambanya, E. P. de Villiers, E. Abuya, E. Awino, J. Gachanja, F. Mbwika, A. M. Muthiani, C. Muriuki, J. K. Nyanjui, F. O. Onono, J. Osaso, V. Riitho, R. M. Saya, S. A. Ellis, D. J. McKeever, N. D. MacHugh, S. C. Gilbert, J.-C. Audonnet, W. I. Morrison, P. van der Bruggen and E. L. N. Taracha (2008). "Characterization of the Fine Specificity of Bovine CD8 T-Cell Responses to Defined Antigens from the Protozoan Parasite Theileria parva." Infection and Immunity 76(2): 685-694.

Hall, R., N. R. Boulter, C. G. Brown, G. Wilkie, E. Kirvar, V. Nene, A. J. Musoke, E. J. Glass and S. P. Morzaria (2000). "Reciprocal cross-protection induced by sporozoite antigens SPAG1 from Theileria annulata and p67 from Theileria parva." Parasite Immunology 22(5): 223-230.

Han, X., A. Aslanian and J. R. Yates (2008). "Mass spectrometry for proteomics." Current Opinion in Chemical Biology 12(5): 483-490. 
Hansson, M., P.-A. k. Nygren and S. Sta ${ }^{\circ}$ hl (2000). "Design and production of recombinant subunit vaccines." Biotechnology and Applied Biochemistry 32(2): 95-107.

Hashemi-Fesharki, R. (1991). "Chemotherapeutic value of parvaquone and buparvaquone against Theileria annulata infection of cattle." Research in Veterinary Science 50(2): 204-207.

Havlíková, S., L. Roller, J. Koči, A. R. Trimnell, M. Kazimírová, B. Klempa and P. A. Nuttall (2009). "Functional role of 64P, the candidate transmission-blocking vaccine antigen from the tick, Rhipicephalus appendiculatus." International Journal for Parasitology 39(13): 1485-1494.

Hayashida, K., T. Abe, W. Weir, R. Nakao, K. Ito, K. Kajino, Y. Suzuki, F. Jongejan, D. Geysen and C. Sugimoto (2013). "Whole-genome sequencing of Theileria parva strains provides insight into parasite migration and diversification in the African continent." DNA Res 20(3): 209-220.

Hayashida, K., Y. Hara, T. Abe, C. Yamasaki, A. Toyoda, T. Kosuge, Y. Suzuki, Y. Sato, S. Kawashima, T. Katayama, H. Wakaguri, N. Inoue, K. Homma, M. Tada-Umezaki, Y. Yagi, Y. Fujii, T. Habara, M. Kanehisa, H. Watanabe, K. Ito, T. Gojobori, H. Sugawara, T. Imanishi, W. Weir, M. Gardner, A. Pain, B. Shiels, M. Hattori, V. Nene and C. Sugimoto (2012). "Comparative Genome Analysis of Three Eukaryotic Parasites with Differing Abilities To Transform Leukocytes Reveals Key Mediators of Theileria-Induced Leukocyte Transformation." $\underline{\text { mBio } 3(5) .}$

Hayashida, K., M. Hattori, R. Nakao, Y. Tanaka, J.-Y. Kim, N. Inoue, V. Nene and C. Sugimoto (2010). "A schizont-derived protein, TpSCOP, is involved in the activation of NF$\kappa \mathrm{B}$ in Theileria parva-infected lymphocytes." Molecular and Biochemical Parasitology 174(1): 8-17.

Hochhaus, A., M. Baccarani, M. Deininger, J. F. Apperley, J. H. Lipton, S. L. Goldberg, S. Corm, N. P. Shah, F. Cervantes, R. T. Silver, D. Niederwieser, R. M. Stone, H. Dombret, R. A. Larson, L. Roy, T. Hughes, M. C. Müller, R. Ezzeddine, A. M. Countouriotis and H. M. Kantarjian (2008). "Dasatinib induces durable cytogenetic responses in patients with chronic myelogenous leukemia in chronic phase with resistance or intolerance to imatinib." Leukemia 22: 1200 .

Holder, A. A., M. A. Mohd Ridzuan and J. L. Green (2012). "Calcium dependent protein kinase 1 and calcium fluxes in the malaria parasite." Microbes and Infection 14(10): 825-830.

Hostettler, I., J. Müller and A. Hemphill (2016). "In vitro screening of the open source MMV malaria box reveals novel compounds with profound activities against Theileria annulata schizonts." Antimicrobial Agents and Chemotherapy. 
Huber, S., R. Theiler, D. de Quervain, O. Wiens, T. Karangenc, V. Heussler, D. Dobbelaere and K. Woods (2017). "The Microtubule-Stabilizing Protein CLASP1 Associates with the $<e m>$ Theileria annulata</em $>$ Schizont Surface via Its Kinetochore-Binding Domain." mSphere 2(4).

Hulliger, L., K. H. Wilde, C. G. Brown and L. Turner (1964). "MODE OF MULTIPLICATION OF THEILERIA IN CULTURES OF BOVINE LYMPHOCYTIC CELLS." Nature 203: 728730 .

Iams, K. P., J. R. Young, V. Nene, J. Desai, P. Webster, O. K. ole-MoiYoi and A. J. Musoke (1990). "Characterisation of the gene encoding a 104-kilodalton micronemerhoptry protein of Theileria parva." Molecular and Biochemical Parasitology 39(1): 47-60.

Ikezawa, H. (2002). "Glycosylphosphatidylinositol (GPI)-Anchored Proteins." Biological and Pharmaceutical Bulletin 25(4): 409-417.

Imamura, S., S. Konnai, S. Vaz Ida, S. Yamada, C. Nakajima, Y. Ito, T. Tajima, J. Yasuda, M. Simuunza, M. Onuma and K. Ohashi (2008). "Effects of anti-tick cocktail vaccine against Rhipicephalus appendiculatus." Jpn J Vet Res 56(2): 85-98.

Imamura, S., B. Namangala, T. Tajima, M. E. Tembo, J. Yasuda, K. Ohashi and M. Onuma (2006). "Two serine protease inhibitors (serpins) that induce a bovine protective immune response against Rhipicephalus appendiculatus ticks." Vaccine 24(13): 2230-2237.

Irvin, A. D. and W. I. Morrison (1987). Immunopathology, immunology, and immunoprophylaxis of Theileria infections. Boca Raton, Florida, CRC Press, Inc.: 223-274.

Ishihama, Y., Y. Oda, T. Tabata, T. Sato, T. Nagasu, J. Rappsilber and M. Mann (2005). "Exponentially Modified Protein Abundance Index (emPAI) for Estimation of Absolute Protein Amount in Proteomics by the Number of Sequenced Peptides per Protein." Molecular \& Cellular Proteomics 4(9): 1265-1272.

Jaworski, D. C., F. A. Simmen, W. Lamoreaux, L. B. Coons, M. T. Muller and G. R. Needham (1995). "A secreted calreticulin protein in ixodid tick (Amblyomma americanum) saliva." Journal of Insect Physiology 41(4): 369-375.

Jeon, K. I., M. S. Byun and D. M. Jue (2003). "Gold compound auranofin inhibits IkappaB kinase (IKK) by modifying Cys-179 of IKKbeta subunit." Exp Mol Med 35(2): 61-66.

Johnson, F. M., B. N. Bekele, L. Feng, I. Wistuba, X. M. Tang, H. T. Tran, J. J. Erasmus, L.L. Hwang, N. Takebe, G. R. Blumenschein, S. M. Lippman and D. J. Stewart (2010). "Phase II Study of Dasatinib in Patients With Advanced Non-Small-Cell Lung Cancer." Journal of Clinical Oncology 28(30): 4609-4615. 
Jones, M. L., E. L. Kitson and J. C. Rayner (2006). "Plasmodium falciparum erythrocyte invasion: A conserved myosin associated complex." Molecular and Biochemical Parasitology 147(1): 74-84.

Kaba, S. A. (2003). Development of a novel subunit vaccine against East Coast fever based on the Theileria parva sporozoite surface protein $\mathrm{p} 67$.

Kariu, T., T. Ishino, K. Yano, Y. Chinzei and M. Yuda (2006). "CelTOS, a novel malarial protein that mediates transmission to mosquito and vertebrate hosts." Molecular Microbiology 59(5): 1369-1379.

Kariuki, D. P., A. S. Young, S. P. Morzaria, A. C. Lesan, S. K. Mining, P. Omwoyo, J. L. Wafula and D. H. Molyneux (1995). "Theileria parva carrier state in naturally infected and artificially immunised cattle." Trop Anim Health Prod 27(1): 15-25.

Khan, S. M., B. Franke-Fayard, G. R. Mair, E. Lasonder, C. J. Janse, M. Mann and A. P. Waters (2005). "Proteome Analysis of Separated Male and Female Gametocytes Reveals Novel SexSpecific Plasmodium Biology." Cell 121(5): 675-687.

Krogh, A., B. Larsson, G. von Heijne and E. L. L. Sonnhammer (2001). "Predicting transmembrane protein topology with a hidden markov model: application to complete genomes1." Journal of Molecular Biology 305(3): 567-580.

Kumar, K. A., G. A. Oliveira, R. Edelman, E. Nardin and V. Nussenzweig (2004). "Quantitative Plasmodium sporozoite neutralization assay (TSNA)." Journal of Immunological Methods 292(1): 157-164.

Lancet (2015). "Efficacy and safety of RTS,S/AS01 malaria vaccine with or without a booster dose in infants and children in Africa: final results of a phase 3, individually randomised, controlled trial." Lancet 386(9988): 31-45.

Lasonder, E., C. J. Janse, G.-J. van Gemert, G. R. Mair, A. M. W. Vermunt, B. G. Douradinha, V. van Noort, M. A. Huynen, A. J. F. Luty, H. Kroeze, S. M. Khan, R. W. Sauerwein, A. P. Waters, M. Mann and H. G. Stunnenberg (2008). "Proteomic Profiling of <italic>Plasmodium</italic> Sporozoite Maturation Identifies New Proteins Essential for Parasite Development and Infectivity." PLoS Pathog 4(10): e1000195.

Latif, A. A. and T. Hove (2011). "History and critical review of Theileria parva (Boleni), the vaccine stock against Zimbabwean cattle theileriosis." Ticks and Tick-borne Diseases 2(3): 163-167.

Lauterbach, S. B. and T. L. Coetzer (2008). "The M18 aspartyl aminopeptidase of Plasmodium falciparum binds to human erythrocyte spectrin in vitro." Malaria Journal 7: 1-10. 
Lawrence, J. A. (1979). "The differential diagnosis of the bovine theilerias of southern Africa." Journal of the South African Veterinary Association 50(4): 311-313.

Li, L., C. J. Stoeckert and D. S. Roos (2003). "OrthoMCL: Identification of Ortholog Groups for Eukaryotic Genomes." Genome Research 13(9): 2178-2189.

Liljeqvist, S. and S. Ståhl (1999). "Production of recombinant subunit vaccines: protein immunogens, live delivery systems and nucleic acid vaccines." Journal of Biotechnology 73(1): 1-33.

Lindner, S. E., K. E. Swearingen, A. Harupa, A. M. Vaughan, P. Sinnis, R. L. Moritz and S. H. Kappe (2013). "Total and putative surface proteomics of malaria parasite salivary gland sporozoites." Mol Cell Proteomics 12(5): 1127-1143.

Marsolier, J., M. Perichon, J. D. DeBarry, B. O. Villoutreix, J. Chluba, T. Lopez, C. Garrido, X. Z. Zhou, K. P. Lu, L. Fritsch, S. Ait-Si-Ali, M. Mhadhbi, S. Medjkane and J. B. Weitzman (2015). "Theileria parasites secrete a prolyl isomerase to maintain host leukocyte transformation." Nature 520(7547): 378-382.

Marsolier, J., M. Perichon, J. D. DeBarry, B. O. Villoutreix, J. Chluba, T. Lopez, C. Garrido, X. Z. Zhou, K. P. Lu, L. Fritsch, S. Ait-Si-Ali, M. Mhadhbi, S. Medjkane and J. B. Weitzman (2015). "Theileria parasites secrete a prolyl isomerase to maintain host leukocyte transformation." Nature 520: 378.

Matson, B. A. (1967). "Theileriosis in Rhodesia: 1. A study of diagnostic specimens over two seasons." Journal of the South African Veterinary Association 38(1): 93-102.

Mbizeni, S., F. T. Potgieter, C. Troskie, B. J. Mans, B. L. Penzhorn and A. A. Latif (2013). "Field and laboratory studies on Corridor disease (Theileria parva infection) in cattle population at the livestock/game interface of uPhongolo-Mkuze area, South Africa." Ticks and Tick-borne Diseases 4(3): 227-234.

McHardy, N., L. S. Wekesa, A. T. Hudson and A. W. Randall (1985). "Antitheilerial activity of BW720C (buparvaquone): a comparison with parvaquone." Research in Veterinary Science 39(1): 29-33.

McKeever, D. J., E. L. Taracha, E. L. Innes, N. D. MacHugh, E. Awino, B. M. Goddeeris and W. I. Morrison (1994). "Adoptive transfer of immunity to Theileria parva in the CD8+ fraction of responding efferent lymph." Proceedings of the National Academy of Sciences 91.

McLeod, A. and R. Kristjanson (1999). "Impact of ticks and associated diseases on cattle in Asia, Australia and Africa. ILRI and eSYS report to ACIAR." 
Mhadhbi, M., M. Chaouch, K. Ajroud, M. A. Darghouth and S. BenAbderrazak (2015). "Sequence Polymorphism of Cytochrome b Gene in Theileria annulata Tunisian Isolates and Its Association with Buparvaquone Treatment Failure." PLoS ONE 10(6): e0129678.

Mhadhbi, M., A. Naouach, A. Boumiza, M. F. Chaabani, S. BenAbderazzak and M. A. Darghouth (2010). "In vivo evidence for the resistance of Theileria annulata to buparvaquone." Veterinary Parasitology 169(3-4): 241-247.

Mogire, R. M., H. M. Akala, R. W. Macharia, D. W. Juma, A. C. Cheruiyot, B. Andagalu, M. L. Brown, H. A. El-Shemy and S. G. Nyanjom (2017). "Target-similarity search using Plasmodium falciparum proteome identifies approved drugs with anti-malarial activity and their possible targets." PLOS ONE 12(10): e0186364.

Morrison, W. I. (2009). "Progress towards understanding the immunobiology of Theileria parasites." Parasitology 136.

Morrison, W. I., T. Connelley, J. D. Hemmink and N. D. MacHugh (2015). "Understanding the basis of parasite strain-restricted immunity to Theileria parva." Annu Rev Anim Biosci 3: 397-418.

Morrison, W. I. and B. M. Goddeeris (1990). Cytotoxic T Cells in Immunity to Theileria parva in Cattle. T-Cell Paradigms in Parasitic and Bacterial Infections. S. H. E. Kaufmann. Berlin, Heidelberg, Springer Berlin Heidelberg: 79-93.

Morrison, W. I., N. D. MacHugh and P. A. Lalor (1996). "Pathogenicity of Theileria parva is influenced by the host cell type infected by the parasite." Infection and Immunity 64(2): 557562.

Morrison, W. I. and D. J. McKeever (2006). "Current status of vaccine development against Theileria parasites." Parasitology 133(S2): S169-S187.

Morrissette, N. S. and L. D. Sibley (2002). "Cytoskeleton of Apicomplexan Parasites." Microbiology and Molecular Biology Reviews 66(1): 21-38.

Morzaria, S., V. Nene, R. Bishop and A. Musoke (2000). "Vaccines against Theileria parva." Annals of the New York Academy of Sciences 916(1): 464-473.

Morzaria, S. P., J. Katende, A. Musoke, V. Nene, R. Skilton and R. Bishop (1999). "Development of sero-diagnostic and molecular tools for the control of important tick-borne pathogens of cattle in Africa." Parassitologia 41 Suppl 1: 73-80. 
Mulenga, A., C. Sugimoto and M. Onuma (2000). "Issues in tick vaccine development: identification and characterization of potential candidate vaccine antigens." Microbes and Infection 2(11): 1353-1361.

Musoke, A., S. Morzaria, C. Nkonge, E. Jones and V. Nene (1992). "A recombinant sporozoite surface antigen of Theileria parva induces protection in cattle." Proceedings of the National Academy of Sciences 89(2): 514-518.

Musoke, A. J., V. M. Nantulya, G. Buscher, R. A. Masake and B. Otim (1982). "Bovine immune response to Theileria parva: neutralizing antibodies to sporozoites." Immunology 45(4): 663-668.

Musoke, A. J., V. M. Nantulya, F. R. Rurangirwa and G. Buscher (1984). "Evidence for a common protective antigenic determinant on sporozoites of several Theileria parva strains." Immunology 52(2): 231-238.

Nam, S., A. Williams, A. Vultur, A. List, K. Bhalla, D. Smith, F. Y. Lee and R. Jove (2007). "Dasatinib (BMS-354825) inhibits Stat5 signaling associated with apoptosis in chronic myelogenous leukemia cells." Mol Cancer Ther 6(4): 1400-1405.

Nene, V., H. Kiara, A. Lacasta, R. Pelle, N. Svitek and L. Steinaa (2016). "The biology of Theileria parva and control of East Coast fever - Current status and future trends." Ticks and Tick-borne Diseases 7(4): 549-564.

Nene, V., D. Lee, S. Kang'a, R. Skilton, T. Shah, E. de Villiers, S. Mwaura, D. Taylor, J. Quackenbush and R. Bishop (2004). "Genes transcribed in the salivary glands of female Rhipicephalus appendiculatus ticks infected with Theileria parva." Insect Biochemistry and Molecular Biology 34(10): 1117-1128.

Nene, V. and W. I. Morrison (2016). "Approaches to vaccination against Theileria parva and Theileria annulata." Parasite Immunology 38(12): 724-734.

Nene, V., A. Musoke, E. Gobright and S. Morzaria (1996). "Conservation of the sporozoite p67 vaccine antigen in cattle-derived Theileria parva stocks with different cross-immunity profiles." Infection and Immunity 64(6): 2056-2061.

Nixon, G. L., D. M. Moss, A. E. Shone, D. G. Lalloo, N. Fisher, P. M. O'Neill, S. A. Ward and G. A. Biagini (2013). "Antimalarial pharmacology and therapeutics of atovaquone." Journal of Antimicrobial Chemotherapy 68(5): 977-985.

Norval, R. A. I., B. D. Perry and A. Young (1992). The epidemiology of theileriosis in Africa, Academic press, London. 
Nyagwange, J., E. Tijhaar, N. Ternette, F. Mobegi, K. Tretina, J. C. Silva, R. Pelle and V. Nene (2018). "Characterization of the Theileria parva sporozoite proteome." International Journal for Parasitology 48(3): 265-273.

O'Flaherty, J. T. and J. F. Cordes (1994). "Human neutrophil degranulation responses to nucleotides." Lab Invest 70(6): 816-821.

O. Salas, C., M. Faundez, A. Morello, J. Diego Maya and R. A. Tapia (2011). "Natural and Synthetic Naphthoquinones Active Against Trypanosoma Cruzi: An Initial Step Towards New Drugs for Chagas Disease." Current Medicinal Chemistry 18(1): 144-161.

Odongo, D. O., J. D. Sunter, H. K. Kiara, R. A. Skilton and R. P. Bishop (2010). "A nested PCR assay exhibits enhanced sensitivity for detection of Theileria parva infections in bovine blood samples from carrier animals." Parasitol Res 106(2): 357-365.

Oxberry, M. E., T. G. Gear and R. K. Prichard (2001). "Assessment of benzimidazole binding to individual recombinant tubulin isotypes from Haemonchus contortus." Parasitology $122(\mathrm{Pt}$ 6): 683-687.

Paesen, G. C., P. L. Adams, K. Harlos, P. A. Nuttall and D. I. Stuart (1999). "Tick histaminebinding proteins: isolation, cloning, and three-dimensional structure." Mol Cell 3(5): 661-671.

Pain, A., H. Renauld, M. Berriman, L. Murphy, C. A. Yeats, W. Weir, A. Kerhornou, M. Aslett, R. Bishop, C. Bouchier, M. Cochet, R. M. R. Coulson, A. Cronin, E. P. de Villiers, A. Fraser, N. Fosker, M. Gardner, A. Goble, S. Griffiths-Jones, D. E. Harris, F. Katzer, N. Larke, A. Lord, P. Maser, S. McKellar, P. Mooney, F. Morton, V. Nene, S. Neil, C. Price, M. A. Quail, E. Rabbinowitsch, N. D. Rawlings, S. Rutter, D. Saunders, K. Seeger, T. Shah, R. Squares, S. Squares, A. Tivey, A. R. Walker, J. Woodward, D. A. E. Dobbelaere, G. Langsley, M.-A. Rajandream, D. McKeever, B. Shiels, A. Tait, B. Barrell and N. Hall (2005). "Genome of the Host-Cell Transforming Parasite Theileria annulata Compared with T. parva." Science 309(5731): 131.

Palacios, R. (1982). "Concanavalin A triggers T lymphocytes by directly interacting with their receptors for activation." The Journal of Immunology 128(1): 337-342.

Parizi, L. F., N. W. Githaka, C. Logullo, S. Konnai, A. Masuda, K. Ohashi and I. da Silva Vaz (2012). "The quest for a universal vaccine against ticks: Cross-immunity insights." The Veterinary Journal 194(2): 158-165.

Patel, E., S. Mwaura, H. Kiara, S. Morzaria, A. Peters and P. Toye (2016). "Production and dose determination of the Infection and Treatment Method (ITM) Muguga cocktail vaccine used to control East Coast fever in cattle." Ticks and Tick-borne Diseases 7(2): 306-314. 
Pelle, R., S. P. Graham, M. N. Njahira, J. Osaso, R. M. Saya, D. O. Odongo, P. G. Toye, P. R. Spooner, A. J. Musoke, D. M. Mwangi, E. L. N. Taracha, W. I. Morrison, W. Weir, J. C. Silva and R. P. Bishop (2011). "Two Theileria parva CD8 T Cell Antigen Genes Are More Variable in Buffalo than Cattle Parasites, but Differ in Pattern of Sequence Diversity." PLOS ONE 6(4): e19015.

Perry, B. D. and A. S. Young (1993). "The naming game: the changing fortunes of East Coast fever and Theileria parva." Vet Rec 133(25-26): 613-616.

Perryman, L. E., M. W. Riggs, P. H. Mason and R. Fayer (1990). "Kinetics of Cryptosporidium parvum sporozoite neutralization by monoclonal antibodies, immune bovine serum, and immune bovine colostrum." Infection and Immunity 58(1): 257-259.

Petersen, T. N., S. Brunak, G. von Heijne and H. Nielsen (2011). "SignalP 4.0: discriminating signal peptides from transmembrane regions." Nature Methods 8(10): 785-786.

Pierleoni, A., P. L. Martelli and R. Casadio (2008). "PredGPI: a GPI-anchor predictor." BMC Bioinformatics 9(1): 392.

Pradel, G. (2007). "Proteins of the malaria parasite sexual stages: expression, function and potential for transmission blocking strategies." Parasitology 134(14): 1911-1929.

Quintas-Cardama, A., H. Kantarjian and J. Cortes (2006). "Targeting ABL and SRC kinases in chronic myeloid leukemia: experience with dasatinib." Future Oncol 2(6): 655-665.

Radley, D. E. (1981). Infection and Treatment Method of Immunization Against Theileriosis. Advances in the Control of Theileriosis: Proceedings of an International Conference held at the International Laboratory for Research on Animal Diseases in Nairobi, 9-13th February, 1981. A. D. Irvin, M. P. Cunningham and A. S. Young. Dordrecht, Springer Netherlands: 227-237.

Radley, D. E., C. G. D. Brown, M. J. Burridge, M. P. Cunningham, I. M. Kirimi, R. E. Purnell and A. S. Young (1975). "East coast fever: 1. Chemoprophylactic immunization of cattle against Theileria parva (Muguga) and five theilerial strains." Veterinary Parasitology 1(1): 3541.

Radley, D. E., C. G. D. Brown, M. P. Cunningham, C. D. Kimber, F. L. Musisi, R. C. Payne, R. E. Purnell, S. M. Stagg and A. S. Young (1975b). "East coast fever: 3. Chemoprophylactic immunization of cattle using oxytetracycline and a combination of theilerial strains." Veterinary Parasitology 1(1): 51-60.

Remarque, E. J., B. W. Faber, C. H. M. Kocken and A. W. Thomas (2008). "Apical membrane antigen 1: a malaria vaccine candidate in review." Trends in Parasitology 24(2): 74-84. 
Ribeiro, J. M., J. M. Anderson, N. C. Manoukis, Z. Meng and I. M. Francischetti (2011). "A further insight into the sialome of the tropical bont tick, Amblyomma variegatum." BMC Genomics 12(1): 136.

Ribeiro, J. M. and T. N. Mather (1998). "Ixodes scapularis: salivary kininase activity is a metallo dipeptidyl carboxypeptidase." Exp Parasitol 89(2): 213-221.

Ribeiro, J. M. C. (1987). "Role of Saliva in Blood-Feeding by Arthropods." Annual Review of Entomology 32(1): 463-478.

Ribeiro, J. M. C., F. Alarcon-Chaidez, I. M. B. Francischetti, B. J. Mans, T. N. Mather, J. G. Valenzuela and S. K. Wikel (2006). "An annotated catalog of salivary gland transcripts from Ixodes scapularis ticks." Insect Biochemistry and Molecular Biology 36(2): 111-129.

Ridley, R. G., B. Takacs, H. Etlinger and J. G. Scaife (1990). "A rhoptry antigen of Plasmodium falciparum is protective in Saimiri monkeys." Parasitology 101(2): 187-192.

Rigobello, M. P., A. Folda, M. C. Baldoin, G. Scutari and A. Bindoli (2005). "Effect of auranofin on the mitochondrial generation of hydrogen peroxide. Role of thioredoxin reductase." Free Radic Res 39(7): 687-695.

Sabadin, G. A., L. F. Parizi, I. Kiio, M. A. Xavier, R. da Silva Matos, M. I. Camargo-Mathias, N. W. o. Githaka, V. Nene and I. da Silva Vaz (2017). "Effect of recombinant glutathione Stransferase as vaccine antigen against Rhipicephalus appendiculatus and Rhipicephalus sanguineus infestation." Vaccine.

Sam-Yellowe, T. Y., L. Florens, T. Wang, J. D. Raine, D. J. Carucci, R. Sinden and J. R. Yates (2004). "Proteome Analysis of Rhoptry-Enriched Fractions Isolated from Plasmodium Merozoites." Journal of Proteome Research 3(5): 995-1001.

Sauer, J. R., R. C. Essenberg and A. S. Bowman (2000). "Salivary glands in ixodid ticks: control and mechanism of secretion." Journal of Insect Physiology 46(7): 1069-1078.

Schetters, T., G. Arts, R. Niessen, R. Van Binsbergen, L. Sanders, T. Mols-Vorstemans, T. Strydom, D. Geysen and D. Schaap (2015). "A recombinant P67 vaccine against Theileria parva in cattle: conflicting results from experimental and field challenges." ICOPA XIII, Mexico.

Schirmer, E. C., J. R. Yates, 3rd and L. Gerace (2003). "MudPIT: A powerful proteomics tool for discovery." Discov Med 3(18): 38-39. 
Schmuckli-Maurer, J., C. Casanova, S. Schmied, S. Affentranger, I. Parvanova, S. Kang'a, V. Nene, F. Katzer, D. McKeever, J. Müller, R. Bishop, A. Pain and D. A. E. Dobbelaere (2009). "Expression Analysis of the Theileria parva Subtelomere-Encoded Variable Secreted Protein Gene Family." PLoS ONE 4(3): e4839.

Shapiro, S. Z., K. Fujisaki, S. P. Morzaria, P. Webster, T. Fujinaga, P. R. Spooner and A. D. Irvin (1987). "A life-cycle stage-specific antigen of Theileria parva recognized by antimacroschizont monoclonal antibodies." Parasitology 94(1): 29-37.

Sharifiyazdi, H., F. Namazi, A. Oryan, R. Shahriari and M. Razavi (2012). "Point mutations in the Theileria annulata cytochrome $\mathrm{b}$ gene is associated with buparvaquone treatment failure." Vet Parasitol 187(3-4): 431-435.

Shaw, M. K. (1995). "Mobilization of intrasporozoite Ca2+ is essential for Theileria parva sporozoite invasion of bovine lymphocytes." Eur J Cell Biol 68(1): 78-87.

Shaw, M. K. (1996). "Theileria parvaSporozoite Entry into Bovine Lymphocytes Involves both Parasite and Host Cell Signal Transduction Processes." Experimental Parasitology 84(3): 344354.

Shaw, M. K. (2003). "Cell invasion by Theileria sporozoites." Trends in Parasitology 19(1): 26.

Shaw, M. K. and L. G. Tilney (1995). "The entry of Theileria parva merozoites into bovine erythrocytes occurs by a process similar to sporozoite invasion of lymphocytes." Parasitology 111 ( Pt 4): 455-461.

Shaw, M. K., L. G. Tilney and D. J. McKeever (1993). "Tick salivary gland extract and interleukin-2 stimulation enhance susceptibility of lymphocytes to infection by Theileria parva sporozoites." Infection and Immunity 61(4): 1486-1495.

Shaw, M. K. and A. S. Young (2009). "Differential development and emission of Theileria parva sporozoites from the salivary gland of Rhipicephalus appendiculatus." Parasitology 111(2): 153-160.

Shiels, B., G. Langsley, W. Weir, A. Pain, S. McKellar and D. Dobbelaere (2006). "Alteration of host cell phenotype by Theileria annulata and Theileria parva: mining for manipulators in the parasite genomes." International Journal for Parasitology 36(1): 9-21.

Šimo, L., M. Kazimirova, J. Richardson and S. I. Bonnet (2017). "The Essential Role of Tick Salivary Glands and Saliva in Tick Feeding and Pathogen Transmission." Frontiers in Cellular and Infection Microbiology 7(281). 
Sivakumar, T., K. Hayashida, C. Sugimoto and N. Yokoyama (2014). "Evolution and genetic diversity of Theileria." Infection, Genetics and Evolution 27: 250-263.

Skilton, R. A., R. P. Bishop, C. W. Wells, P. R. Spooner, E. Gobright, C. Nkonge, A. J. Musoke, M. Macklin and K. P. Iams (1998). "Cloning and characterization of a $150 \mathrm{kDa}$ microsphere antigen of Theileria parva that is immunologically cross-reactive with the polymorphic immunodominant molecule (PIM)." Parasitology 117 ( Pt 4): 321-330.

Skilton, R. A., A. J. Musoke, C. W. Wells, Y. Yagi, V. Nene, P. R. Spooner, J. Gachanja, J. Osaso, R. P. Bishop and S. P. Morzaria (2000). "A $32 \mathrm{kDa}$ surface antigen of Theileria parva: characterization and immunization studies." Parasitology 120 ( Pt 6): 553-564.

Steinberg, M. (2007). "Dasatinib: a tyrosine kinase inhibitor for the treatment of chronic myelogenous leukemia and philadelphia chromosome-positive acute lymphoblastic leukemia." Clin Ther 29(11): 2289-2308.

Tachado, S. D., P. Gerold, M. J. McConville, T. Baldwin, D. Quilici, R. T. Schwarz and L. Schofield (1996). "Glycosylphosphatidylinositol toxin of Plasmodium induces nitric oxide synthase expression in macrophages and vascular endothelial cells by a protein tyrosine kinasedependent and protein kinase C-dependent signaling pathway." The Journal of Immunology 156(5): 1897-1907.

Talpaz, M., N. P. Shah, H. Kantarjian, N. Donato, J. Nicoll, R. Paquette, J. Cortes, S. O'Brien, C. Nicaise, E. Bleickardt, M. A. Blackwood-Chirchir, V. Iyer, T. T. Chen, F. Huang, A. P. Decillis and C. L. Sawyers (2006). "Dasatinib in imatinib-resistant Philadelphia chromosomepositive leukemias." N Engl J Med 354(24): 2531-2541.

Tan, A. W. L., I. M. B. Francischetti, M. Slovak, R. M. Kini and J. M. C. Ribeiro (2015). "Sexual differences in the sialomes of the zebra tick, Rhipicephalus pulchellus." Journal of Proteomics 117: 120-144.

Tebaldi, G., L. B. Williams, A. E. Verna, F. Macchi, V. Franceschi, L. M. Fry, D. P. Knowles and G. Donofrio (2017). "Assessment and optimization of Theileria parva sporozoite fulllength p67 antigen expression in mammalian cells." PLOS Neglected Tropical Diseases 11(8): e0005803.

Theiler, A. (1912). "The immunisation of cattle against East Coast fever." Second Rep. Dir. Vet. Res. 1912: 216-314.

Toye, P., J. Nyanjui, B. Goddeeris and A. J. Musoke (1996). "Identification of neutralization and diagnostic epitopes on PIM, the polymorphic immunodominant molecule of Theileria parva." Infection and Immunity 64(5): 1832-1838. 
Toye, P., J. Nyanjui, B. Goddeeris and A. J. Musoke (1996). "Identification of neutralization and diagnostic epitopes on PIM, the polymorphic immunodominant molecule of Theileria parva." Infection and Immunity 64(5): 1832-1838.

Toye, P. G., B. M. Goddeeris, K. Iams, A. J. Musoke and W. I. Morrison (1991). "Characterization of a polymorphic immunodominant molecule in sporozoites and schizonts of Theileria parva." Parasite Immunology 13(1): 49-62.

Toye, P. G., M. J. Metzelaar, P. L. Wijngaard, V. Nene, K. Iams, J. Roose, J. K. Nyanjui, E. Gobright, A. J. Musoke and H. C. Clevers (1995). "Characterization of the gene encoding the polymorphic immunodominant molecule, a neutralizing antigen of Theileria parva." The Journal of Immunology 155(3): 1370-1381.

Treeck, M., S. Zacherl, S. Herrmann, A. Cabrera, M. Kono, N. S. Struck, K. Engelberg, S. Haase, F. Frischknecht, K. Miura, T. Spielmann and T. W. Gilberger (2009). "Functional Analysis of the Leading Malaria Vaccine Candidate AMA-1 Reveals an Essential Role for the Cytoplasmic Domain in the Invasion Process." PLoS Pathog 5(3): e1000322.

Tretina, K., H. T. Gotia, D. J. Mann and J. C. Silva (2015). "Theileria-transformed bovine leukocytes have cancer hallmarks." Trends in Parasitology 31(7): 306-314.

Tretina, K., R. Pelle and J. C. Silva (2016). "Cis regulatory motifs and antisense transcriptional control in the apicomplexan Theileria parva." BMC Genomics 17(1): 128.

Tyagi, N., L. S. Swapna, S. Mohanty, G. Agarwal, V. S. Gowri, K. Anamika, M. L. Priya, O. Krishnadev and N. Srinivasan (2009). "Evolutionary Divergence of Plasmodium falciparum: Sequences, Protein- Protein Interactions, Pathways and Processes." Infectious Disorders - Drug TargetsDisorders) 9(3): 257-271.

Uilenberg, G. (1999). "Immunization against diseases caused by Theileria parva." Tropical Medicine and International Health 4: A12-A20.

Van Voorhis, W. C., J. H. Adams, R. Adelfio, V. Ahyong, M. H. Akabas, P. Alano, A. Alday, Y. Alemán Resto, A. Alsibaee, A. Alzualde, K. T. Andrews, S. V. Avery, V. M. Avery, L. Ayong, M. Baker, S. Baker, C. Ben Mamoun, S. Bhatia, Q. Bickle, L. Bounaadja, T. Bowling, J. Bosch, L. E. Boucher, F. F. Boyom, J. Brea, M. Brennan, A. Burton, C. R. Caffrey, G. Camarda, M. Carrasquilla, D. Carter, M. Belen Cassera, K. Chih-Chien Cheng, W. Chindaudomsate, A. Chubb, B. L. Colon, D. D. Colón-López, Y. Corbett, G. J. Crowther, N. Cowan, S. D’Alessandro, N. Le Dang, M. Delves, J. L. DeRisi, A. Y. Du, S. Duffy, S. Abd ElSalam El-Sayed, M. T. Ferdig, J. A. Fernández Robledo, D. A. Fidock, I. Florent, P. V. T. Fokou, A. Galstian, F. J. Gamo, S. Gokool, B. Gold, T. Golub, G. M. Goldgof, R. Guha, W. A. Guiguemde, N. Gural, R. K. Guy, M. A. E. Hansen, K. K. Hanson, A. Hemphill, R. Hooft van Huijsduijnen, T. Horii, P. Horrocks, T. B. Hughes, C. Huston, I. Igarashi, K. Ingram-Sieber, M. A. Itoe, A. Jadhav, A. Naranuntarat Jensen, L. T. Jensen, R. H. Y. Jiang, A. Kaiser, J. 
Keiser, T. Ketas, S. Kicka, S. Kim, K. Kirk, V. P. Kumar, D. E. Kyle, M. J. Lafuente, S. Landfear, N. Lee, S. Lee, A. M. Lehane, F. Li, D. Little, L. Liu, M. Llinás, M. I. Loza, A. Lubar, L. Lucantoni, I. Lucet, L. Maes, D. Mancama, N. R. Mansour, S. March, S. McGowan, I. Medina Vera, S. Meister, L. Mercer, J. Mestres, A. N. Mfopa, R. N. Misra, S. Moon, J. P. Moore, F. Morais Rodrigues da Costa, J. Müller, A. Muriana, S. Nakazawa Hewitt, B. Nare, C. Nathan, N. Narraidoo, S. Nawaratna, K. K. Ojo, D. Ortiz, G. Panic, G. Papadatos, S. Parapini, K. Patra, N. Pham, S. Prats, D. M. Plouffe, S.-A. Poulsen, A. Pradhan, C. Quevedo, R. J. Quinn, C. A. Rice, M. Abdo Rizk, A. Ruecker, R. St. Onge, R. Salgado Ferreira, J. Samra, N. G. Robinett, U. Schlecht, M. Schmitt, F. Silva Villela, F. Silvestrini, R. Sinden, D. A. Smith, T. Soldati, A. Spitzmüller, S. M. Stamm, D. J. Sullivan, W. Sullivan, S. Suresh, B. M. Suzuki, Y. Suzuki, S. J. Swamidass, D. Taramelli, L. R. Y. Tchokouaha, A. Theron, D. Thomas, K. F. Tonissen, S. Townson, A. K. Tripathi, V. Trofimov, K. O. Udenze, I. Ullah, C. Vallieres, E. Vigil, J. M. Vinetz, P. Voong Vinh, H. Vu, N.-a. Watanabe, K. Weatherby, P. M. White, A. F. Wilks, E. A. Winzeler, E. Wojcik, M. Wree, W. Wu, N. Yokoyama, P. H. A. Zollo, N. Abla, B. Blasco, J. Burrows, B. Laleu, D. Leroy, T. Spangenberg, T. Wells and P. A. Willis (2016). "Open Source Drug Discovery with the Malaria Box Compound Collection for Neglected Diseases and Beyond." PLOS Pathogens 12(7): e1005763.

von Heijne, G. (1990). "The signal peptide." The Journal of Membrane Biology 115(3): 195201.

von Schubert, C., G. Xue, J. Schmuckli-Maurer, K. L. Woods, E. A. Nigg and D. A. E. Dobbelaere (2010). "The Transforming Parasite Theileria Co-opts Host Cell Mitotic and Central Spindles to Persist in Continuously Dividing Cells." PLOS Biology 8(9): e1000499.

Wampande, E. M., J. Richard McIntosh and G. W. Lubega (2007). "Classical ligands interact with native and recombinant tubulin from Onchocerca volvulus with similar rank order of magnitude." Protein Expr Purif 55(2): 236-245.

Witschi, M., D. Xia, S. Sanderson, M. Baumgartner, J. M. Wastling and D. A. E. Dobbelaere (2013). "Proteomic analysis of the Theileria annulata schizont." International Journal for Parasitology 43(2): 173-180.

Xu, T., A. Lew-Tabor and M. Rodriguez-Valle (2016). "Effective inhibition of thrombin by Rhipicephalus microplus serpin-15 (RmS-15) obtained in the yeast Pichia pastoris." Ticks and Tick-borne Diseases 7(1): 180-187.

Xue, G., C. von Schubert, P. Hermann, M. Peyer, R. Maushagen, J. Schmuckli-Maurer, P. Bütikofer, G. Langsley and D. A. E. Dobbelaere (2010). "Characterisation of gp34, a GPIanchored protein expressed by schizonts of Theileria parva and T. annulata." Molecular and Biochemical Parasitology 172(2): 113-120.

Zhang, H., M. K. Compaore, E.-g. Lee, M. Liao, G. Zhang, C. Sugimoto, K. Fujisaki, Y. Nishikawa and X. Xuan (2007). "Apical membrane antigen 1 is a cross-reactive antigen 
between Neospora caninum and Toxoplasma gondii, and the anti-NcAMA1 antibody inhibits host cell invasion by both parasites." Molecular and biochemical parasitology 151(2): 205-212. 
146 | Ac k n o w l e d g e m e n t 


\section{ACKNOWLEDGEMENT}




\section{ACKNOWLEDGEMENT}

However far a stream flows, it never forgets its origin African proverb

There are many people and organizations that have supported me over the course of this $\mathrm{PhD}$. It was a long marathon consisting of fright, happiness, frustration and victory but overall satisfactory. To all of you who contributed towards this success, I'm extremely grateful for all of the support you've given me. This thesis appears in its current form because of your assistance and guidance. Undoubtedly, there is likely to be some omissions, for which I sincerely regret and apologize

Firstly, I would like to thank my promoters and co-promoters; Vish Nene, Huub Salvekuol, Roger Pelle and Edwin Tijhaar for giving me opportunity to undertake this joint $\mathrm{PhD}$ between ILRI and Wageningen University. Special thanks to Roger for his guidance in the lab and kind words of encouragement and discussions. Special thanks to Vish and Edwin for insightful discussions, and for dedicating time to read and promptly offer critical comments and correction to the manuscripts that form this thesis. Thank you all very much for invaluable advice you offered that led to this accomplishment.

Thanks also to senior members of the ECF group including Lucilla Steinaa, Nicholas Svitek and Anna Lacasta for the critical comments and corrections during lab meetings. I would also like to acknowledge my laboratory colleagues: Benjamin Nzau for keeping me sane whilst in the lab, making sure I don't 'burn the lab'. Charity Muthoni for her patience whilst I remembered how to 'do western blots', Stephen Mwalimu for his dedication to the immunization and collection of blood from mice. Thanks to Liz Kibwana for her kind words of encouragement. Robert Muriuki thank you very much for always offering to collect blood from the farm and for playing good music. To Rosemary Saya and Elias Awino 'Prof' thanks for your guidance on culturing cells and for encouragement. Thanks to Thomas Njoroge for accepting to examine the slides and for guidance on sporozoite purification by DE-52 column.

The animal attendants at ILRI also deserve a mention, this work would not be possible without their hard work and dedication to keeping the animals in such good condition. Simon Otieno and Jane Ikanye. Special thanks to the members of the ILRI tick unit including Stephen Mwaura, Milton Owido and Naftally Githaka without your steadfast supply of sporozoites this study would not be possible.

To my fellow PhD students at ILRI, there's always comfort in knowing that others are going through the same experiences as you. I'd like to acknowledge Paul Sajjakambwe, Barberine Assongo, Gaston Amzati, Triza Tonui, Milcah Wagio and Rachel Miller for the all the discussions and suggestions during journal club. I would also like to thank friends including Faten Almani, Malbert Rogers, Jared Kirui, Velma Kivali, Martin, Cecilia, Alice, Kenneth and David for keeping the stress at bay with laughter and kind words.

My accomplishments wouldn't be possible without the unconditional love and support from my family. Gratitude to my loving mother mama Abigael Nyagwange, you sacrificed everything to make sure I succeed in life. Thanks for all the invaluable life lessons you taught me about independence, responsibility, hard work, and open-mindedness. Thanks to my brothers Amos Nyagwange, Joseph Nyagwange, Elvis Nyagwange, sisters Oliver Nyagwange 
and Elizabeth Nyagwange. Special thanks to Millicent and Job Nyaoke for believing in me and giving me financial support throughout my education. Thanks to sisters in law Agnes and Hazel, aunt Millicent Wandiga and Josiah Odero for all your sacrifices. Many thanks to my new family, mama Maria Chidzanga, Mr. Gweru, Mr. and Mrs. Mugari, Munenyasha, Harmony and Murandashe for the prayers and guidance. You are best in laws.

Finally, I would like to thank my wife Charity Chidzanga for her patience, love, and immense support during this $\mathrm{PhD}$. Thank you very much for coping with all of the ups and downs over the past four years, putting up with my divided attention between studies and family time without complaint and for listening to my sporozoite stories patiently.

"From them will come songs of thanksgiving and the sound of rejoicing, I will add to their numbers, and they will not be decreased; I will bring them honor, and they will not be disdained" [Jeremiah 30:19]. Above all, thanks to God for seeing me through four years of relentless effort to acquire knowledge providing good health and resources. 


\section{ABOUT THE AUTHOR}




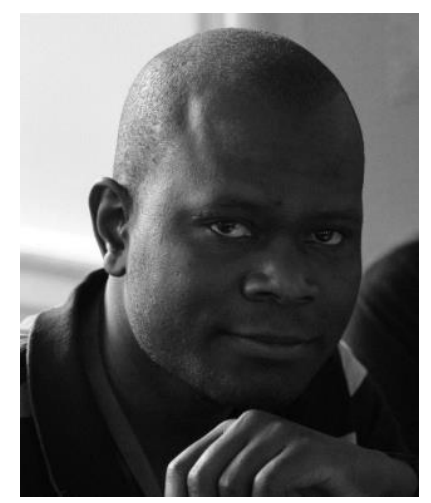

James Jimmy Nyagwange was born on the $31^{\text {st }}$ of December 1983 in Nyando, Kenya. He obtained his primary education certificate in 1997 and a high school certificate in 2001. Thereafter, he joined Kenyatta University in Nairobi, Kenya to pursue a Bachelor of Sciences degree in Biochemistry and graduated (Hons) in 2008. Before his graduation, he took an internship with PathCare laboratories Kenya, where he learnt many techniques and skills for disease diagnosis. After his graduation James' worked as a field research officer for the University of Nairobi Institute of Tropical and Infectious diseases' (UNITID) HaPI project collecting field data to help stop HIV infections caused by pregnancy intention. James' persistent quest for further education resulted in a Netherlands Fellowship Program (NFP) scholarship administered by NUFFIC in 2010 for a Masters course at Wageningen University and Research Centre (WUR), the Netherlands. He graduated, in 2012, with a Master of Sciences degree in Molecular Life science (Biomedical research). His major thesis entitled "Gut bacteria subsisting on antibiotics" was completed under the auspices of Dr. Mark van Passel at the Laboratory of Microbiology, WUR. His minor thesis entitled "Optimisation of $M$. tuberculosis Multiplex Ligation dependent Probe Amplification (MLPA)" was completed at the Royal tropical Institute (KIT) in Amsterdam, the Netherlands, under the auspices of Prof. Richard Anthony (KIT). Afterwards, James returned to Kenya and lectured at Meru University of Science and Technology (MUST), Meru. In April 2014, he joined the International Livestock Research Institute (ILRI) as a PhD fellow in Molecular Biology and Immunology, a $\mathrm{PhD}$ registered and supervised at WUR. He has developed scientific interest in vaccinology, and he aims to translate knowledge of immunology and molecular biology into vaccines for control and eradication of diseases. James is currently a joint postdoctoral fellow at the KEMRI-Wellcome Trust, Kenya and the Pirbright Institute, UK. 


\section{List of publications}

Nyagwange, J., V. Nene, S. Mwalimu, S. Henson, L. Steinaa, B. Nzau, E. Tijhaar and R. Pelle (2018). "Antibodies to in silico selected GPI-anchored Theileria parva proteins neutralize sporozoite infection in vitro." Veterinary Immunology and Immunopathology 199: 8-14.

Nyagwange, J., E. Tijhaar, N. Ternette, F. Mobegi, K. Tretina, J. C. Silva, R. Pelle and V. Nene (2018). "Characterization of the Theileria parva sporozoite proteome." International Journal for Parasitology 48(3): 265-273.

Nyagwange, J., E. E. Awino, E. Tijhaar, N. Svitek, R. Pelle, V. Nene (2019). "Leveraging the Medicines for Malaria Venture malaria and pathogen boxes to discover chemical inhibitors of East Coast fever". International Journal for Parasitology: Drugs and Drug Resistance 9: 80-86.

Nyagwange,J., E. Tijhaar, N. Ternette, M. Kigoni, R. Pelle, V. Nene (2018). "Characterization of Rhipicephalus appendiculatus salivary glands proteins co-purified with Theileria parva sporozoites". In preparation.

\section{Abstract and presentation}

Nyagwange, J., et al: Proteomics of the Theileria parva sporozoites. New Approaches to Vaccines for Human and Veterinary Tropical Diseases, Keystone symposium, May 22-26, 2016; Cape Town, South Africa (Poster presentation). 
The research described in this thesis was financially supported by the CGIAR Research Program on Livestock and Fish, Kenya, the Norman Borlaug Commemorative Research Initiative, an initiative between the Feed the Future program of United States Agency for International Development, USA and United States Department of Agriculture-Agricultural Research Service, USA (58-5348-2-117F) and the Department for International Development of the United Kingdom and the Bill and Melinda Gates Foundation, USA (OPP1078791).

Cover design by James Nyagwange 
- 1 



\section{Propositions}

1. Reverse vaccinology presents a tool for identification of novel Theileria parva vaccine candidates.

(this thesis)

2. Repurposing of drugs or drug like compounds can accelerate the process of drug discovery for Theileria.

(this thesis)

3. Cross presentation by dendritic cells is a mechanism for presenting exogenous antigens on MHC class I pathway, common for viruses but still poorly acknowledged for parasites.

4. Intermittent funding is a major factor that slows down scientific discoveries.

5. The irony of many social media networks is that they greatly contribute to anti-social behaviour.

6. In scientific research, imagination is a more important driver of discovery than knowledge.

Propositions belonging to the thesis, entitled

Identification of novel Theileria parva candidate vaccine antigens and discovery of new therapeutic drugs for the control of East Coast fever

James J. Nyagwange

Wageningen, 14 May 2019 